
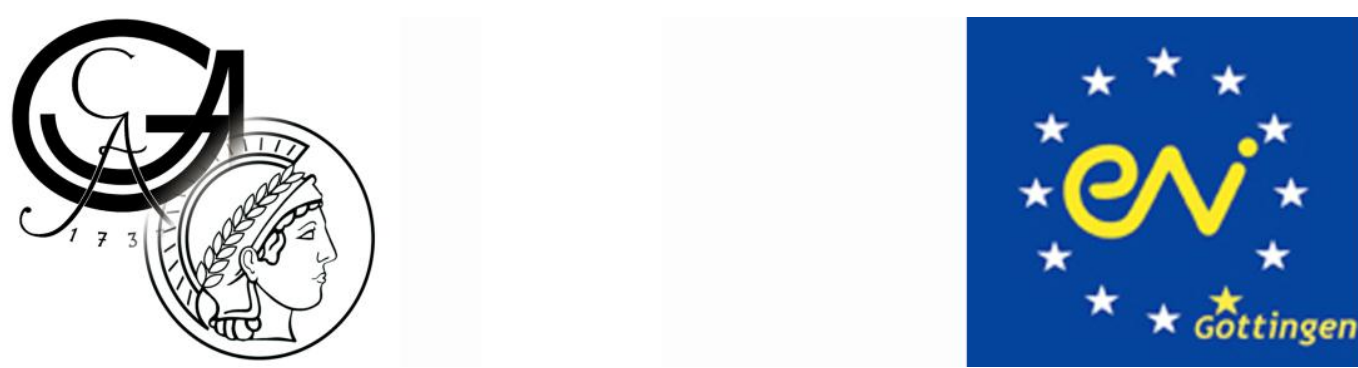

\title{
Assessment of Epigenetic profile in Alzheimer's disease
}

\section{Ph.D Thesis}

\author{
in partial fulfilment of the requirements \\ for the degree "Ph.D." \\ in the Neuroscience Program \\ at the Georg August University Göttingen, \\ Faculty of Biology
}

submitted by

Hope Yao Agbemenyah

born in

Akatsi, Ghana 
I hereby declare that the $\mathrm{Ph} . \mathrm{D}$ thesis entitled, "Assessment of Epigenetic profile in Alzheimer's disease", was written independently and with no other sources and aids than quoted. 
Thesis committee members:

Prof. Dr. Andre Fischer

Prof. Dr. Armin Klaus Nave

Dr. Judith Stegmueller
European Neuroscience Institute,

Max Planck Institute for Experimental Medicine

Max Planck Institute for Experimental Medicine 


\section{Contents}

ABBREVIATIONS AND UNITS....................................................................................................... VII

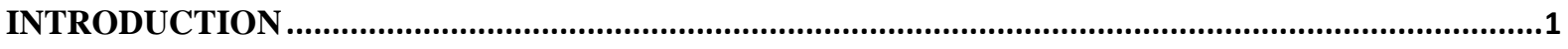

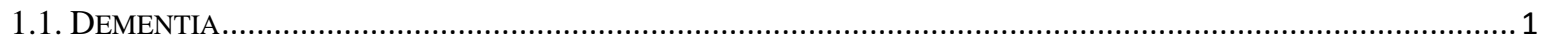

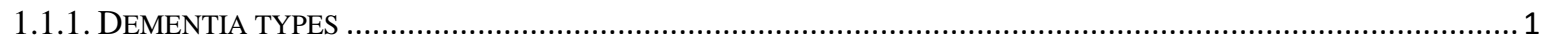

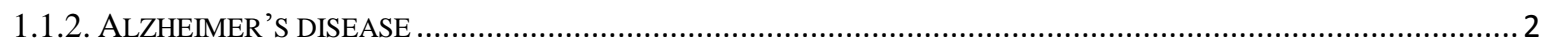

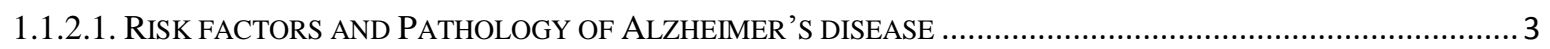

1.1.2.3. GENETIC RISK FACTORS AND AMYLOID HYPOTHESIS ............................................................... 4

1.1.2.4. SPORADIC ALZHEIMER'S DISEASE AND ENVIRONMENTAL INFLUENCE ............................................ 5

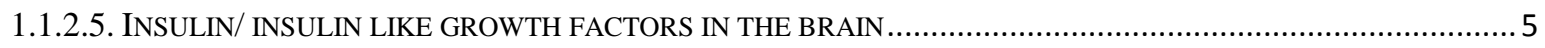

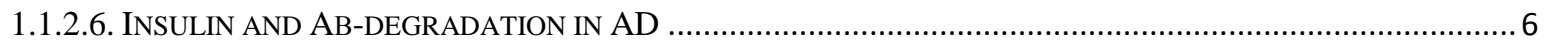

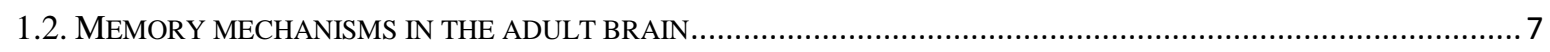

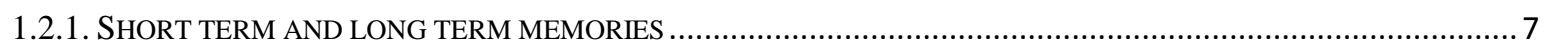

1.2.2. DECLARATIVE AND NON-DECLARATIVE MEMORIES .................................................................. 7

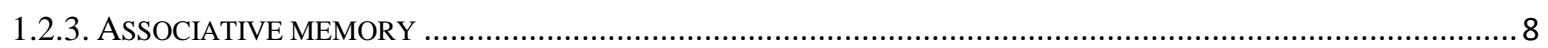

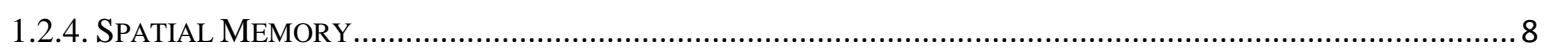

1.3. ANATOMICAL VIEW OF MEMORY CODING AND MOLECULAR MECHANISMS............................................

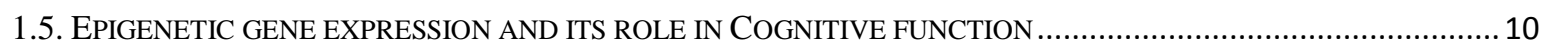

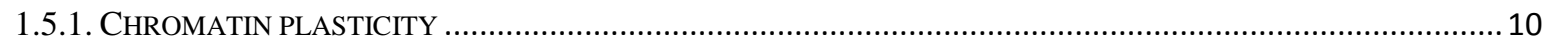

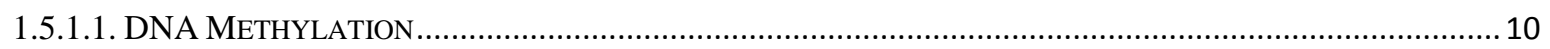

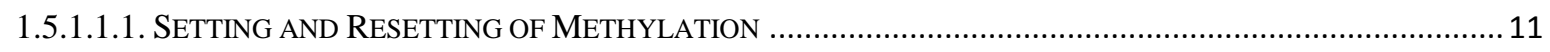

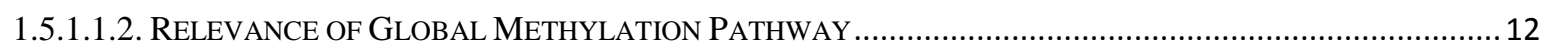

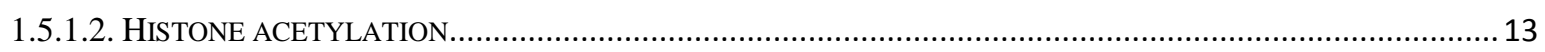

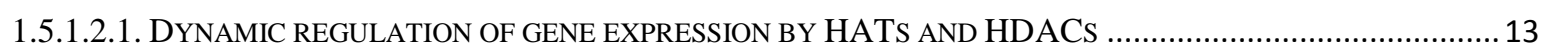

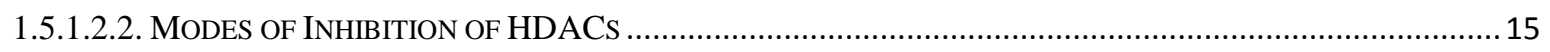

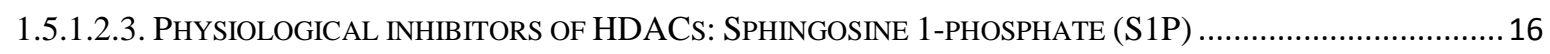

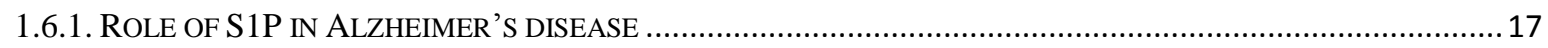

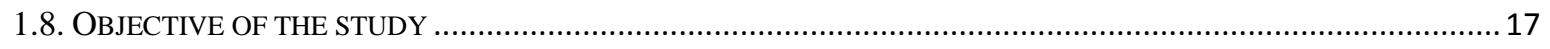

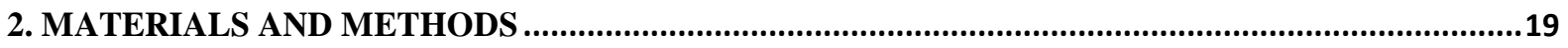

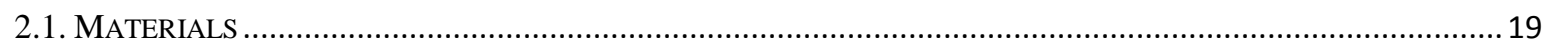

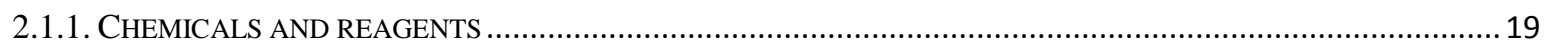

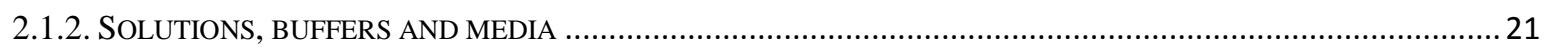

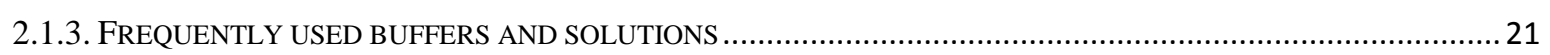

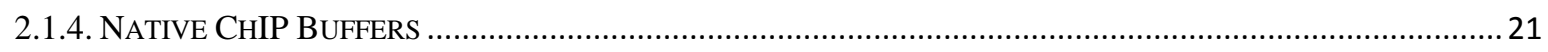

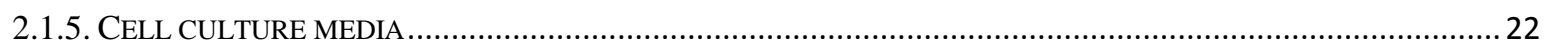

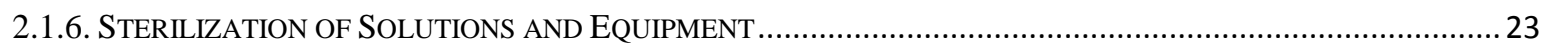

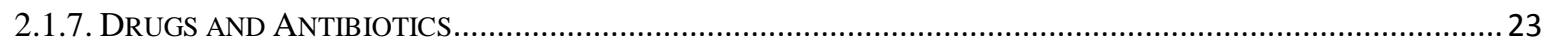

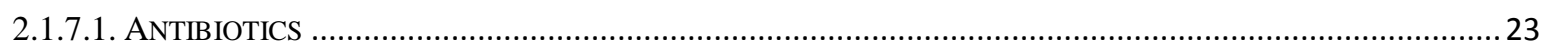

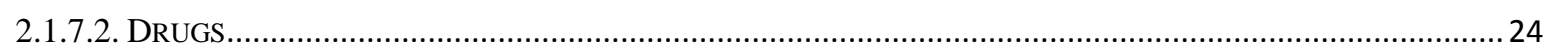

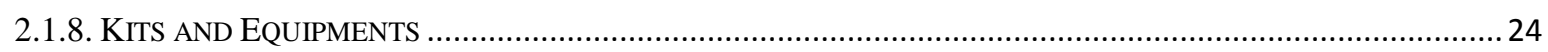

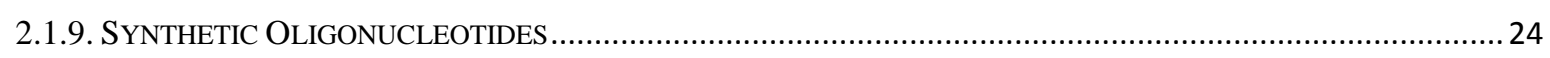

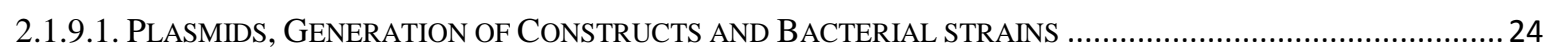

2.1.9.1.1. ISOLATION OF NUCLEIC ACIDS (SMALL SCALE ISOLATION OF PLASMID DNA) ................................24

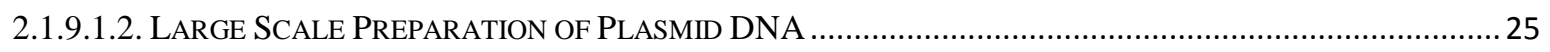

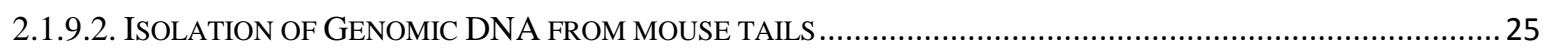

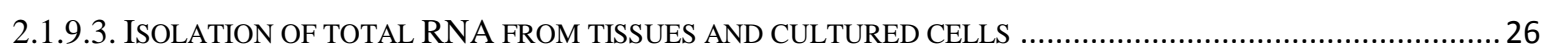

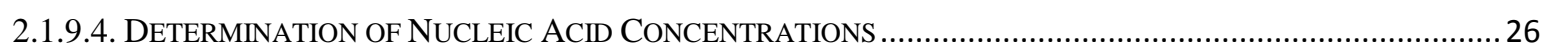


2.1.9.5. NUCLEIC ACID ELECTROPHORESIS (AGAROSE GEL ELECTROPHORESIS OF DNA).................................. 26

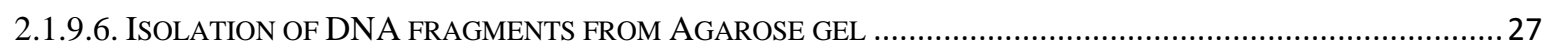

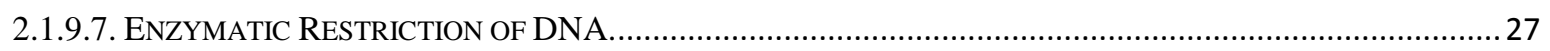

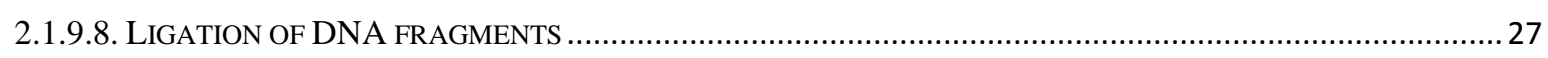

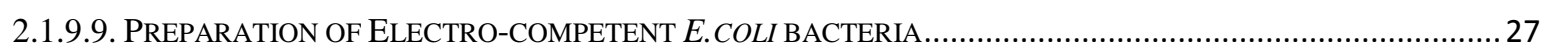

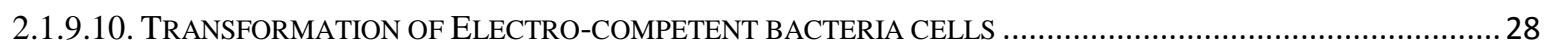

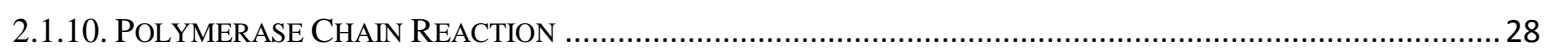

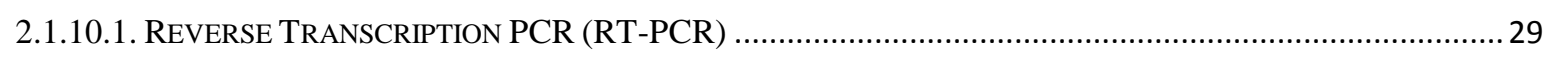

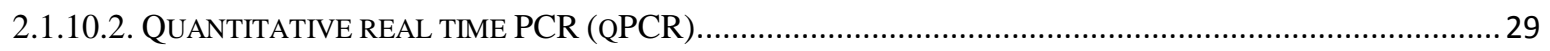

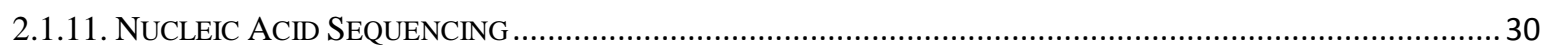

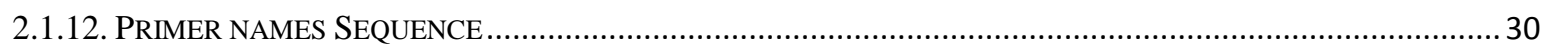

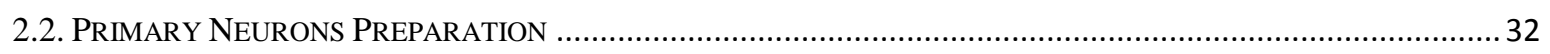

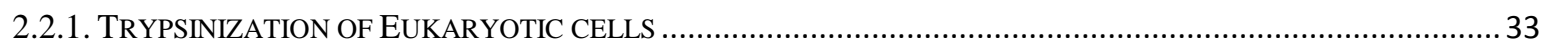

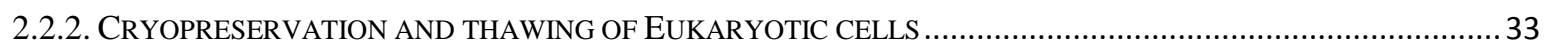

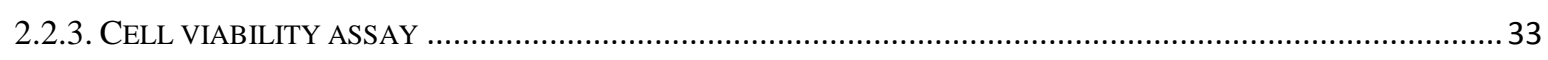

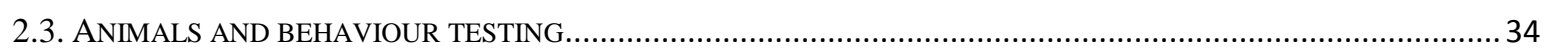

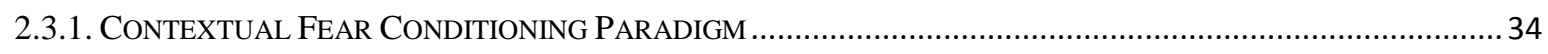

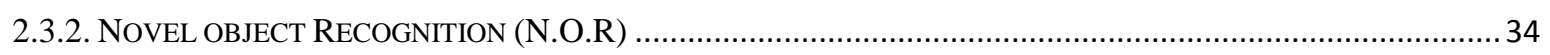

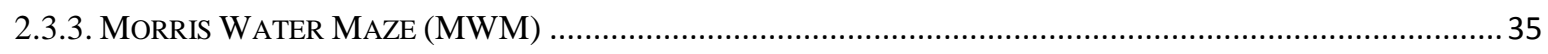

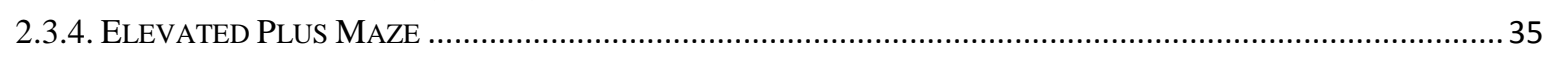

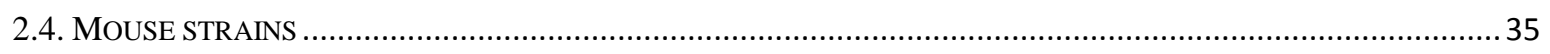

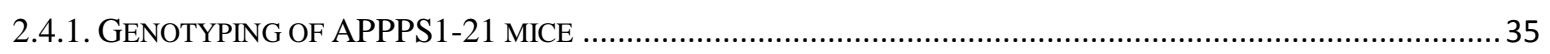

2.5. IMPLANTATION OF MICROCANNULAE AND IN VIVO INTRAHIPPOCAMPAL MANIPULATIONS ...........................36

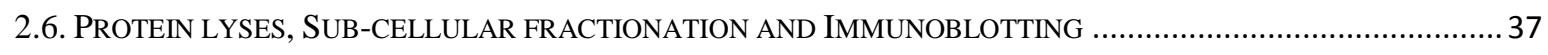

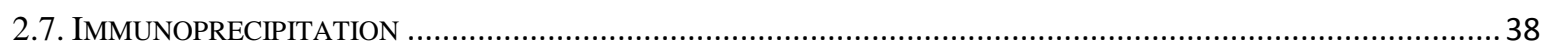

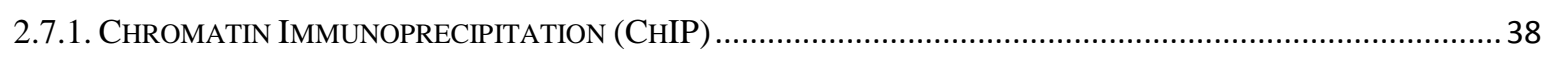

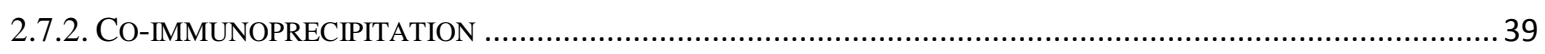

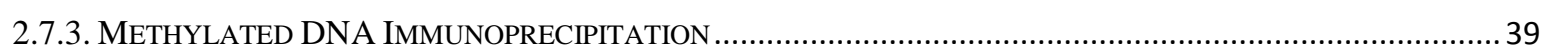

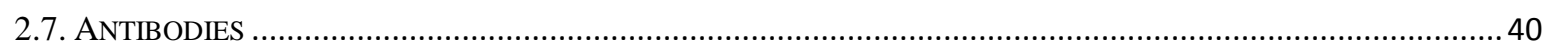

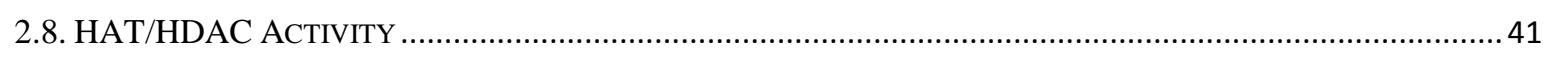

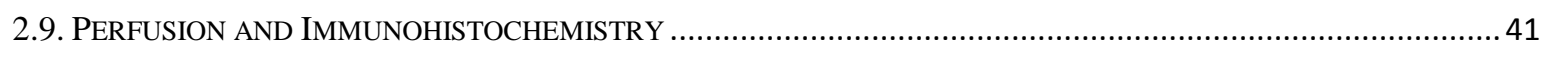

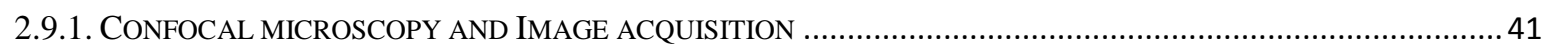

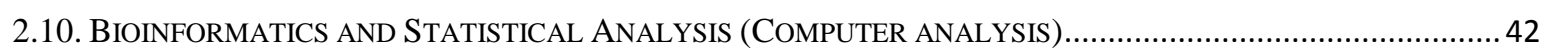

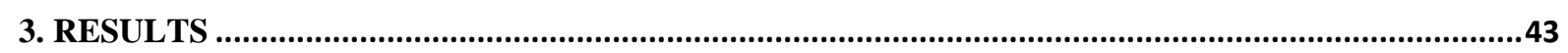

3.1. THE ROLE OF DNA METHYLATION IN AGING AND ALZHEIMER'S DISEASE ............................................. 43

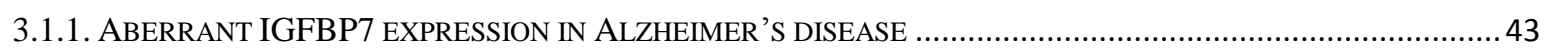

3.1.2. CPG METHYLATION ON THE PROMOTER IGFBP7 WAS LOWER THAN CONTROLS ..................................... 44

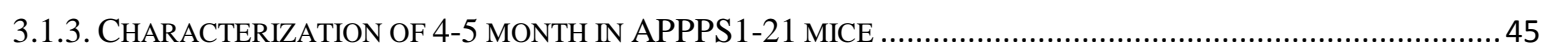

IN CONCLUSION THESE DATA SUGGEST THAT 4-5 MONTH OLD APPPS1-21 MICE EXHIBIT MILD COGNITIVE DEFICIT IN MEMORY TASKS. THESE MICE ALSO SHOW ANXIETY PHENOTYPE.............................................. 47

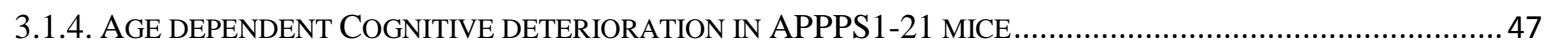

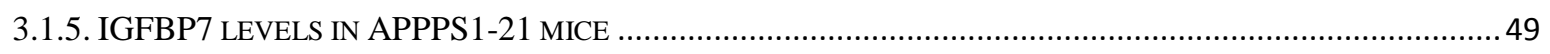

3.1.6. RECOMBINANT IGFBP7 IMPAIRS MEMORY FORMATION IN-VIVO …………………................................ 51

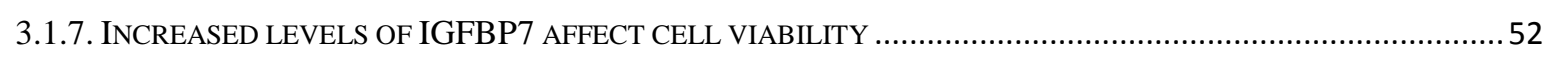

3.1.8. IMMUNIZATION AMELIORATES COGNITIVE DEFICIT ........................................................................... 53

3.2. REDUCED NUCLEAR SPHINGOSINE KINASE 2 ACTIVITY UNDERLIES ALTERED AC-H4K12 ACETYLATION IN

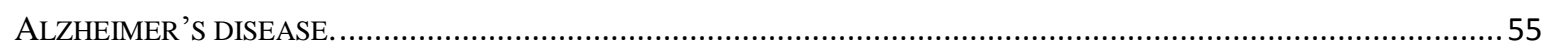

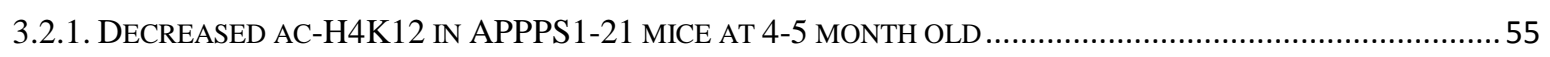

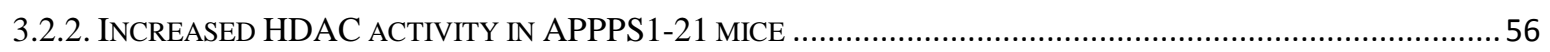


3.2.3. SPHINGOSINE KINASE LEVELS MEDIATE INCREASED HDAC ACTIVITY IN APPPS1-21 MICE 57

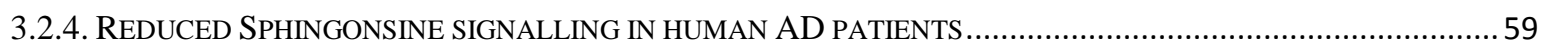

3.2.6. SPHK2 IS DIFFERENTIALLY EXPRESSED DURING MEMORY CONSOLIDATION........................................61

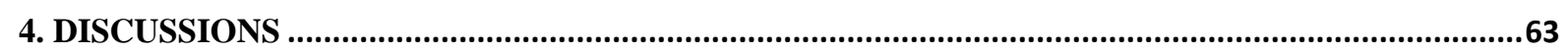

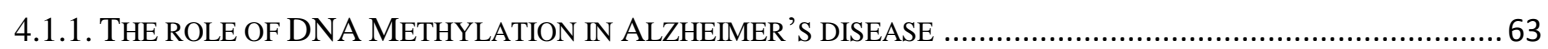

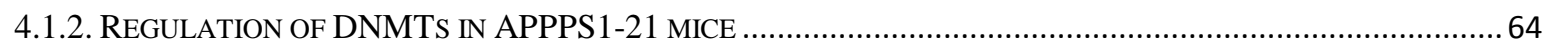

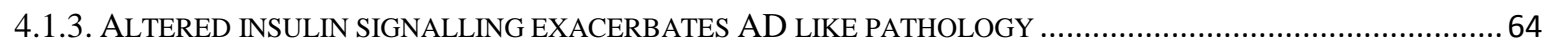

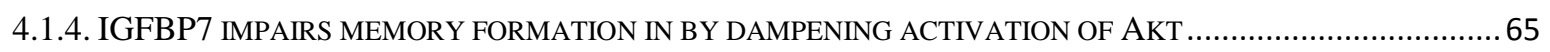

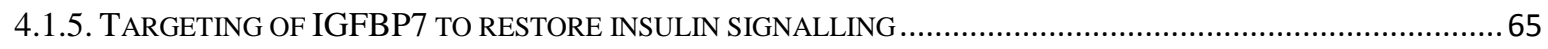

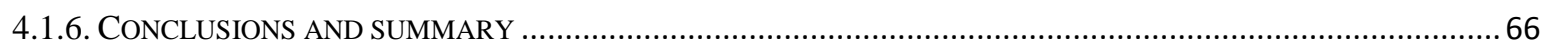

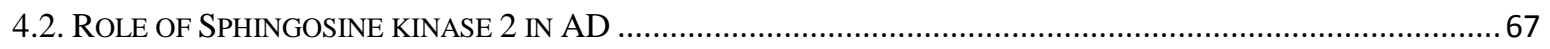

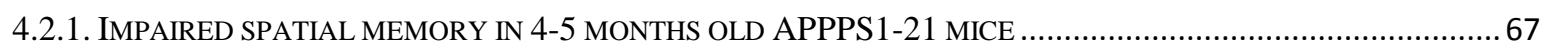

4.2.2. FOUR MONTH OLD APPPS1-21 MICE SHOWED REDUCTION IN AC-H4K12 _........................................67

4.2.3. TARGETING SPHINGOSINE KINASE 2 TO REINSTATE HISTONE ACETYLATION IN AD................................69

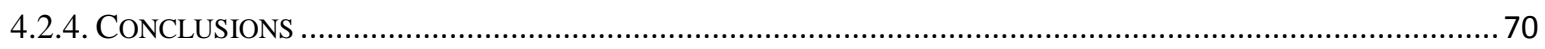

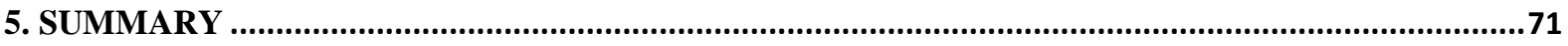

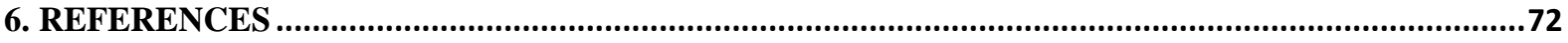

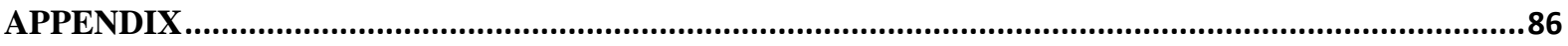

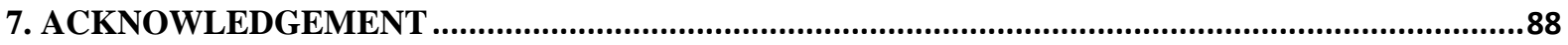

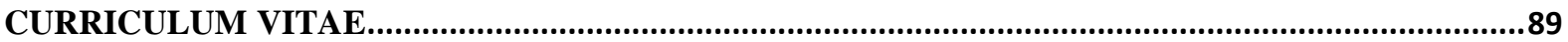


AA Amino acids

\section{Abbreviations and units}

$\alpha / \beta / \gamma / \varepsilon$-secretase alpha/beta/gamma/epsilon secretase

ac-HXKX acetylated histone $\mathrm{X}$ lysine $\mathrm{X}$

ADAM10/17 a disintegrin metalloproteinases 10/17

AD Alzheimer's disease

APP Amyloid precursor protein

A $\beta$ Amyloid beta peptide

Av.(RoQ) Average of Rest of Quadrant

BACE $\beta$-site APP cleaving enzyme

ChIP Chromatin immunoprecipitation

CoIP Co-immunoprecipitation

Cdk5 Cyclin dependent kinase 5

CTF83 Carboxyl terminal fragment 83

CTF99 Carboxyl terminal fragment 99

F/SAD familial/sporadic Alzheimer's disease

FTDP-17-Fronto temporal dementia chromosome 17

HATs Histone acetyltransferases

HDACs Histone deacetylases

ICF immunodeficiency, centromeric instability, and facial anomalies

IGF/IGFBP insulin like growth factor/ insulin like growth factor binding protein

IR Insulin resistance

$\mathrm{NaN}_{3}$ Sodium azide

NFT Neurofibrillary tangles

PHF Paired helical fragment

PS1/2 Presenilin 1/ 2

PRC polycomb repressor complex

qPCR quantitative polymerase chain reaction

rpm revolutions per minute

SAM S-adenosyl methionine

s.e.m standard error of mean

Sphk1/2 Sphingosine kinase 1/2

S1P Sphingosine-1 phosphate 
Abbreviations and units Assessment of Epigenetic profille in Alzheimer's disease

sAPP $\alpha / \beta$ soluble alpha/beta APP ectodomain

SDS Sodium dodecyl sulphate

TBS/TBS-T Tris buffered saline/ Tris buffered saline-tween

WT wild type

\section{Units}

$\mu \mathrm{g}$ microgram

$\mu l$ microlitre

$\mu \mathrm{m}$ micrometer

bp base pair

cm centimeter

h hour

kb kilobase

kDa kilodalton

$\mathrm{kV}$ kilovolt

M molar (= moles per liter)

$\mathrm{mA}$ milliampere

Mg milligram

Min minute

$\mathrm{ml}$ milliliter

$\mathrm{mM}$ millimolar

ng nanogram

$\mu \mathrm{M}$ micromolar

$\mathrm{nm}$ nanometer

${ }^{\circ} \mathrm{C}$ degree Celsius

pmol picomole

v/v volume per volume

w/v weight per volume

$\mathrm{x} g$ relative centrifugal force

$\%$ percent. 
Introductions Assessment of Epigenetic profile in Alzheimer's disease

\section{Introduction}

\subsection{Dementia}

Dementia is not a specific disease but rather an overall term that describes gradual deterioration of memory functioning such as concentration, memory and judgement which affects a person's ability to perform daily activities. The diagnosis of dementia requires a gradual decline of cognitive function that impedes daily functioning, accompanied by aphasia, apraxia, agnosia. There are many other conditions that can cause symptoms of dementia, including some that are reversible, such as thyroid problems and vitamin deficiencies.

\subsubsection{Dementia types}

Dementia may be categorized based on the cause as well as clinical observations often evaluated posthumously. The most common type of dementia is Alzheimer's disease (AD). It accounts for 60 to $80 \%$ of the cases. The second most prevalent form of dementia is the vascular dementia often suffered by patients after stroke. This occurs largely due to brain injuries. Mild Cognitive Impairment (MCI) deemed to be a transitional stage between normal aging and dementia (Grundman et al., 2004), is rather a term than a specific disease. It describes memory loss apparent to the individual, and those around them. The memory loss is supported by formal memory tests, but other features of dementia are absent. MCI could be due to stress, anxiety, depression or physical illness. People with MCI usually have impaired memory but no impairments in other areas of brain function, such as planning or attention, and no significant problems in everyday living.

Fronto-temporal dementia with Parkinsonism linked to chromosome 17 (FTDP-17) covers a range of conditions, including Pick's disease, frontal lobe degeneration and dementia associated with motorneurone disease (Foster et al., 1997; Kowalska et al., 2002; Litvan et al., 1996; Neary et al., 1998). These are caused by damage to the frontal lobe and/or the temporal parts of the brain involved in behaviour, emotional and language skills. Overall occurrence is less frequently than other conditions like AD. However, it is a significant cause in younger people below age 65 and the second or third most common dementia in age group (Ratnavalli et al., 2002; Rosso et al., 2003; Taipa et al., 2012). 
Parkinson's disease (PD), a progressive degenerative disorder of the central nervous system that leads to impaired motor skills, speech and cognition (Jankovic, 2008) and dementia with Lewy bodies (DLB) are two neurodegenerative disorders diagnosed by the presence of lewy bodies and Lewy neurites. Dementia with Lewy bodies accounts for about $10 \%$ of dementias in elderly people (McKeith et al., 1996). Many people who are initially diagnosed with Parkinson's disease later go on to develop a dementia that closely resembles DLB (Aarsland and Kurz, 2010; Aarsland et al., 2005). DLB is characterized by core clinical neuropsychiatric features of fluctuating cognitive function, visual hallucinations and spontaneous parkinsonian motor signs (McKeith et al., 2004; McKeith et al., 2005).

Other forms of dementia include Huntington's disease (HD) characterized by a progressive neurodegeneration and cognitive decline, uncontrollable physical movements called chorea and changes in personality (Walker, 2007). Wernicke-Korsakoff syndrome (WKS) is a clinical manifestation of alcohol abuse and thiamine deficiency that causes changes in vision, ataxia and memory impairment (Kopelman et al., 2009). Although different cortical regions might be affected, memory loss is the cardinal observation with the diseases.

\subsubsection{Alzheimer's disease}

Alzheimer's disease (AD) discovered and named after Alois Alzheimer is a debilitating disorder that severely affects cognitive abilities considerably accelerating the rate of developing dementia compared to age-associated cognitive decline (Berchtold and Cotman, 1998). Clinically, the disease is initially characterized by subtle short-term memory problems, difficulty remembering names, apathy, depression and orientation disturbances. As the disease progresses, higher cognitive functions: (impaired judgment, disorientation, confusion, behaviour changes and difficulty speaking, swallowing and walking) become affected and the patients become entirely dependent. $\mathrm{AD}$ accounts for 60 to $80 \%$ of all dementia cases and could be both familial and sporadic. AD is currently estimated to affect $1 / 8^{\text {th }}(13 \%)$ of persons older than 65 years (Alzheimer's Association 2009) and up to 50\% of persons older than 85 years. In 2001, the incidence of AD patients in Europe is estimated to reach 4.9 million people and expected to double by 2040 (Ferri et al., 2005) and current global incidence is estimated to be 18 million people and this might surge to 34 million by 2025 (http://www.searo.who.int/en/Section1174/Section1199/Section1567/Section1823_8066.htm) 
Introductions $\mid$ Assessment of Epigenetic profile in Alzheimer's disease

and unless an alternative medical therapeutics is discovered correspondingly, medical expenses will also continue to surge.

\subsubsection{Risk factors and Pathology of Alzheimer's disease}

Risk factors of $\mathrm{AD}$ are multivariate in nature and probably $\mathrm{AD}$ is caused by a complex interaction of environmental and genetic factors. Aging processes are major non-genetic definitive risk factors and the propensity to develop the disease increases considerably in people above the age of 65 years (Brookmeyer et al., 1998). Strong genetic association with the disease is due to autosomal dominant mutations in 3 genes: APP, Presenilins (PS1 and PS2) but account for less than $5 \%$ of AD cases (Bertram, 2008). It is yet to be known the proportion of the disease that is influenced by single nucleotide polymorphisms (SNPs) in other genes. Other risk factors include alcohol, blood pressure, diabetes mellitus, homocysteine, hormone therapy, inflammation, nutritional antioxidants and physical activity (http://www.alzrisk.org/). Post-traumatic stress disorder (PTSDs) and low educational level have also been linked with AD (Letenneur et al., 1999; Yaffe et al., 2010; Zhang, 1990).

Posthumous examination of $\mathrm{AD}$ brain exhibit mainly two key pathological hallmarks: extracellular senile amyloid plaques and intracellular neurofibrillary tangles (NFTs) (Kosik et al., 1986). Plaques are product of the main genetic components of the disease Amyloid Precusor Protein $(A P P)$ gene in which dominant mutations potentiate $\mathrm{A} \beta$ generation. APP dosage can also accelerate $\mathrm{AD}$ since Down syndrome patients with an extra copy of chromosome 21, on which APP is encoded, develop early onset AD. Also, mutations of the presenilin genes, which encode an essential subunit of the gamma-secretase that is critical for the final step of APP cleavage to generate A $\beta$-peptides, will result in early onset AD (Haass and Selkoe, 2007; Selkoe and Podlisny, 2002). Data obtained in transgenic mouse models (Palop et al., 2006; Palop and Mucke, 2010) and identification of cognitive intact human beings with high plaque load (Snowdon, 1997) however caution against the interpretation that plaques and plaque-associated dystrophic neurites as the main substrate of cognitive decline in $\mathrm{AD}$. The second hallmark of $\mathrm{AD}$, intracellular NFTs made up of hyperphosphorylated tau (Kosik et al., 1986; Nukina and Ihara, 1986; Wischik et al., 1988; Wood et al., 1986), correlate more closely with cognitive decline in AD than plaques (Braak and Braak, 1995; Giannakopoulos et al., 2003) establishing a causal role for tau hyperphosphorylation and neurofibrillary tangles in $\mathrm{AD}$, despite lack of causal mutation(s) in tau in classical AD. 
Altered tau function continued to gain relevance in $\mathrm{AD}$ field and it was recently reported that ectopic expression of tau mediates the toxic $A \beta$ function. Furthermore contextual memory and motor task were rescued by suppression of tau in transgenic mice carrying a mutant tau (Ittner et al., 2010; Roberson et al., 2007). Mutant tau is also involved in another type of dementia the familial FTDP-17 (Foster et al., 1997). Stability of microtubule impacted by tau is affected by phosphorylation (Higuchi et al., 2005; Weingarten et al., 1975; Zhang et al., 2004). Truncated tau was recently shown to have a higher tendency of aggregation than its native form suggesting participation of a possible proteolytic modification of tau in tangle formation (Filipcik et al., 2009; McMillan et al., 2011). Although the link of NFT and plaques pathology to neuronal and synaptic loss is unclear (Wenk, 2003) the progressive reduction in brain volume is a key aspect of AD pathogenesis (Karow et al., 2010). Besides, reactive astrogliosis, Lewy bodies, aggregates of $\alpha$-synuclein are also observed in the brains of AD patients (Kotzbauer et al., 2001). Furthermore, amyloid may be deposited in the walls of cerebral blood vessels (cerebral amyloid angiopathy) thus hindering cerebral blood flow which culminates in vascular dementia, the second prevalent form of dementia seemingly observed in stroke.

\subsubsection{Genetic Risk Factors and Amyloid Hypothesis}

A $\beta$-oligomers are defining lesions associated with Familial AD (FAD). Mutations in APP, a $400 \mathrm{~kb}$ gene located in the mid portion of the long arm of chromosome 21 (Goldgaber et al., 1987; Tanzi et al., 1987) that encodes APP protein and the PS1 and PS2 genes, which encode the subunits of the $\gamma$-secretase that processes APP have been strongly implicated in FAD. These mutations rather cause an early onset of the disease. APP is a type 1 membrane glycoprotein that undergoes proteolytically ectodomain shedding from $\alpha$-secretase (Selkoe and Podlisny, 2002), a disintegrin metalloproteinases, ADAM 10 and ADAM 17 (Buxbaum et al., 1998; Lammich et al., 1999) acting as $\alpha$-secretases. Alternatively, APP is cleaved by a membrane anchored aspartyl protease called $\beta$-secretase, $\beta$-site cleavage enzyme (BACE) sixteen amino acid (aa) residues $\mathrm{N}$-terminal proximal to the $\alpha$-secretase site (Vassar and Citron, 2000). Constitutive cleavage of the retained membrane C-terminal fragment CTF-83 and C99 (Fig. 1) releases the p3 peptide that comprises of residues 17-40/42 of $A \beta, A \beta$ respectively (Selkoe and Podlisny, 2002) and the APP intracellular domain (AICD) believed to localize in both cytoplasm and nucleus (Cupers et al., 2001; Kimberly et al., 2001; Sastre et al., 2001). Functionally, APP may be involved in in cell adhesion, neuronal survival, 
synaptogenesis, vesicular transport, neuronal migration, modulation of synaptic plasticity, neurite outgrowth and insulin and glucose homeostasis (Mark et al., 1997a; Mark et al., 1997b; Perez et al., 1997; Qiu et al., 1995; Turner et al., 2003; Zheng et al., 1995). In addition, inheritance of variants of Apolipoprotein E4 (ApoE- $\varepsilon 4)$ does have a gene dosage effect (Corder and Woodbury, 1993; Farrer et al., 1997) thus increasing one's risk of developing the disease (usually late-onset).

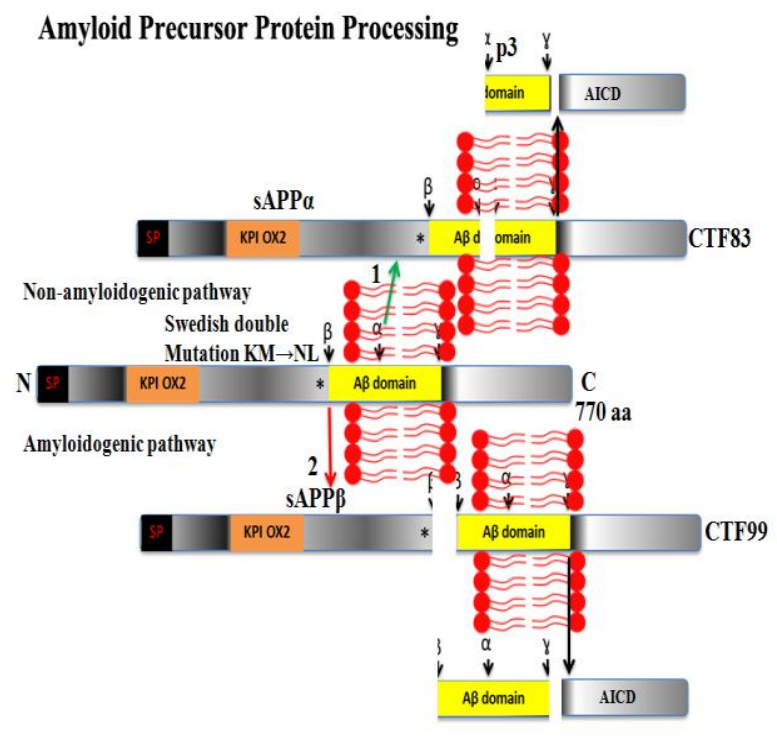

Fig.1.1: Schematic diagram showing the processing of Amyloid precursor protein (APP).APP cleavage by $\alpha-$ secretase within the $\mathrm{A} \beta$ domain precludes the amyloidogenic pathway producing a $\operatorname{SAPP} \alpha$ and a Cterminus fragment product, CTF83. Alternative cleavage by $\beta$-secretase generates SAPP $\beta$ and CTF99. Subsequent cleavage of $\gamma$-secretase CTF83 and 99 releases shorter fragment, $\mathrm{p} 3, \mathrm{~A} \beta$ respectively and AICD. Inadequate clearance and accumulation of the A $\beta$ aggregates to form oligomers and plaques. AICD is believed to translocate to the nucleus and activates gene expression upon binding of Tip60.

\subsubsection{Sporadic Alzheimer's disease and Environmental influence}

The genetic component of $\mathrm{AD}$ is appreciably well studied but does not fully explain the cause of all AD cases. Almost $95 \%$ of the cases until now cannot be explained by genetics hence considered to occur sporadically. Sporadic AD (SAD) rather manifests late in life contrary FAD. Late stage occurrence, thus suggests a concomitant increased imbibitions of toxic components like heavy metal poisoning thus genome-environment interaction, altered genomic plasticity (epigenetics) and possibly its involvement in the disease (Fischer et al., 2010; Takiguchi et al., 2003; Zhao et al., 1997).

\subsubsection{Insulin/ insulin like growth factors in the brain}

Insulin is an evolutionarily conserved hormone produced by the pancreas and acts downstream of neuronal signals to integrate metabolic output with reproductive capacity (Burks et al., 2000; Fielenbach and Antebi, 2008; Garofalo, 2002; Tissenbaum and Ruvkun, 1998). The canonical insulin signalling pathway can also be activated by insulin-like growth 
factors, IGF-I and IGF-II. Insulin and IGFs are developmentally expressed in many brain areas by neuro-epithelial lineages. In the adult brain IGF-I/II but not insulin is produced in some brain areas (Aguado et al., 1994; Ayer-le Lievre et al., 1991; Bach et al., 1991; Sandberg et al., 1988). Instead insulin largely crosses the blood brain barrier by a receptordependent mechanism (Baura et al., 1996; Yu et al., 2006). Insulin/IGFs act by binding to insulin or IGF receptors. In spite of the promiscuous manner of interaction between them and their receptors, downstream signalling usually recruits the same specific intracellular cascades: Phosphoinositide 3-kinase (PI3K)-Akt and Ras-Mitogen-activated protein kinase (MAPK) pathways which modulate gene transcription and a myriad of downstream kinasephosphatase that ultimately affect key cellular processes such as protein synthesis, autophagy, glucose and fat metabolism necessary elements for learning and establishment of memory, apoptosis, resistance to oxidative stress, longevity, stress response and fertility (de la Monte, 2009; Tatar et al., 2003). Impaired insulin signalling can result in weight gain, lethargy, memory disturbances, hunger and high blood pressure. Intranasal administration of insulin enhances the verbal memory, acute thermoregulatory and gluco-regulatory response to food intake (Benedict et al., 2011; Craft et al., 2012), suggesting that CNS insulin contributes to the control of the whole-body energy homeostasis in humans. IGF-II was also recently shown to be involved in both coding of memory and necessary for fear extinction (Agis-Balboa et al., 2011; Chen et al., 2011).

\subsubsection{Insulin and $A \beta$-degradation in $A D$}

Amyloid- $\beta$ degradation is mediated by a number of proteases including insulin degrading enzyme (IDE) or insulysin, a zinc binding metalloprotease and matrix metalloprotease 9 (MM9) and neprisylin (Backstrom et al., 1996; Iwata et al., 2001; Qiu et al., 1998). In light of this, mice generated lacking IDE showed 50\% decrease in $\mathrm{A} \beta$ degradation (Farris et al., 2003) and age associated decrease in IDE was reported in the brain (Affholter et al., 1990; Espinosa et al., 1991; Farris et al., 2004) thus linking insulin (diabetes) function to A $\beta$ processing, AD pathogenesis. Interestingly, mutations in IDE have been observed to cause diabetes in a rat model of type II diabetes mellitus and also result in enhanced cerebral deposition of $A \beta$ (Farris et al., 2004). 
\begin{tabular}{l|l} 
Introductions & Assessment of Epigenetic profile in Alzheimer's disease
\end{tabular}

\subsection{Memory mechanisms in the adult brain}

Memory is an organism's ability to store, retain, and recall information and experiences. Memory is a fundamental process without which we are not capable of doing anything except for simple reflexes and stereotyped behaviours. In a society constantly changing, we are defined by experience: feeling, wanting, perceiving, curiosity etc. Therefore memory can be defined as behavioural changes induced by experience. Learning is therefore the process leading to the acquisition of such behavioural changes. At the helm of affairs controlling the coding is the brain which is the organ responsible for what we call the mind. This also implies that there are different forms of memory. Some of which concern events and facts and are available to us consciously and other types that are unconscious. Some memory types persist whilst others are ephemeral and fade over time suggesting different forms of memory depending on duration of occupation of thought and intensity. Concepts regarding memory types are further described below.

\subsubsection{Short term and long term memories}

Memory can be distinguished on the basis of duration and molecular demands. Short term memory (STM) lasts between minutes to hours (Goelet et al., 1986; Tully and Quinn, 1985) while long term memory (LTM) lasts hours to days. The human brain has vast capacity to consolidate memory that is subsequently available for a long period of time. This is facilitated by learning and encoding it in a stable way, therefore retrieval is dependent on how information is stored. Coding of LTM involves stages such as learning and storage. Memory storage involves consolidation. This makes it robust easy to retrieve. Stimulus intensity could also influence the state of memory coding.

\subsubsection{Declarative and Non-declarative memories}

Memory is a collection of mental abilities that depend on different systems within the brain. Careful studies can isolate memory from perception and other intellectual abilities and examine each kind of memory separately. The most important distinction between forms of memory divides our conscious recall of facts and events about our world and experience (declarative memory) (Ullman, 2004) from various skills, habits, and reactions we remember without conscious effort (non-declarative memory). Declarative memory can also be divided into episodic memory that stores specific personal experiences and semantic memory that 
\begin{tabular}{l|l} 
Introductions & Assessment of Epigenetic profile in Alzheimer's disease
\end{tabular}

stores factual information (Tulving, 1972). Episodic memory handles information about where, when and how one experienced an event. Both hippocampus and pre-frontal cortex (PFC) are involved in declarative memories (Eichenbaum, 2001; Levine et al., 2004) and shown to be facilitated by sleep (Ellenbogen et al., 2006). However, PFC is involved in episodic memory more than semantic memory (Levine et al., 2004). Impairment of declarative memory affecting formation of both new and retrieval of old memories is called amnesia and memory loss affecting knowledge of what someone once knew is called an agnosia. Procedural memory, the most vital task of non-declarative memory and handles specific procedure involving cognitive and motor skills often gradually acquired over time. Striatal neurons are involved in this memory processing (Kreitzer, 2009) and the cerebellum is an integral part of this memory type processing (Saywell and Taylor, 2008).

\subsubsection{Associative memory}

Memory organization in which the memory is accessed by its content (as opposed to an explicit memory eg. postal address is referred to as associative memory. Organisms retrieve information more efficiently when it is linked to other related information. Hence reference cues are "associated" with actual memory contents until a desirable match (or set of matches) is found. First described by Ivan Pavlov, a solicited response in a form of salivation was obtained when a dog was presented with food which served as the unconditioned stimulus (US). A second stimulus that did not elicit salivation when presented alone (sound of a bell) was chosen as the conditioned stimulus (CS). However, when the US was coupled with the CS and presented to the dog, it was observed that after repeated training, the dog began to salivate; a response termed a conditional response (CR). In rodents, fear conditioning paradigm is used in testing associative memory (Blanchard and Blanchard, 1969). Tone or light is often employed as the CS and electric shock as the US. Re-exposure of a mouse to only CS (previously subjected to the CS followed by a mild electric shock) cringes at one spot, shivers and stops any exploratory behaviour. This phenomenon is called 'freezing' and requires an intact hippocampal network (Kim and Fanselow, 1992).

\subsubsection{Spatial Memory}

Spatial memory employs the information conveyed from visio-proprioception to form geographical representation of our environment enabling us to navigate. This is made 
possible by the help of bearings and spatial cues, associated with paths traversed. Spatial memory is measured in rodents using the Morris Water Maze task developed by Richard Morris (Morris, 1981). The rodent is required to locate a hidden platform in a pool of opaque water with the help of visual cues provided. The escape latency; the time required by the animal to find the platform inversely correlates with duration of training. Retention of acquired memory is then tested after training for several days by exposing the animal to the pool without the platform. Spatial memory acquisition and consolidation is dependent on the hippocampus (Crusio and Schwegler, 2005; Rossi-Arnaud et al., 1991; Schwegler and Crusio, 1995).

\subsection{Anatomical view of memory coding and molecular mechanisms}

Memory consolidation correlates with structural and molecular changes in different brain parts. New synapse and new neurons are born leading to more connections to other cells, enhanced neurotransmitter release capacity and activation of cascades leading to long lasting effect of transduced signals. Lesion and neuro-imaging studies demonstrated the involvement of different cortical regions during activities. Credence is lent from the famous H.M. case. He had both his left and right medial temporal lobe (MTL) surgically removed as a result of the bicycle accident which led to persistent epileptic seizures. Although, nearly two-thirds of his hippocampus, parahippocampal gyrus and amygdala were removed along with his MTLs (Scoville and Milner, 1957), his perception, abstract thinking and reasoning ability were not affected. In addition, his ability to learn new motor skills were also not affected (Corkin, 2002). Even so he suffered severe anterograde amnesia: inability to form new lasting memories and loss of cognitive ability (Scoville and Milner, 1957) demonstrating the extent of task division and independence of different cerebral pathways. The case also orchestrates the organizational levels of the brain with some regions such as the hippocampus serving as cortical conduits for memory processing and storage. Signal transduction in neurons can be modified in a stimulus dependent manner either by post-translational modifications e.g. phosphorylation of a receptor or via de-novo transcription of gene. STM is largely dependent on existing neuronal circuits (Tarnow, 2009) and is de novo protein synthesis independent (Castellucci et al., 1989; Kandel, 2001). In contrast LTM and Long Term Potentiation (LTP), which is considered as a molecular correlate of LTM, are however, dependent on protein synthesis (Costa-Mattioli and Sonenberg, 2008; Kandel, 2001; Lisman et al., 2002). Gene expression is however, regulated by epigenetic mechanisms discussed below. 
Introductions Assessment of Epigenetic profile in Alzheimer's disease

\subsection{Epigenetic gene expression and its role in Cognitive function}

The warehouse of genetic material, DNA of most living being is the nucleus. The limited space due to length is overcome by nature's design for packaging these essential materials in the form of chromosomes made of sub-packing units called histones in association with the DNA making up the chromatin. The basic structure of chromatin consists of nucleosome, which comprises $\sim 147$ bp of DNA wrapped around an octamer of core histones (Kouzarides, 2007). The octamer is composed of two (H2A-H2B) histone dimers and a tetramer of $\mathrm{H} 3$ and $\mathrm{H} 4$ with histone $\mathrm{H} 1$ as a linker. The chromatin structure is however, extremely plastic and offers an important mechanism to translate environmental stimuli into alterations in gene expression, which was termed by Conrad H. Waddington as "Epigenetic". This is the inheritance of changes in gene expression and self-perpetuating marks without mutations in the underlying genetic components. Covalent modifications of DNA and histones enable the chromatin to assume mainly two main states: euchromatin, which makes gene accessible and the counter state of heterochromatin.

\subsubsection{Chromatin plasticity}

Access to the gene by the transcriptional machinery allowing gene expression is determined by the state of chromatin. This is dependent on the modifications that are on both the DNA and as well the histones. The $\mathrm{N}$-termini of histones are susceptible to modifications such as acetylation, phophorylation, methylation, ubiquitination, sumoylation and ADP-ribosylation (Strahl and Allis, 2000; Vaquero et al., 2003). Apart from histones tail modifications, DNA can also be methylated and hydroxymethylated (Cannon-Carlson et al., 1989; Gold et al., 1964; Kriaucionis and Heintz, 2009). Histone modifications have important roles in transcriptional regulation, DNA repair (Huertas et al., 2009) DNA replication, alternative splicing (Luco et al., 2010) and chromosome condensation (Kouzarides, 2007).

\subsubsection{DNA Methylation}

DNA methylation is an important biological process that regulates gene expression in living organisms. It is the earliest known epigenetic modification. Altering of DNA on 5-position of cytosine $(\mathrm{C})$ that precede guanosine in $\mathrm{CpG}$ dinucleotides of gene promoters has profound impact on transcriptional states and cellular identity and serves as a critical epigenetic mark by modifying DNA-protein interactions. As such methylation modulates core epigenomic 
processes; including gene expression, X-chromosome inactivation (Goto and Monk, 1998), silencing of repetitive elements, imprinting ( $\mathrm{Li}$ et al., 1993), and regulation of centromeric and telomeric heterochromatin (Bourc'his et al., 2001). Maintenance of this is essential to avoid perturbation of the cellular integrity.

\subsection{Setting and Resetting of Methylation}

DNA methylation occurs in three different nucleotide sequence contexts: CG, CHG, and $\mathrm{CHH}$ (where $\mathrm{H}=\mathrm{C}, \mathrm{T}$, or $\mathrm{A}$ ). Methylation patterns in the genome are established by DNA methyltransferases, (MTases), which catalyze transfer of $\mathrm{CH}_{3}$ to $\mathrm{C} 5$ of cytosine and adenine residues. Transmethylation proceeds generally through a nucleophilic $S_{N} 2$ attack of a target atom onto the sulfonium-bound methyl group of $S$-adenosyl-L-methionine (Fig. 1.2) (Klimasauskas and Weinhold, 2007). Methylation is established by three active DNA methyltransferase (DNMT) 1, 3a and 3b (Bird and Macleod, 2004; Goll and Bestor, 2005) although 5 methyltransferases have been described until now. The first group, de-novo methyltransferase DNMT3a and DNMT3b preferentially methylates unmethylated cytosines on both strands. The DNMT3 family contains a third member, DNMT3L, which is required for establishing maternal genomic imprinting, despite being catalytically inactive (Bourc'his et al., 2001). DNMT1 is believed to be copying already existing methylation profile in the genome, maintaining DNA methylation profile. It recognizes an already hemi-methylated strand and adds methyl groups to cytosine on the complementary strand. The last member DNMT2 is believed to methylate tRNAs (Goll et al., 2006) and targeted deletion had no impact on global DNA methylation of the cell (Okano et al., 1998).

Reversal of methylation pattern is an area of intense deliberation. Cytosines are relatively underrepresented probably due to deamination of methylated cytosines to thymines making the overall frequency of CpGs within the genome less than statistically expected (Herman and Baylin, 2003). In spite of their relative underrepresentation, $\mathrm{CpG}$ dinucleotides can be accumulated in small stretches of DNA called CpG islands (CGI). CGIs are often associated with gene promoter regions and are usually unmethylated. In contrast, about $80 \%$ of the $\mathrm{CpG}$ dinucleotides outside CpG islands are methylated (Bird, 2002; Herman and Baylin, 2003). Stepwise conversion of methylated cytosine to hydroxymethylcytosine was recently described to be the mechanism of removal of demethylation (Cannon-Carlson et al., 1989). On-going works might shed light on exact mechanism and the enzymes involved. Alternative 
mechanism was believed to be due to Growth arrest and DNA Damage inducible $45 \beta$ (GADD45ß) (Gavin et al., 2012; Matrisciano et al., 2011).

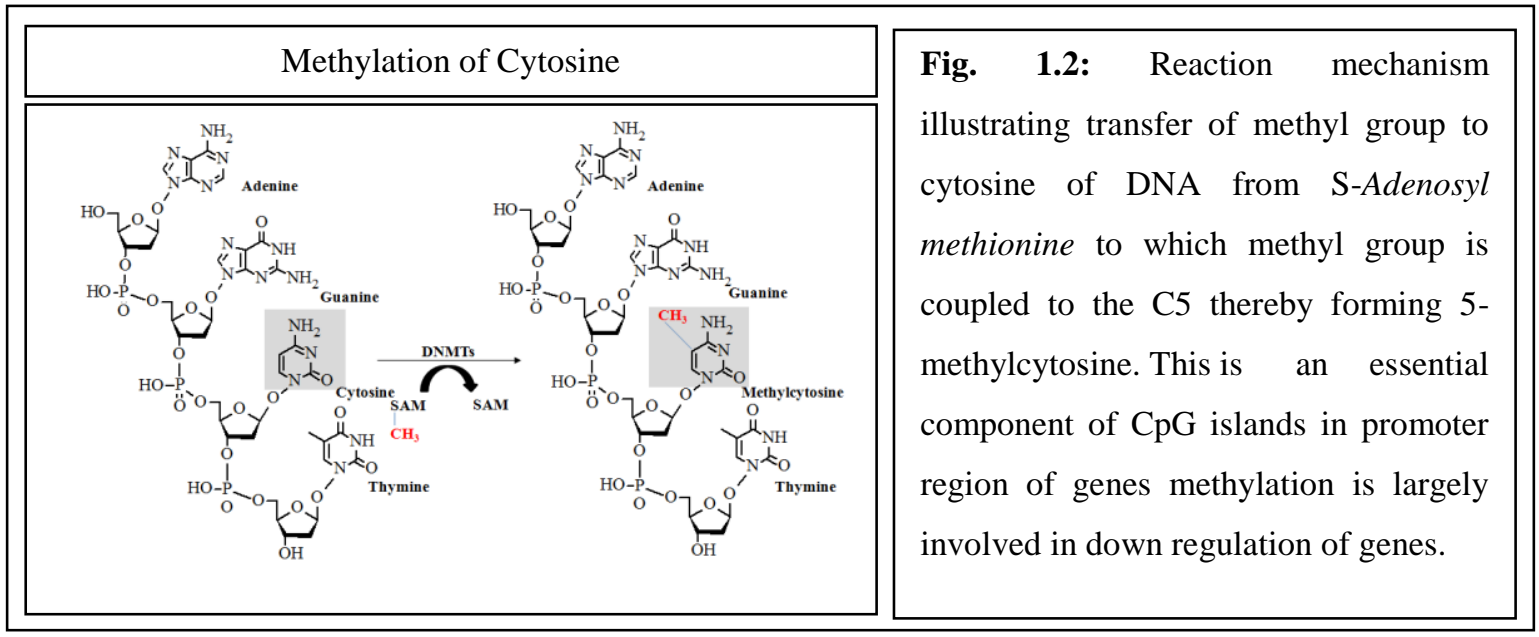

\subsection{Relevance of Global Methylation Pathway}

Imbalance in DNA methylation may lay the appropriate ground for the threshold of developing diseases to be reached with ease as methylation is unique and critical for health and is involved in a plethora of events. Methylation plays a pivotal role in establishing and maintaining an inactive state of a gene by rendering the chromatin structure inaccessible to the transcription machinery. Neuro-developmental disorders immunodeficiency, centromeric instability, and facial anomalies (ICF) involving deregulation of both coding genes and repetitive elements (Hansen et al., 1999; Okano et al., 1999; Xu et al., 1999) and Rett syndrome (Amir et al., 1999; Chao et al., 2007; Moretti and Zoghbi, 2006) are due to mutations in DNMT3B and methyl CpG binding domain protein 2 (MeCP2) respectively. Loss of DNA methylation can induce embryonic lethality as observed with DNMT1 deletion leading death around day (E) 8.5-9. DNMT1 mutant retain only one-third of the normal amount of DNA methylation ( $\mathrm{Li}$ et al., 1992). Duplication of section of spinal vertebrae in the posterior portion of the body due to mutations in Axin, an inhibitor of Wnt in a twin study was mimicked by aberrant methylation of the promoter of Axin (Oates et al., 2006). A positive correlation in methylation with parameters of myelination was observed during development thereby increasing methylation capacity in animal studies (Crang and Jacobson, 1982). Down syndrome and spina bifida were shown to result from deficiency in methylation due to mutations in MTFHR, essential in the methylation pathway lead to decreased B12 (Hobbs et al., 2000; James et al., 1999). 
Introductions Assessment of Epigenetic profile in Alzheimer's disease

Role of methylation is not only restricted to developmental processes rather it is global and also involved in learning paradigms. In contextual fear conditioning paradigm, dynamic effect of methylation leading to regulation of genes have been observed (Day and Sweatt, 2010; Miller et al., 2010; Miller and Sweatt, 2007). Both inhibition of DNMTs in the hippocampus using both 5-Aza, RG-108 and conditional forebrain and neuron-specific deletion of DNMT1 and DNMT3a produced the same deleterious effect on memoryassociated neuronal plasticity, providing a vital cellular link of learning deficits induced by jamming DNA methylation (Feng et al., 2010; Levenson et al., 2006; Miller et al., 2010; Miller and Sweatt, 2007).

\subsubsection{Histone acetylation}

Histone modifications on lysine tail are different ranging from acetylation, methylation, ubiquitylation, crotonylation and phosphorylation. However, one of the modifications which have been consistent with gene expression and also one of the focuses of this study is histone acetylation and will be discussed more in depth. Histone hype-racetylation and hypoacetylation are associated with elevation and repression of gene expression respectively (Kurdistani et al., 2004; Li et al., 2007). Acetylation is believed to lower the positive charge on the $\mathrm{N}$-terminal tails of histones thus reducing interaction with the negatively charged DNA-histone interaction (Lee et al., 1993; Zhang et al., 1998).

\subsection{Dynamic regulation of gene expression by HATs and HDACs}

Histone acetylation conferring an open state on chromatin is set by Histone acetyltransferases (HATs), enzymes which add an acetyl group to lysine residues on histone tails (Narlikar et al., 2002). HATs are divided into two main types: Type A and Type B HATs (Narlikar et al., 2002). Type A HATs can be further subdivided into three families: the GNAT family, the MYST family and the P300/CBP family (Narlikar et al., 2002). The type A HATs play essential roles in gene transcription regulation, DNA damage response and repair (Avvakumov and Cote, 2007). The type B HATs have not been very well characterised so far. A known member, HAT1 is involved in the acetylation of newly formed histones during chromatin assembly (Parthun, 2007), catalyses the acetylation of lysines 5 and 12 on histone $\mathrm{H} 4$ and is also involved in DNA repair (Benson et al., 2007). 
The effect of HATs are counteracted by eighteen histone deactylases (HDACs) classified into 4 classes (class I, IIa, IIb, III and IV) primarily on basis of protein sequence similarity and cofactor dependence counteract. Class I HDACs comprise HDAC1, 2, 3 and 8 are homologs of RPD3 are constitutively nuclear proteins and are widely expressed (Taunton et al., 1996). They associate with multi-protein repressor complexes such as Sin3A, NcoR/SMRT, CoREST, Mi2/NuRD and EST1B (Inche and La Thangue, 2006). Hdac8 is the only fully functional enzyme in isolation (Hu et al., 2000; Lee et al., 2004). HDAC1 has a deacetylase activity in embryonic stem (ES) cells (Haberland et al., 2009b). Hdacland Hdac2- null mice die before embryonic day 10.5 (E10.5) and $24 \mathrm{~h}$ after birth respectively due to excessive proliferation of cardiomyocytes (Lagger et al., 2002; Montgomery et al., 2007). Overexpression of Hdacl had no overt detrimental effect on memory formation whereas Hdac2 reduced spine density, synapse number and cognition when over-expressed in a neuronspecifically in mice and loss of Hdac2 was found to be beneficial (Guan et al., 2009). Additionally, Loss of Hdac3 is shown to cause defective DNA double-stranded break repair (Bhaskara et al., 2008) and Hdac8 is however essential for skull formation (Haberland et al., 2009a).

Class-II HDACs are sub-divided into two classes: class-IIa HDACs (4, 5, 7 and 9) and classIIb HDACs (6 and 10) which undergo stimulus-dependent nucleo-cytosplasmic shuttling. HDAC5 and HDAC9 are enriched in the muscle, HDAC7 in the endothelial cells and thymocytes and HDAC4 is abundant in the brain and growth plates of the skeleton (Haberland et al., 2009b) and over-expression was protective in retina ganglion cell degeneration (Chen and Cepko, 2009). HDAC 5 and 9 have been shown to be essential for cardiovascular growth and development (Chang et al., 2004). HDAC9 modulates motor innervations of skeletal muscle (Mejat et al., 2005). HDAC9 and 10 inhibition can also prevent homologous recombination (Kotian et al., 2011). An interesting study has shown that HDAC4 is exported out of the nucleus upon spontaneous electrical stimulation in neurons (Chawla et al., 2003). However, in the same study, HDAC5 translocation required the stimulation of calcium flux (Chawla et al., 2003). This shows that, in neurons, HDAC4 and HDAC5 could be associated with neuronal activity. With exception of inhibition of HDAC6 might be beneficial for the treatment of $\mathrm{AD}$ by virtue of its cytoplasmic residence and deacetylation of $\alpha$-tubulin leading to its instability (Haggarty et al., 2003; Hubbert et al., 2002; Verdel et al., 2000). HDAC11 is the only member of class IV. 
Class III (Silent Information Regulator-2 (Sir2)-related protein (sirtuin) HDACs have 7 members, SIRT 1-7 that share homology with the yeast SIR2. Unlike class I and II HDACs that have $\mathrm{Zn}^{2+}$ as a cofactor, the sirtuins require $\mathrm{NAD}^{+}$as cofactor. These enzymes are promiscuous and fidelity to histones is not guaranteed. Therefore the name HDAC and HAT might be a misnomer and instead these enzymes might simply be referred to as lysine deacetylases (KDACs) and lysine acetyltransferases (KATs).

\begin{tabular}{|c|c|}
\hline Regulation of Histone Acetylation & $\begin{array}{l}\text { Fig.1.3: Gene regulation mediated by chromatin } \\
\text { modification. A: A cell with chromosome of condensed } \\
\text { nucleosome as a result of reduced acetylation acetyl } \\
\text { group shown with the yellow bubbles and DNA wound } \\
\text { around the nucleosome. B: Opened chromatin resulting } \\
\text { from increased acetylation on lysine residues of histone } \\
\text { leading to the relaxation of DNA and chromatin } \\
\text { interaction. mRNA trancription is then enabled by } \\
\text { allowing of RNAPII to traverse the chromatin. }\end{array}$ \\
\hline
\end{tabular}

\subsection{Modes of Inhibition of HDACs}

The gene expression has gained relevance in the field of cancer and targeting of HDACs using synthetic inhibitors had had important influence on some cancer forms like leukaemia for which SAHA has been approved by the FDA for clinical use. In spite of the high recognition of beneficial role HDAC inhibitors have had so far on experimental neurodegenerative diseases, none has being approved for clinical due to their unspecific mode of action and secondly a setback from the ability to cross the blood brain barrier. Largely, HDAC inhibitors are divided into 4 groups: short chain fatty acids, hydroxamic acids, cyclic tetrapeptides and benzamides described below

Short chain fatty acids (SCFA): This group of inhibitors are generally not very potent requiring concentrations in the $\mathrm{mM}$ range; however, they serve as useful tool in studying mechanisms and structures of HDAC inhibitors. Notable examples of inhibitors are the valproic acid and butyrate shown to be helpful in restoring cognition in APPPS1-21 mice (Govindarajan et al., 2011; Ricobaraza et al., 2009). Hydroxamic acids: Required in the range of of micromolar to subnanomolar concentrations and deemed to be potent inhibitors of HDACs. TSA derived from Streptomyces and Suberoylanilide hydroxamic acids (SAHA) 
also have inhibitory effects. SAHA inhibits HDACs by binding to a zinc ion in the catalytic domain of the enzyme, thus preventing the deacetylation of histones (Finnin et al., 1999). This was postulated to be the mechanisms of inhibition of other hydroxamates. Cyclic tetrapeptides: These are believed to inhibit HDACs through the use of the epoxyketone group that is used to alkylate the catalytic pocket of HDACs. Depsipeptide, the best know HDAC inhibitor from this group, has antitumor activity against chronic lymphocytic leukaemia and myelogenous leukaemia and other refractory neoplasms. Benzamides: MS-275 and CI-994 are the two most well known synthetically derived inhibitors of HDACs in this group. $\mathrm{Zn}^{2+}$ ion binding of the benzamide is believed to be the mechanism of inhibition of HDACs.

\subsection{Physiological inhibitors of HDACs: Sphingosine 1-phosphate (S1P)}

Aside the small synthetic molecules described above, inhibition of HDACs physiologically is in different forms like phosphorylation, s-nitrosylation, acetylation and polyubiquitylation leading to sequestration from site of action. Phosphorylation also leads to docking/binding to a site which makes the bound enzyme ineffective. Sub-cellular localization also serves to regulate the enzymatic function of the HDACs. Another but quite recent level of inhibition of class I HDACs namely: Hdac1 and Hdac2 that has been described is through the activity of Sphingosine kinase 2. This inhibition occurs through phosphorylation of sphingolipid to generate Sphingosine 1-phosphate (S1P). Sphingosine (2-amino-4-octadecene-1,3-diol), an 18-C amino alcohol with an unsaturated hydrocarbon chain, which forms a primary part of sphingolipids, a class of cell membrane lipids that include sphingomyelin. Sphingosine is generated by either stepwise biosynthesis from serine and palmitoyl-CoA or hydrolysis from sphingomyelin by sphingomyelinases (SMases) to ceramide which then serves as substrate for ceramidase to generate sphingosine (Andrieu-Abadie and Levade, 2002; Clarke et al., 2006; Hannun and Obeid, 2002). Two sphingosine kinases SPHK1 and SPHK2 have been cloned and characterized, they mediate phosphorylation of sphingosine in vivo (Kohama et al., 1998; Liu et al., 2000) to yield S1P. SphK1 and SphK2 share overall homology however, they display different catalytic properties, sub-cellular locations, tissue distribution, and temporal expression patterns during development. SphK1 is mainly localized to the cytosol, while SphK2 is mainly nuclear (Kohama et al., 1998; Liu et al., 2000) and shuttling between the cytosol and the nucleus, and mainly associates with chromatin but not detected in the nucleoplasm. 


\subsubsection{Role of S1P in Alzheimer's disease}

S1P a unique and potent signalling lipid with broad effects on cytoskeleton dynamics and cell growth, proliferation, differentiation, survival, migration, apoptosis, calcium homeostasis, neurite retraction and angiogenesis (Huang et al., 2009; Moriue et al., 2008; Roztocil et al., 2009; Takuwa et al., 2010). S1P has been implicated with many cellular functions such as chemotaxis, thereby inducing lymphocyte egression from secondary lymphoid organs and migration of eosinophils and mast cells to sites of inflammation (Spiegel and Milstien, 2003). Most of the physiological functions attributed to S1P so far have been linked to the binding to G protein-coupled receptors (Lee et al., 1998; Spiegel and Milstien, 2003). Lipid rafts enrichment of sphingolipids, glycerophospholipids and cholesterol suggested their involvement in APP processing (Castro et al., 2009; Grosgen et al., 2010). This hypothesis was tested by depletion of sphingolipid using an inhibitor of serine-palmitoyl-CoA. Findings of this experiment alluded to the beneficial role of sphingosine as increased levels of $A \beta-42$ were observed by depleting sphingolipid biosynthesis, interestingly, the levels/ratio of A $\beta-42$ was restored upon addition of sphingosine (Sawamura et al., 2004). Furthermore, sphingosine levels have previously been reported to be decreased in AD (He et al., 2010). The role of sphingolipids became more interesting as nuclear S1P has been shown to have inhibitory effect on class 1 Hdacs. The finding that S1P and SphK2 are part of a co-repressor complex, that modulate histone acetylation and gene expression opens an interesting scenario both for nuclear lipid signalling and class I HDAC regulation.

\subsection{Objective of the study}

Recent studies suggest that epigenetic mechanisms contribute to the pathogenesis of Alzheimer's disease (AD). The aim of this work was to further elucidate the role of DNA methylation and histone acetylation in AD. With this end in view, I employed the APPPS121 mouse model for amyloid pathology and first performed a detailed characterization of learning behaviour in these mice in order to identify the time point marking the onset of cognitive deficits.

To investigate a potential role of DNA-methylation in AD pathogenesis, I decided to take a specific approach by analysing the regulation and role of insulin binding protein 7 (IGFBP7). This was based on the fact that insulin and IGFs, as well as IDE, have been implicated with AD. Although IGFBPs have received less attention, previous data from our laboratory 
Introductions Assessment of Epigenetic profile in Alzheimer's disease

demonstrated that IGFBP7 is linked to the pathogenesis of post traumatic stress disorder, which is a risk factor for sporadic AD (Agis-Balboa et al., 2011; Yaffe et al., 2010).

The second aim of my thesis was to further elucidate the role of histone-acetylation in $A D$ pathogenesis. Using the same APPPPS1-21 mouse model, my plan was to describe histonechanges that are accompanied by the onset of memory disturbances and to further study the mechanistic cause of such deregulation. 


\section{Materials and methods}

\subsection{Materials}

\subsubsection{Chemicals and reagents}

Acetic acid

Roth, Karlsruhe

Acrylamide

Roth, Karlsruhe

Agarose

Roth, Karlsruhe

Ammonium persulfate

Roth, Karlsruhe

Ampicillin

Applichem, Darmstadt

Ampuwa

Fresenius AG, Bad Homburg

Arabinoside Cytosine

B27-Suppplement

Sigma, Deisenhofen

bFGF

Gibco/Life Technology, Aukland

BSA

Roth, Karlsruhe

Roth, Karlsruhe

Bromophenol blue

Roth, Karlsruhe

$\mathrm{CaCl}_{2} \cdot 2 \mathrm{H}_{2} \mathrm{O}$

Roth, Karlsruhe

Chloroform

Applichem, Darmstadt

DAPI

Vectarshield, Burlingame, CA

DEPC

Sigma, Deisenhofen

dNTPs

Bioline, Luckenwalde

DNA Marker

Fermentas, Heidelberg

DTT

Roth, Karlsruhe

Dynabeads

Invitrogen, Oslo

EDTA

VWR, Leuven

EGTA

Fermentas, Heidelberg

Ethanol

Roth, Karlsruhe

Ethidium bromide

Roth, Karlsruhe

Formaldehyde

Applichem, Darmstadt

Gentamicin

Applichem, Darmstadt

Glutamax

Gibco/Life Technology, Aukland

Glutamine

Gibco/Life Technology, Aukland

Glycerol

Roth, Karlsruhe

Glycine

Applichem, Darmstadt

Guanidine hydrochloride

Roth Karlsruhe 
HEPES

Horse serum

Insulin

$\mathrm{KCl}$

$\mathrm{LiCl}$

Dulbecco's MEM

$\beta$-Mercaptoethanol

Methanol

$\mathrm{MgCl}_{2}$

Milk powder

MNase

$\mathrm{NaF}$

$\mathrm{NaH}_{2} \mathrm{PO} 4$

$\mathrm{Na}_{2} \mathrm{HPO} 4$

$\mathrm{NaOH}$

$\mathrm{NaCl}$

Neurobasal-A-Medium

Pierce Protein A/G Plus-Agarose

Proteinase K

Roti-Quant for Bradford

SeeBlue Plus2 loading dye

Nonidet

Paraformaldehyde

PBS

Penicillin/Streptomycin

Peptone

Phenol

PMSF

Sodium acetate

Sodium azide, $\mathrm{NaN}_{3}$

Sodium orthovanadate

Sodium dodecyl sulphate

Salmon sperm DNA

Sucrose
Roth, Karlsruhe

PAN Biotech, Aidenbach

Sigma, Deisenhofen

VWR, Leuven

Applichem, Darmstadt

Biochrom, Berlin

Roth, Karlsruhe

Roth Karlsruhe

Roth Karlsruhe

Roth Karlsruhe

Roth Karlsruhe

VWR, Leuven

VWR, Leuven

VWR, Leuven

Roth Karlsruhe

Applichem, Darmstadt

Gibco/Life Technology, Aukland

Pierce/Thermo-Scientific, Rockford

Roth, Karlsruhe

Roth, Karlsruhe

Fermentas, Heidelberg

Fluka, Aldrich Deisenhofen

Roth, Karlsruhe

Roth, Karlsruhe

Roth, Karlsruhe

Sigma, Deisenhofen

Applichem, Darmstadt

Applichem, Darmstadt

Applichem, Darmstadt

Applichem, Darmstadt

Sigma, Deisenhofen

Roth, Karlsruhe

Applichem, Darmstadt

Applichem, Darmstadt 
TEMED

Transferrin

Tris

Triton-X-100

TRI-reagent

Tween-20

Yeast extract
Roth, Karlsruhe

Sigma, Deisenhofen

Applichem, Darmstadt

Roth, Karlsruhe

Sigma, Deisenhofen

Roth, Karlsruhe

Applichem, Darmstadt

\subsubsection{Solutions, buffers and media}

Agarose gel electrophoresis buffers

50 X TAE (Tris-Acetate-EDTA) preparation protocol

242 Tris base, $57.1 \mathrm{~mL}$ Acetic acid, $100 \mathrm{~mL}$ 0.5 M EDTA (before use shake vigorously). Add $\mathrm{H}_{2} \mathrm{O}$ to $1 \mathrm{~L}$ and adjust $\mathrm{pH}$ to 8.5 using $\mathrm{KOH}$

SDS-PAGE buffers: $40 \%$ Acrylamide stock solution, Acrylamide 29.2\% (w/w), Bisacrylamide, $0.8 \%$ (w/w), solution in $\mathrm{H}_{2} \mathrm{O}$

APS solution (10\%): Ammonium persulfate in $\mathrm{H}_{2} \mathrm{O}$

Running buffer (5x) for 5 L: $75.5 \mathrm{~g}$ Tris/HCl (pH 8.3), $360.0 \mathrm{ml}$ Glycine, $25.0 \mathrm{~g}$ SDS $\mathrm{pH} 8.3$

Sample buffer (2x): $0.5 \mathrm{M}$ Tris/HCl (pH 6.8), 20\% Glycerol, 10\% $\beta$-Mercaptoethanol, $4 \%$ SDS

Separating gel (12\%) per ml: $1.6 \mu 1 \mathrm{H}_{2} \mathrm{O}, 1.3 \mu 1$ of $1.5 \mathrm{M}$ Tris/ $\mathrm{HCl}(\mathrm{pH} 8.3), 0.05 \mu 1$ of $10 \%$ SDS and $10 \%$ APS, $2.0 \mu 1$ of $30 \%$ acrylamide mix and $0.002 \mu 1$ of TEMED

Stacking gel (5\%) per ml: $\quad 0.68 \mu 1 \mathrm{H}_{2} \mathrm{O}, 0.13 \mu \mathrm{l}$ of $1.0 \mathrm{M}$ Tris/ $\mathrm{HCl}(\mathrm{pH} 6.8), 0.01 \mu \mathrm{l}$ of $10 \%$ SDS and $10 \%$ APS, $0.17 \mu \mathrm{l}$ of $30 \%$ acrylamide mix and $0.001 \mu \mathrm{l}$ of TEMED

Transfer buffer: $5.8 \mathrm{~g}$ Tris- $\mathrm{HCl}, 2.92 \mathrm{~g}$ Glycine, 20\% Methanol, $3.7 \mathrm{ml}$ 10\% SDS, $\mathrm{ddH}_{2} \mathrm{O}$ to $1000 \mathrm{ml}$

\subsubsection{Frequently used buffers and solutions}

TX-Extraction buffer: 50 mM Tris-HCl, pH 7.4, 150 mM NaCl, 1 mM EDTA, $1 \%$ Nonidet P40 (IPTGAL) and $0.1 \%$ SDS

4\% PFA (Fixation buffer): $4 \mathrm{~g}$ PFA in PBS dissolved with few drops of $10 \mathrm{M} \mathrm{NaOH}, \mathrm{pH}$ 7.4 , PBS to $100 \mathrm{ml}$

\subsubsection{Native ChIP Buffers}

Hypotonic solution: $320 \mu \mathrm{l}$ of $500 \mathrm{mM}$ EDTA, pH 8.0 and adjust volume to $800 \mathrm{ml}$ 
Materials and methods $\quad$ Assessment of Epigenetic profile in Alzheimer's disease

Dounce buffer: $0.242 \mathrm{~g}$ Tris, $0.163 \mathrm{~g} \mathrm{MgCl}_{2}, 0.03 \mathrm{~g} \mathrm{CaCl}_{2}$, adjust $\mathrm{pH}$ to 7.5 and volume to $200 \mathrm{ml}$ with $\mathrm{ddH}_{2} \mathrm{O}$

FSB Buffer: $20 \mathrm{ml}$ of $500 \mathrm{mM}$ EDTA, $\mathrm{pH} 8.0,4.85 \mathrm{~g}$ of Tris, $5.84 \mathrm{~g}$ of $\mathrm{NaCl}$, adjust $\mathrm{pH}$ to 7.5 and volume to $200 \mathrm{ml}$

Low Salt buffer: $2 \mathrm{ml}$ of 10\% SDS, $2 \mathrm{ml}$ Triton X-100, $0.8 \mathrm{ml}$ of $500 \mathrm{mM}$ EDTA, pH 8.0, $4 \mathrm{ml}$ of $1 \mathrm{M}$ Tris- $\mathrm{HCl}, \mathrm{pH} 8.0,10 \mathrm{ml}$ of $3 \mathrm{M} \mathrm{NaCl}$ adjust volume to $200 \mathrm{ml}$

High Salt Buffer: $2 \mathrm{ml}$ of 10\% SDS, $2 \mathrm{ml}$ Triton X-100, $0.8 \mathrm{ml}$ of $500 \mathrm{mM}$ EDTA, pH 8.0, $4 \mathrm{ml}$ of $1 \mathrm{M}$ Tris- $\mathrm{HCl}, \mathrm{pH} 8.0,33 \mathrm{ml}$ of $3 \mathrm{M} \mathrm{NaCl}$ adjust volume to $200 \mathrm{ml}$

0.1 M PMSF (phenylmethanesulfonylfluoride, M.W.=174.19 $\mathrm{g} / \mathrm{mol}$ ): $0.017 \mathrm{~g} / 1 \mathrm{ml}$ of Isopropanol

TE Buffer: $2 \mathrm{ml}$ of $1 \mathrm{M}$ Tris, $\mathrm{pH} 8.0,0.4 \mathrm{ml}$ of $500 \mathrm{mM}$ EDTA, $\mathrm{pH} 8.0$, adjust volume to $200 \mathrm{ml}$ with $\mathrm{ddH}_{2} \mathrm{O}$

Elution buffer: $0.21 \mathrm{~g} \mathrm{NaHCO}_{3}, 2.5 \mathrm{ml}$ of $10 \% \mathrm{SDS}$ and adjust volume to $25 \mathrm{ml}$ with $\mathrm{ddH}_{2} \mathrm{O}$ Lysis Buffer (10X) for proteinase $\mathrm{K}$ digestion:

$7.78 \mathrm{~g}$ Tris- $\mathrm{HCl}, 5 \mathrm{ml}$ of $500 \mathrm{mM}$ EDTA, $\mathrm{pH} 8.0,10 \mathrm{ml}$ of $10 \%$ SDS, $5.85 \mathrm{~g}$ $\mathrm{NaCl}$, adjust $\mathrm{pH} 8.0$ and make up volume to $50 \mathrm{ml}$

Lithium Chloride buffer: $2 \mathrm{ml}$ IGEPAL-CA 630, 2 g Sodium Deoxycholate, $2.12 \mathrm{~g} \mathrm{LiCl}$ $0.4 \mathrm{ml}$ of $500 \mathrm{mM}$, EDTA, $\mathrm{pH} 8.0$, and $2 \mathrm{ml}$ of $1 \mathrm{M}$ Tris, $\mathrm{pH} 8.0$, adjust volume to $200 \mathrm{ml}$

3M Sodium Acetate: $19.69 \mathrm{~g}$ anhydrous sodium acetate (M.W.=82.03), adjust $\mathrm{pH}$ to 5.2 with concentrated acetic acid and volume to $80 \mathrm{ml}$

3M 1,4-Dithio-DL-threitol (DTT) $\left(\right.$ M.W. = 154.3): $1 \mathrm{~g} / 2 \mathrm{ml}$ autoclaved $\mathrm{ddH}_{2} \mathrm{O}$

\subsubsection{Cell culture media}

Primary Neuronal culture (PNC) media:

HANKS solution: $6 \mathrm{~g}$ D-Glucose, $500 \mu \mathrm{l}$ Gentamicin (stock solution $10 \mathrm{mg} / \mathrm{ml}$ ) $0.35 \mathrm{~g}$ $\mathrm{NaHCO}_{3}, 2.383$ g HEPES, pH adjusted to 7.3-7.4

Dissection solution: $240 \mathrm{ml}$ HANKS, $0.72 \mathrm{~g}$ Albumin, bovine, $0.347 \mathrm{~g} \mathrm{MgSO}_{4}$

Digestion solution: $\quad 0.8 \mathrm{~g} \mathrm{NaCl}, 0.035 \mathrm{~g} \mathrm{NaHCO}_{3}, 0.037 \mathrm{~g} \mathrm{KCl}, 0.099 \mathrm{~g} \mathrm{Na}_{2} \mathrm{HPO}_{4}, 100 \mathrm{ml}$ $\mathrm{H}_{2} \mathrm{O}, \mathrm{pH}$ adjust to 7.3-7.4

Culture medium A: $0.5 \mathrm{~g}$ D-Glucose, $0.2 \mathrm{ml}(12.5 \mathrm{mg} / \mathrm{ml})$ Insulin, $90 \mathrm{ml}$ MEM Eagle, $1 \mathrm{ml}$ $(200 \mathrm{mM})$ Glutamax, $0.05 \mathrm{ml}(10 \mathrm{mg} / \mathrm{ml})$ Gentamicin, $10 \mathrm{mg}$ Transferrin, 10 ml Horse serum

Culture medium B: $100 \mathrm{ml}$ Neurobasal-A-Medium, $50 \mu \mathrm{l}$ Gentamicin, $125 \mu \mathrm{l}$ bFGF, $250 \mu \mathrm{l}$ L-Glutamine, $2 \mathrm{ml} \mathrm{B27} \mathrm{Supplement,} 125 \mu \mathrm{l} 4 \mathrm{mM}$ stock Cytosine-arabinoside

30\% Sucrose: $30 \mathrm{~g}$ of Sucrose dissolved in $100 \mathrm{ml}$ of PBS, pH 7.4 
\begin{tabular}{l|l} 
Materials and methods & Assessment of Epigenetic profile in Alzheimer's disease
\end{tabular}

Media for bacteria: $\mathrm{LB}$ Medium ( $\mathrm{pH} 7.5), 1 \%$ Peptone, $1 \% \mathrm{NaCl}, 0.5 \%$ Yeast extract

LB-Agar (pH 7.5): $1 \%$ Peptone, $1 \% \mathrm{NaCl}, 0.5 \%$ Yeast extract, $1.5 \%$ Agar

The LB medium was prepared with distilled water, autoclaved and stored at $4^{\circ} \mathrm{C}$.

PBS buffer: $8 \mathrm{mM} \mathrm{Na}_{2} \mathrm{HPO}_{4}, 140 \mathrm{mM} \mathrm{NaCl}, 2 \mathrm{mM} \mathrm{KH}{ }_{2} \mathrm{PO}_{4}, 2.7 \mathrm{mM} \mathrm{KCl}$, pH 7.4

TBST (10x) : 12.11g Tris, 87.66g NaCl, $5 \mathrm{ml}$ Tween $20,1 \mathrm{~g} \mathrm{NaN}_{3}$, Water up to $1 \mathrm{~L}$

PBS-BSA 0.1\%: $\quad 9 \mathrm{ml}$ PBS, $1 \mathrm{ml}(10 \mathrm{mg} / \mathrm{ml}$ stock $)$ BSA

\section{Buffers for MeDIP}

10x IP buffer:100 mM Na-Phosphate $\mathrm{pH} 7.0,1.4 \mathrm{M} \mathrm{NaCl}(\mathrm{MW}: 58.44 \mathrm{~g} / \mathrm{mol}$ ) and $8.2 \mathrm{~g}$, $0.5 \%$ Triton X-100

1 M Na-Phosphate pH 7.0:

$39 \mathrm{ml} 2 \mathrm{M} \mathrm{NaH}_{2} \mathrm{PO}_{4}, 31.2 \mathrm{~g}, 61 \mathrm{ml}(2 \mathrm{M}) \mathrm{Na}_{2} \mathrm{HPO}_{4} 35.6 \mathrm{~g}$ in $100 \mathrm{ml} \mathrm{H} \mathrm{H}_{2} \mathrm{O}$

100 mM (0.1M) Na-Phosphate, pH 7.0:

$39 \mathrm{ml} 200 \mathrm{mM} \mathrm{NaH}{ }_{2} \mathrm{PO}_{4}, 61 \mathrm{ml} 200 \mathrm{mM} \mathrm{Na}_{2} \mathrm{HPO}_{4}, 100 \mathrm{ml} \mathrm{H} 2 \mathrm{O}$

3M NaAcetate, pH 4.8-5.2

\subsubsection{Sterilization of Solutions and Equipment}

Heat insensitive solutions were sterilized at $121^{\circ} \mathrm{C}$ for $20 \mathrm{~min}$ in an autoclave (Provit 2200, Holzner $\mathrm{GmbH})$. Heat sensitive solutions were filtered through a disposable sterile filter $(0.22$ $\mu \mathrm{m}$ pore size).

\subsubsection{Drugs and Antibiotics}

\subsubsection{Antibiotics}

The stock solutions were filtered through sterile disposable filters and stored at $-20^{\circ} \mathrm{C}$. Before usage, antibiotics were added after the autoclaved medium had cooled down to a temperature lower than $55^{\circ} \mathrm{C}$. Stock solution (Ampicillin $100 \mathrm{mg} / \mathrm{ml}$ ). 


\subsubsection{Drugs}

\begin{tabular}{|l|l|}
\hline Drug & Company \\
\hline Metapyrine & Serumwerk, Bernburg \\
\hline Ketamine & Medistar Arzneimittel, Arschberg \\
\hline Xylazine & Riemser Arzneimittel, Greifswald \\
\hline Isoflurane & Abbot, Wiesbaden \\
\hline Mouse IgG & Santa cruz Biotechnology, CA \\
\hline IGFBP7 recombinant protein & R\&D Systems, Minneapolis \\
\hline
\end{tabular}

\subsubsection{Kits and Equipments}

\begin{tabular}{|l|l|}
\hline Kit/Equipments & Company \\
\hline MethylCollector & Active Motif, Belgium \\
\hline Mini Plasmid Kit & Qiagen, Hilden \\
\hline MTT Assay & Cayman, Ann Arbor \\
\hline Nucleobond PC 2000 column kit & Machery-Nagel, Dueren \\
\hline One-day ChIP kit & Diagenode, Belgium \\
\hline RT-PCR kit & Roche, Mannheim \\
\hline QIA quick Gel Extraction kit & Qiagen, Hilden \\
\hline Hamilton syringe & Hamilton Company, Nevada \\
\hline Videomot systems & TSE Systems, Bad Homburg \\
\hline Syringe pump & WPI, Sarasota FL USA \\
\hline Stereotactic device & myNeurolab, Leica \\
\hline
\end{tabular}

\subsubsection{Synthetic Oligonucleotides}

The synthetic oligonucleotides used in this study were ordered from Sigma-Aldrich (Deisenhofen, Germany). The oligonucleotides were dissolved in water to a stock concentration $100 \mathrm{pmol} / \mu \mathrm{l}$. The working solution was made up of concentration $10 \mathrm{pmol} / \mu \mathrm{l}$.

\subsubsection{Plasmids, Generation of Constructs and Bacterial strains}

Adenoviral associated viral constructs of $S p h k 2$ was generated and bacterial strain from the SURE cell (E. coli) and transformed by electroporation.

\subsection{Isolation of Nucleic acids (Small scale isolation of Plasmid DNA)}

A single $E$. coli colony was inoculated in $3.0 \mathrm{ml}$ of LB medium with ampicillin and incubated in shaker for $16 \mathrm{hrs}$ at $37^{\circ} \mathrm{C}$ at speed of $150 \mathrm{rpm}$. Bacteria was harvested by centrifuging at 4000xg for $10 \mathrm{~min}$. Plasmid DNA was isolated according to the QuickLyse Mini-prep protocol (Qiagen, Hilden). 


\subsection{Large Scale Preparation of Plasmid DNA}

A single clone was inoculated in $5 \mathrm{ml} \mathrm{LB}$ medium with appropriate antibiotic as a pre-culture for $8 \mathrm{hrs}$ in $37^{\circ} \mathrm{C}$ shaker. This pre-culture was further inoculated at a dilution of 1:250 in LB medium with appropriate antibiotic and was cultured overnight at $37^{\circ} \mathrm{C}$. The bacterial culture was harvested by centrifuging at $6000 \mathrm{xg}$ for $15 \mathrm{~min}$ at $4^{\circ} \mathrm{C}$. The pellet was re-suspended in $45 \mathrm{ml}$ of S1+RNase A (Nucleospin). Forty-five millilitres of S2 (Nucleospin) was added and mix gently by inverting 6-8 times without vortexing. The mixture was incubated for maximum of $5 \mathrm{~min}$ at RT. Then, $45 \mathrm{ml}$ of pre-chilled Buffer S3 was added and the mixture inverted 6-8 times for a homogeneous suspension to form. The solution was then incubated on ice for $5 \mathrm{~min}$. The solution was then centrifuged for $50 \mathrm{~min}$. During this time the Nucleobond column and filter paper were equilibrated with $20 \mathrm{ml}$ of Buffer N2. The clear lysate was then loaded onto the equilibrated Nucleobond Column and washed with $35 \mathrm{ml}$ of Buffer N3. Elution of plasmid DNA was done with $22 \mathrm{ml}$ of Buffer N5. To precipitate DNA, $18 \mathrm{ml}$ of Isopropanol was added and the solution centrifuged at $15000 \mathrm{~g}$ for $30 \mathrm{~min}$ at $4{ }^{\circ} \mathrm{C}$. The pellet was dissolved in $2 \mathrm{ml}$ of TE buffer. The DNA was then purified by adding 1:10 of $3 \mathrm{M}$ Sodium acetate and 2.5 volumes of ice-cold $100 \%$ ethanol. The mixture was centrifuge at $4^{\circ} \mathrm{C}$ for $30 \mathrm{~min}$ at maximum speed. The DNA pellet was washed once with $7 \mathrm{ml}$ of $70 \%$ ethanol and centrifuged at maximum speed for $10 \mathrm{~min} 4^{\circ} \mathrm{C}$. The DNA pellet was dried for 30 min and reconstituted in final volume of $500 \mu 1 \mathrm{TE}$ buffer.

\subsubsection{Isolation of Genomic DNA from mouse tails}

STE buffer: $12.5 \mathrm{ml} 2 \mathrm{M}$ Tris- $\mathrm{HCl}, 12.5 \mathrm{ml} 100 \mathrm{mM}$ EDTA, $2 \mathrm{M} \mathrm{NaCl}, 10 \%$ SDS, $\mathrm{H}_{2} \mathrm{O}$ added to $250 \mathrm{ml}$

Genomic DNA was extracted by incubating $1 \mathrm{~cm}$ of mouse tails obtained from the animal house in $360 \mu \mathrm{l}$ of STE buffer and $15 \mu \mathrm{l}$ of Proteinase $\mathrm{K}$ for $3 \mathrm{hrs}$ on a Thermomixer 5436 for $3 \mathrm{hrs}$ at full speed. The lysed tail samples were then spun down for $20 \mathrm{~min}$ at $13000 \mathrm{rpm}$ and the supernatant taken and precipitated with an equal amount of isopropanol. The solution was then spun again at full speed for $20 \mathrm{~min}$ and the pellet was washed with $500 \mu 170 \%$ ethanol added and spun at full speed for $20 \mathrm{~min}$. The ethanol was discarded and the precipitated DNA air dried and $50 \mu \mathrm{l}$ of water was added and dissolved. 


\subsubsection{Isolation of total RNA from tissues and cultured cells}

Total RNA from brain samples was extracted using the Tri-Reagent (Sigma-Aldrich, Deisenhofen). The Tri-Reagent is a monophasic solution of phenol and guanidine isothiocyanate. Autoclaved and RNase away treated homogenizers and tubes were used for the extraction. The tissue was homogenized in $500 \mu 1$ of Tri-Reagent and incubated for 5 min and $500 \mu \mathrm{l}$ extra reagent added. The solution was then incubated at RT for $5 \mathrm{~min}$. Afterwards, $200 \mu \mathrm{l}$ of $\mathrm{CHCl}_{3}$ was added and vortexed to obtain a homogeneous mixture. The suspension was then incubated at RT for $5 \mathrm{~min}$. To obtain a pure RNA, the mixture was centrifuged at $12000 \mathrm{xg}$ for $15 \mathrm{~min}$ at $4^{\circ} \mathrm{C}$ and the colourless aqueous phase was transferred into a new microfuge tube. Isopropanol, $500 \mu 1$ was then added and the mixed vigorously and incubated at $-20^{\circ} \mathrm{C}$ for $30 \mathrm{~min}$ after which the mixture was centrifuged at $12000 \mathrm{xg}$ for $30 \mathrm{~min}$ at $4^{\circ} \mathrm{C}$. The supernatant was then discarded and the pellet washed twice with $75 \%$ Ethanol and dissolved in $50 \mu$ l of DEPC- $\mathrm{H}_{2} \mathrm{O}$.

\subsubsection{Determination of Nucleic Acid Concentrations}

Nano-drop-spectrophotometer was used to determine the concentration and quality of nucleic acid by measuring absorption of the samples at $260 \mathrm{~nm}$ and $280 \mathrm{~nm}$ respectively.

\subsubsection{Nucleic acid electrophoresis (Agarose gel electrophoresis of DNA)}

Gel electrophoresis is the technique by which mixture of charged macromolecules, especially nucleic acids and proteins are separated in an electrical field according to their mobility which is directly proportional to macromolecule's charge to mass ratio. Agarose gels are used to electrophorese nucleic acid molecules from as small as $50 \mathrm{bp}$ to more than $50 \mathrm{~kb}$, depending on the concentration of the agarose and the precise nature of the applied electrical field (constant or pulse). Usually, $1 \mathrm{~g}$ of agarose was added in $100 \mathrm{ml}$ of $0.5 \mathrm{x}$ TAE buffer and boiled in the microwave to dissolve the agarose. The agarose solution was cooled to about $60^{\circ} \mathrm{C}$ before adding $3 \mu \mathrm{l}$ ethidium bromide $(10 \mathrm{mg} / \mathrm{ml})$ and poured into a horizontal gel chamber. The 0.5x TAE buffer was used also as electrophoresis running buffer in the gel chamber. The DNA samples were mixed with 5x loading buffer and then loaded into the wells of the gel. The electrophoresis was carried out at a steady voltage (50-120 V). The size of the DNA fragments on agarose gels was determined by extrapolating the size from a DNA 
size marker which was also loaded along with the samples in a separate lane of the gel. After electrophoresis, the DNA in the gel was photographed using a UV gel documentation system.

\subsubsection{Isolation of DNA fragments from Agarose gel}

In order to purify PCR product and enzymatically digested product from excess primers, nucleotides and cut fragments, products were first run of Agarose gel of appropriate percentage and excised. Three volumes of excised product is added and melted at $37^{\circ} \mathrm{C}$ for 5 min. One volume of Isopropanol was added and the mixture added to a column provided (Qiagen) and centrifuged at RT at $13000 \mathrm{rpm}$ for $1 \mathrm{~min}$. The flow-through was decanted and $750 \mu \mathrm{l}$ of PE buffer added to the column and again centrifuged at $13000 \mathrm{rpm}$. The outflow was discarded and residual buffer remove by repeating the centrifugation step. The column was then put onto a new microfuge tube and the bound DNA eluted with $30 \mu \mathrm{l}$ of EB buffer and concentration determined at the Nano-drop (Peqlab).

\subsubsection{Enzymatic Restriction of DNA.}

For oriented cloning, approximately $2 \mu \mathrm{g}$ of both vector and PCR products were digested with an appropriate restriction enzyme from Fermentas for about $10 \mathrm{~min}$ to $1 \mathrm{hr}$ to ensure complete digestion. The products were then loaded onto 1.5\% Agarose gel. The resolved DNA was excised from the gel and then purified. The cleaned product was ligated to AAV vector with hSyn promoter.

\subsubsection{Ligation of DNA fragments}

Ligation of linearized DNA in to a vector was carried out using the reaction below:

25-50 ng vector DNA (linearized), 50-100 ng insert DNA, $1 \mu 1$ 10x ligation buffer (or $5 \mu \mathrm{l}$ of $2 \mathrm{x}$ ligation buffer), $0.3 \mu \mathrm{T} 4 \mathrm{DNA}$ ligase $(5 \mathrm{U} / \mu \mathrm{l})$, in a total volume of $10 \mu \mathrm{l}$ with $\mathrm{H}_{2} \mathrm{O}$

\subsubsection{Preparation of Electro-competent E.coli bacteria}

The competent bacterial cells were generated by a physical cell wall modification that facilitates DNA uptake. LB medium $(100 \mathrm{ml})$ was inoculated with a single colony of $E$. coli 
and the culture was grown at $37^{\circ} \mathrm{C}$ to $\mathrm{OD}_{600}=0.6$. Bacteria were centrifuged $\left(10 \mathrm{~min}, 4^{\circ} \mathrm{C}\right.$, $3000 \mathrm{xg}$ ) and the pellet was re-suspended in $50 \mathrm{ml}$ of sterile $50 \mathrm{mM} \mathrm{sCaCl}_{2}$ solution $\left(4^{\circ} \mathrm{C}\right)$ and incubated on ice for $30 \mathrm{~min}$. The suspension of bacteria was centrifuged $\left(10 \mathrm{~min}, 4^{\circ} \mathrm{C}\right.$, $3000 \mathrm{xg}$ ) and the pellet was re-suspended in $10 \mathrm{ml}$ of sterile $50 \mathrm{mM} \mathrm{CaCl}_{2}$ solution $\left(4^{\circ} \mathrm{C}\right)$ with $15 \%$ glycerol. The mixture was dispensed into aliquots of $50 \mu \mathrm{l}$ quick chilled in liquid nitrogen and stored at $-80^{\circ} \mathrm{C}$.

\subsubsection{Transformation of Electro-competent bacteria cells}

Transformation of the bacteria was done by gently mixing one aliquot of the competent bacterial cells $(50 \mu \mathrm{l})$ with $1 \mu \mathrm{l}$ of ligated product on ice. The bacteria-DNA complex was then transferred to the cuvette, and electroporated. Thereafter, $300 \mu \mathrm{l}$ of S.O.C. medium was added to the bacteria plated on LB-agar plates containing appropriate antibiotic.

\subsubsection{Polymerase Chain Reaction}

Polymerase Chain Reaction (PCR) is a very sensitive and powerful technique that is widely used for the exponential amplification of specific DNA sequences in vitro by using sequence specific synthetic oligonucleotides (primers) in the field of molecular biology. The general principle of PCR is based upon a pair of oligonucleotide primers that are designed so that a forward or sense primer directs the synthesis of DNA towards a reverse or antisense primer, and vice versa. In a PCR, a heat stable Taq DNA polymerase catalyses the synthesis of a new DNA strand complementary to a template DNA from 5' to 3 ' direction by a primer extension reaction, resulting in the production of the DNA region flanked by the two primers. It allows unlimited amplification of specific template that may be present at very low concentrations in any sample. Amplification is done in an automatic thermocycler. The reaction composition is

20-50 ng DNA, $0.5 \mu$ forward primer ( 5 pmol), $0.5 \mu$ reverse primer ( 5 pmol) $0.5 \mu \mathrm{l} 2 \mathrm{mM}$ dNTPs, $2.5 \mu \mathrm{l}$ 10x PCR buffer, $0.75 \mu \mathrm{l} 50 \mathrm{mM}, \mathrm{MgCl}_{2}, 0.1 \mu \mathrm{l}$ Taq DNA Polymerase ( $5 \mathrm{U} / \mu \mathrm{l})$, up to $25 \mu \mathrm{l}$ with $\mathrm{H}_{2} \mathrm{O}$

A standard PCR program is for 35 cycles with denaturation at $95^{\circ} \mathrm{C}$ for $30 \mathrm{sec}$, annealing at $60^{\circ} \mathrm{C}$ for $35 \mathrm{sec}$ and extension at $72^{\circ} \mathrm{C}$ for $1 \mathrm{~min}$. 


\subsubsection{Reverse Transcription PCR (RT-PCR)}

mRNA isolated was reverse transcribed into cDNA with Transcriptor First Strand cDNA Synthesis Kit (Roche Applied Science) according to the manual. Generally amplification of mRNA up to $4 \mathrm{~kb}$ was done using the Random hexamer primers. For detection of mature miRNA, miScript Reverse Transcriptase Mix (Qiagen) optimized blend of enzymes comprising poly (A) polymerase was used according to the manufacturer's protocol.

\subsubsection{Quantitative real time PCR (qPCR)}

Comparative analysis of differences in gene expression for different treatments and genotypes was done using the qPCR. Specific primers and respective universal library probes as well as SYBR reaction mix was obtained from Roche Applied Science (https://www.roche-appliedscience.com/sis/rtpcr/upl/). Once cDNA is synthesized, a serial dilution of $1: 5,1: 10,1: 50,1: 100,1: 500$ and 1:1000 were made out of $5-10 \mu 1$ pooled from each sample with 1:10 serving as calibrator. The working solution of the treatments was usually 1:10. Amplification of diluted samples is done with the protocol below.

For mRNA: $\quad 5.05 \mu \mathrm{l}$ PCR grade $\mathrm{H}_{2} \mathrm{O}, 0.15 \mu \mathrm{l}$ forward and reverse primers $(20 \mu \mathrm{M}) 7.5 \mu \mathrm{l}$ LC480 Master-mix (2x conc., Roche Applied Science) and 0.15 $\mu$ l UPL (10 $\mu \mathrm{M}$, Roche Applied Science) $+2 \mu \mathrm{l}$ cDNA per sample.

\begin{tabular}{|c|c|c|c|}
\hline \multicolumn{4}{|c|}{ qPCR for mRNA amplification } \\
\hline Step & Temperature & Time & Number of cycles \\
\hline Initial denaturation & $95^{\circ} \mathrm{C}$ & $5 \mathrm{~min}$ & 1 \\
\hline Amplification & $95^{\circ} \mathrm{C}$ & $10 \mathrm{~s}$ & \\
& $60^{\circ} \mathrm{C}$ & $30 \mathrm{~s}$ & $30 \mathrm{x}$ \\
& $72^{\circ} \mathrm{C}$ & $1 \mathrm{~s}$ & \\
\hline Cooling & $40^{\circ} \mathrm{C}$ & $30 \mathrm{~s}$ & \\
\hline
\end{tabular}

For miRNA, the SYBR Green PCR system from Qiagen was used and the protocol is below.

For miRNA: $5 \mu \mathrm{l}$ PCR mix (Qiagen), $1 \mu$ l Universal Primer 1 and Primer Assay and $2 \mu 1$ $\mathrm{H}_{2} \mathrm{O}+1 \mu \mathrm{l}$ cDNA. 
Materials and methods Assessment of Epigenetic profile in Alzheimer's disease

\begin{tabular}{|c|c|c|c|}
\hline \multicolumn{4}{|c|}{ qPCR for miRNA/ChIP DNA amplification } \\
\hline Step & Temperature & Time & Number of cycles \\
\hline Initial denaturation & $95^{\circ} \mathrm{C}$ & $5 \mathrm{~min}$ & 1 \\
\hline Amplification & $95^{\circ} \mathrm{C}$ & $10 \mathrm{~s}$ & $45 \mathrm{x}$ \\
& $55-65^{\circ} \mathrm{C}$ & $30 \mathrm{~s}$ & \\
& $72^{\circ} \mathrm{C}$ & $1 \mathrm{~s}$ & $1 \mathrm{x}$ \\
\hline Melting & $95^{\circ} \mathrm{C}$ & $10 \mathrm{~s}$ & $1 \mathrm{x}$ \\
\hline Cooling & $40^{\circ} \mathrm{C}$ & $30 \mathrm{~s}$ & \\
\hline
\end{tabular}

\subsubsection{Nucleic Acid Sequencing}

Sequencing of nucleotides was out-sourced in the sequencing facility (www.seqlab.de). A total reaction mix of $7 \mu \mathrm{l}$ consisting of $700 \mu \mathrm{g}$ of plasmid DNA and appropriate volume of water and $2 \mu \mathrm{l}$ of $(20 \mu \mathrm{M})$ Primers (each of them in a different reaction tube). The obtained sequences were anlyzed with a BLAST program (Altschul et al., 1990) by using the sequence database from either Genbank (www.ncbi.nlm.nih.gov) or EMBL (www.ebi.ac.uk).

\subsubsection{Primer names Sequence}

\begin{tabular}{|l|l|}
\hline Name & Sequence \\
\hline Sphk2-cDNA-F & CCGGAATTCCGCATGGCCCCACCACCACTACTGCCAGT \\
\hline Sphk2-cDNA-R & CCGACCGGTCGCGGCTTGTGGCTTTTGACCTGCAGGCCC \\
\hline
\end{tabular}

Table 1a: (Human) Primer-Sequences for ChIP-qPCR analysis Gene Sequence

\begin{tabular}{|l|l|l|}
\hline Primer & Sequence $(\mathbf{5}$ '- $\mathbf{3}$ ') Forward & Sequence $(\mathbf{5}$ '- $\mathbf{3}$ ) Reverse \\
\hline SPHK2-prom & TACCACGATCCGGACTTCTC & CTCCCAGATCCCTTTCTTCC \\
\hline Ex1-Sphk2 & ACTGACTAGCCGGGCGATA & TGCTAGCTACACGCATCTCG \\
\hline Ex2-SPHK2 & CTGAAGGTCAGGCCAGGA & CTGGTCCTGCTGCTCCTCCT \\
\hline Ex3-SPHK2 & TTTGCCCTCACCCTTACATC & GAAGTAGGCCGCTGAGTCTG \\
\hline PRKCD prom & AACAGGAAGAGCAGGAGTGG & AAGGGGCCCATTTTACAGAG \\
\hline PRKCD ex3 & GCCGACCATGTATCCTGAGT & TGCCATTGTTCTTCTTGCAG \\
\hline PRKCD ex5 & CAGTCTATGCGCGCAGTGAGGA & AAAGTCTTTGCACACAGAACAGA \\
\hline IGFBP2 & GCTGTTTGGGTCTAGCTTGG & GTTCAGTTCGCGAGGACTTC \\
\hline IGFBP4 & TGTACGCTTTACCCCACCTC & CTCAGTCTCCCACCGAGAAA \\
\hline IGFBP5 & AGCAGCAACGTTGAGTGATG & TTTTCGAAGTTGAGCCCTTG \\
\hline IGFBP7 MET & AAATTAGAGGGTGGAAGAGTCGT & CTACTAACGTCGAAAAATAAACGAA \\
\hline IGFBP2 MET & GCTGTTTGGGTCTAGCTTGG & GTTCAGTTCGCGAGGACTTC \\
\hline IGFBP4 MET & TGTACGCTTTACCCCACCTC & CTCAGTCTCCCACCGAGAAA \\
\hline
\end{tabular}


\begin{tabular}{l|l} 
Materials and methods & Assessment of Epigenetic profile in Alzheimer's disease
\end{tabular}

Table 1b: Human qPCR primer sequences for mRNA Gene Sequence, UPL\#

\begin{tabular}{|l|l|l|l|}
\hline Primer & Sequence (5'- 3') Forward $^{\prime}$ & Sequence (5' 3') Reverse $^{\prime}$ & UPL\# \\
\hline HDAC1 & CCAAGTACCACAGCGATGAC & TGGACAGTCCTCACCAACG & 58 \\
\hline HDAC2 & GGGTTGTTCAATCTAACAGTCAA & CAACATTACGGATTGTGTAGCC & 25 \\
\hline HDAC3 & TCTGGGCTGTGATCGATTG & CTTGACATATTCAACGCATTCC & 89 \\
\hline HDAC4 & GTGGTAGAGCTGGTCTTCAAGG & GACCACAGCAAAGCCATTC & 24 \\
\hline HDAC5 & TTGACATCACCGCAGCTC & CGACCTGACATCCCATCC & 4 \\
\hline HDAC6 & AGTTCACCTTCGACCAGGAC & GCCAGAACCTACCCTGCTC & 58 \\
\hline HDAC7 & TGATCCGGGTGCACAGTA & CCCAGGAGTCTGGACAGG & 45 \\
\hline HDAC8 & GGCAGTTGGCAACACTCAT & GTCAAGTATGTCCAGCATCGAG & 52 \\
\hline HDAC9 & GCAGGCTGCTTTTATGCAA & TGTTTCTCTAATCCATCCATGC & 71 \\
\hline HDAC10 & TGGGAAGCTCCTGTACCTCTT & GGCTGGAGTGGCTGCTATAC & 42 \\
\hline HDAC11 & ATCACGCTCGCCATCAAG & GGCATCAAGATCAATGATGGTA & 80 \\
\hline p300 & TGGAGGAATGCCCAACAT & GGCAACTGGAGTCACCAGAC & 60 \\
\hline SPHK1 & ATCCAGAAGCCCCTGTGTAG & TGGTGACCTGCTTCATAGCC & 3 \\
\hline SPHK2 & TGAATGGACACCTTGAAGCA & CGGTCAGCTCCTGGTCTG & 18 \\
\hline SGPP2 & GACCCTTATTTATCCAGAAGATTGAT & CAAGACATCCTTGGCCACTT & 9 \\
\hline SGPL1 & GGGTCCCATTGACGAAGAT & TGGCAGTGTTCCTGGAGATA & 10 \\
\hline PRKCD & ATTATCCCCGCTGGATCAC & CTTGGTTGGTTCCCTTTCAA & 80 \\
\hline DNMT1 & GATGTGGCGTCTGTGAGGT & CCTTGCAGGCTTTACATTTCC & 66 \\
\hline DNMT3A & CCTGAAGCCTCAAGAGCAGT & TGGTCTCCTTCTGTTCTTTC & 46 \\
\hline DNMT3B & AGAGGGACATCTCACGGTTC & GGTTGCCCCAGAAGTATCG & 84 \\
\hline IGFBP1 & CCATGTCACCAACATCAAAAA & CCTTGGCTAAACTCTCTACGACTC & 12 \\
\hline IGFBP2 & GGTGGCAAGCATCACCTT & ACCTGGTCCAGTTCCTGTTG & 25 \\
\hline IGFBP3 & AACGCTAGTGCCGTCAGC & CGGTGTTCCTCCGACTCAC & 1 \\
\hline IGFBP4 & CCTCTACATCATCCCCATCC & GGTCCACACACCAGCACTT & 44 \\
\hline IGFBP5 & CTACCGCGAGCAAGTCAAG & GTCTCCTCGGCCATCTCA & 77 \\
\hline IGFBP6 & TGACCATCGAGGCTTCTACC & CATCCGATCCACACACCA & 52 \\
\hline IGFBP7 & GGCCCAGAAAAGCATGAA & GGATGCATGGCACTCATATTC & 20 \\
\hline GAPDH & AGCCACATCGCTCAGACAC & GCCCAATACGACCAAATCC & 60 \\
\hline
\end{tabular}

Table 2a: (Mouse) Primer-Sequences used for ChIP-qPCR analysis Gene Sequence

\begin{tabular}{|l|l|l|}
\hline Primer & Sequence (5'- $\mathbf{3}$ ') Forward & Sequence (5'- $\mathbf{3}$ ) Reverse \\
\hline Sphk2-prom & TGCACTTCTACGCATTTTGC & TTAGGCTCGTTCAGGCTTGT \\
\hline Ex1-Sphk2 & ACCACAATTTGGGTTTCTCG & TCCCTTTACCCCTGGAGAGT \\
\hline Ex3-Sphk2 & CCTAGGAGTGCTTGGGACTG & CGCTGTATGTGTAGGGCTTG \\
\hline Ex4-Sphk2 & AAATCACCCCTGAATTCTG & CTGTCTGTATGAGGTTGAAGGACA \\
\hline Ex6-Sphk2 & ACTGCTCGCTTCTTCTCTGC & CACTGCACCCAGTGTGAATC \\
\hline Prkcd prom & CTTCCATGGCTTCTCCTTTG & CAGCAGAAATCAGCCAGTCA \\
\hline Prkcd ex3 & AGCCCACCATGTATCCTGAG & CCTTGCCGTTGTTCTTCTTG \\
\hline Prkcd ex5 & TTGCAAACAGTCTATGCGTAGTG & TTGCACACAGAACAGAAGGTG \\
\hline Prkcd ex12 & CAGAGCTGAAGGGCAAAGAC & TACAGATGAGGTGGGTGAGG \\
\hline Prkcd ex16 & AAATGCTCATCGGCCAGTC & GTCCTTGGATTCCTTGGTGA \\
\hline Igfbp7-Prom & CCCAGACCCACGAGAATTA & CTGTCCTCACTCTGCAGCAC \\
\hline Igfbp2-Prom & CGGGACTCACTCAAGGTCAT & GAGCCTGTGCTTTTGTCTCC \\
\hline Igfbp4-Prom & CGCGGTCTCTAGAGGTTGAC & ACGAAGGGGATGTTGATTTG \\
\hline
\end{tabular}


\begin{tabular}{l|l} 
Materials and methods & Assessment of Epigenetic profile in Alzheimer's disease
\end{tabular}

Table 2b: Mouse qPCR primer sequences for mRNA Gene Sequence, UPL Probe

\begin{tabular}{|c|c|c|c|}
\hline Primer & Sequence (5'- 3') Forward & Sequence (5'- 3') Reverse & UPL\# \\
\hline Hprt1 & TCCTCCTCAGACCGCTTTT & CCTGGTTCATCATCGCTAATC & 95 \\
\hline Myst2 & AACTTCCAGGGCAAGGAGAT & AATGTCCACGGGATTCACA & 72 \\
\hline Myst3 & CTCGTGTTTACCTCCCGTGT & AGATGGGGATTGGTTCAGC & 38 \\
\hline Myst4 & GCAACAAAGGGCAGCAAG & AGACATCTTTAGGAAACCAAGACC & 19 \\
\hline Hdac1 & TGCTGGACTTACGAAACAGC & GTCGTTGTAGGGCAGCTCAT & 81 \\
\hline Hdac2 & CTCCACGGGTGGTTCACT & CCCAATTGACAGCCATATCA & 45 \\
\hline Hdac3 & TTCAACGTGGGTGATGACTG & TTAGCTGTGTTGCTCCTTGC & 32 \\
\hline Hdac4 & $\begin{array}{l}\text { CACACCTCTTGGAGGGTACAA } \\
\end{array}$ & AGCCCATCAGCTGTTTTGTC & 53 \\
\hline Hdac5 & GAGTCCAGTGCTGGTTACAAAA & TACACCTGGAGGGGCTGTAA & 105 \\
\hline Hdac6 & GAAGGAGGAGCTGATGTTGG & TCATGTACTGGGTTGTCTCCAT & 64 \\
\hline Hdac7 & GCCCTTGAGAGAACAGTCCA & CCAAGGGCTCAAGAGTTCTG & 45 \\
\hline Hdac8 & GCAGCTGGCAACTCTGATT & GTCAAGTATGTCCAGCAACGAG & 63 \\
\hline Hdac9 & TTGCACACAGATGGAGTGG & GGCCCATAGGAACCTCTGAT & 32 \\
\hline Hdac10 & TTCCAGGATGAGGATCTTGC & ACATCCAATGTTGCTGCTGT & 60 \\
\hline Hdac11 & ATCATGGCAGGGAAGCTG & CACTGGAGCAGTGGTGGA & 77 \\
\hline Gcn5 & GAAGAGGACCСТCATCCTCA & GGAGAATTTGCCCCGTAGAT & 60 \\
\hline pCAF & GGAGAAACTCGGCGTGTACT & CAGCCATTGCATTTACAGGA & 13 \\
\hline p300 & ACATGATGCCTCGGATGAC & TAGGGGGCTGTGGCATATT & 64 \\
\hline Cbp & CAGGCAGGTGTTTCACAGG & GCATGTTCAGAGGGTTAGGG & 1 \\
\hline SphK1 & GAAGCGATGCGAAGATAGAGA & GAGGGTGTCTGGCGACT & 10 \\
\hline SphK2 & AGGAAACTCGGCCAGACAC & TCCTAGGCTCTTGGCTTGTG & 17 \\
\hline Sgpp1 & GAATACAGCATGCCCTCCAC & $\begin{array}{l}\text { GCCCGTAGATAAGAGGATACTGC } \\
\end{array}$ & 15 \\
\hline Sgpp2 & TGTCCAGAAGATTGGTTGTGA & CCACTTCAGGATGTCCTTGG & 9 \\
\hline Sgpl1 & GGATGACTTGTTCCCTCTTCA & TTTCCGTTCCCCCAGAAG & 93 \\
\hline Prkcd & CAAGAAGAACAACGGCAAGG & TGCACACACATCAGCACCT & 20 \\
\hline Dnmt1 & TTTGCCAGGTTCAATAAGACG & CGTCATCATGAAGGTAGAGTTGG & 15 \\
\hline Dnmt3a tv1 & AACGGAAACGGGATGAGTG & ACTGCAATTACCTTGGCTTTCT & 75 \\
\hline Dnmt3b & AATCCAGGGCCTTCTTTCAG & TGGCACCCTCTTCTTCATTC & 94 \\
\hline Igfbp1 & CGGTCATCACCTGGAAGAAG & TGGACAGCTATATTGACATGGTCT & 25 \\
\hline Igfbp2 & GCGGGTACCTGTGAAAAGAG & CCTCAGAGTGGTCGTTCATCA & 62 \\
\hline Igfbp3 & GCAGCCTAAGCACCTACCTC & TCCTCCTCGGACTCACTGAT & 1 \\
\hline Igfbp4 & AAGATCGTGGGGACACCTC & GTGGGTACGGCTCTGTGAG & 1 \\
\hline Igfbp5 & GGCGAGCAAACCAAGATAGA & AGGTCTCTTCAGCCATCTCG & 77 \\
\hline Igfbp6 & GGGCTCTATGTGCCAAACTG & CCTGCGAGGAACGACACT & 110 \\
\hline Igfbp7 & CCCTCCATGAAATACCACTGA & GGCTGTCTGAGAGCACCTTT & 110 \\
\hline
\end{tabular}

\subsection{Primary Neurons Preparation}

Mice were decapitated and the whole brain was isolated and put into dissection medium on ice. The hippocampus was carefully dissected and put into a new petri dish with dissection medium on ice and cut into small pieces for easy digestion. The pieces were then collected into a centrifuge tube and washed two times with dissection medium. Five millilitres of HANKS solution was added to the hippocampal tissues and incubated on ice for $5 \mathrm{~min}$. The tissues were then digested at RT for $5 \mathrm{~min}$ with sterile filtered solution of $6 \mathrm{mg}$ of trypsin and $60 \mu \mathrm{g}$ DNAse (Sigma, Deisenhofen) $(2 \mathrm{KUnits} / \mu \mathrm{l})$ in $2 \mathrm{ml}$ of digestion solution at $37^{\circ} \mathrm{C}$ for $10 \mathrm{~min}$. The digestion solution was removed upon centrifugation and the tissues washed three times with culture medium. The hippocampal tissues were afterwards triturated in $1 \mathrm{ml}$ of 
dissection medium to dissociate the cells. The homogenate was then added to a pre-wet strainer and washed with $4 \mathrm{ml}$ culture medium. Ten microlitres of cell suspension was taken counting with a Neubauer chamber. The pre-incubated culture plates with coverslips coated with poly-D-Lysine and laminin (BD Bioscience, Heidelberg) were then taken out of the incubator and seeded in dissection medium with about 250000-500000 cells per well. The cells were then incubated at $37^{\circ} \mathrm{C}$ for $30 \mathrm{~min}$ in a $5 \% \mathrm{CO}_{2}$. Culture medium was then added to the cultured neurons. After overnight incubation with medium, cells were washed with PBS to remove cell debris and dead cells. Next, the cultured neurons were inoculated in culture medium B after fourth day. Medium was changed every two days till the day of neuronal cell analysis.

\subsubsection{Trypsinization of Eukaryotic cells}

The eukaryotic cells were washed with sterile PBS and incubated in a minimal amount of trypsin-EDTA solution ( $0.5 \mathrm{~g} / 1$ trypsin, $0.2 \mathrm{~g} / \mathrm{l}$ EDTA) at $37^{\circ} \mathrm{C}$, until cells detached from the plastic surface. The process was checked under an inverted microscope. The trypsin reaction was inhibited by addition of growth medium containing FBS. The trypsin solution was removed by centrifugation at 3000xg for $10 \mathrm{~min}$. The cells were re-suspended in an appropriate volume of cell culture medium and transferred into a new flask.

\subsubsection{Cryopreservation and thawing of Eukaryotic cells}

Trypsinised cells were spun down (3000xg for $5 \mathrm{~min}$ ) in $4 \mathrm{ml}$ of growth medium. The supernatant was aspirated and the cells were re-suspended in ice-cold freezing medium (DMEM, 20\% FBS, 10\% DMSO). Aliquots of the cells were frozen for $1 \mathrm{hr}$ at $-20^{\circ} \mathrm{C}$, afterwards they were transferred to $-80^{\circ} \mathrm{C}$ for $3 \mathrm{hrs}$ and then stored in a liquid nitrogen container. For revitalization, the frozen cells were quickly thawed and the cells were diluted in a suitable amount of growth medium.

\subsubsection{Cell viability assay}

To assess cell death in cultured cells, primary cultured neurons were treated with either IGFBP7. The viability of the cells was then evaluated using the MTT cell Proliferation Assay Kit (Cayman, Catalog No. 10009365) according to the manufacturer's recommendation. 


\subsection{Animals and behaviour testing}

\subsubsection{Contextual Fear Conditioning Paradigm}

Mice (C57B16/J, Janvier) were housed under standard conditions with free access to food and water. All experiments were carried out in accordance with the animal protection law and were approved by the District Government of Germany. Behaviour testing was performed as described previously (Fischer et al., 2007) using TSE Systems apparatuses and software as well as Freeze Scan software (Clever Systems). In brief mice were single housed and habituated to the testing room at least 3 days before behaviour experiments. To measure associative learning we employed the contextual fear-conditioning paradigm. The training consisted of a single exposure to the conditioning context $(3 \mathrm{~min}$ ) followed by a single electric foot shock (0.70 mA, constant current for 2 seconds) and the memory test was performed $24 \mathrm{~h}$ later (Figure 2). During the 3 min memory test, the freezing behaviour was determined every 10 seconds. For each mouse, a total of 18 measurements were taken. The freezing behaviour was quantified by calculating the number of measurements when the mouse showed a freezing behaviour divided by the total number of measurements. (\% Freezing $=$ Freezing counts $/ 18 * 100)$. The testing cage was carefully cleaned with $70 \%$ ethanol and then dried before placing new mice in the cage.

\subsubsection{Novel object Recognition (N.O.R)}

The novel object recognition test is evaluates the desire in rodents to explore novelty by showing preference to a novel object over familiar ones. This test consists of three phases: habituation, training and testing. Mice were put in an open field and allowed to explore for 5 min to habituate. The following day two similar objects in size and shape are introduced and again the mice were made to explore for $5 \mathrm{~min}$. This is repeated until anxiety levels are observed to be appreciably reduced compared to the first day of object exposure. The mice were then test on the object recognition task which again involves two similar object introduced to the mice for the first time on the day of testing. The mice were again allowed to explore for $5 \mathrm{~min}$ after which they are returned to home cage. After $5 \mathrm{~min}$ the mice were brought back to the arena with one of the objects changed with a novel one and again allowed to explore for $5 \mathrm{~min}$. Exploration was scored on the basis of sniffing, direct contact with the object. The index for scoring is calculated as percent time spent with novel object with the relation below. 


$=\left\{\frac{\text { time spent with novel object }}{\text { time spent with both familiar and novel object }}\right\} 100 \%$

\subsubsection{Morris Water Maze (MWM)}

The water maze (Morris, 1981) training was performed in a circular tank (diameter $1.2 \mathrm{~m}$ ) filled with opaque water (1.5 Liters SAKRET Tiefengrund). A platform $(11 \times 11 \mathrm{~cm})$ was submerged $1 \mathrm{~cm}$ below the water's surface in the centre of the target quadrant. The swimming path of the mice was recorded by a video camera and analyzed by the Videomot 2 software (TSE). Four trials per day was performed by gently lowering the mice into the pool from different spatial cues and allowed to swim for $60 \mathrm{~s}$. A mouse that is not able to find the platform was aided by tail guide to the platform. The mouse was then allowed to rest for 10 min before the next section is initiated. Probe test (Memory retention) was performed by removal of the platform and the mice allowed for $60 \mathrm{~s}$ to swim.

\subsubsection{Elevated Plus Maze}

Elevated plus maze was performed to test the anxiety levels of the mice. This test is based on the principle of rodent preferring narrow, dark and closed spaces over open and bright places. The maze consists of four arms, two walled arms facing each other and two unfenced. Each arm is of length $45 \mathrm{~cm}$ and $10 \mathrm{~cm}$ broad. The walled arms are of height $30 \mathrm{~cm}$. The anxiety level is tested in the mice by introducing them into the centre of the maze facing the open arm and allowed to explore for $5 \mathrm{~min}$. Tracking of the mice was done by the VideoMot2, Version 7.5 The anxiety level was determined by plotting the percentage time spent in both close and open arms (Lister et al., 1987; Rodgers and Cole1993). The elevation of the maze from the ground is $40 \mathrm{~cm}$.

\subsection{Mouse strains}

\subsubsection{Genotyping of APPPS1-21 mice}

Mouse lines generated were housed in the animal facility of European Neuroscience Institute, Goettingen and C57BL/6J strains were used for the breeding. Food was provided ad libitum. APPPS1-21 mice were genotyped using the protocol below. Only the PCR for the APP gene 
was performed using a Mastercycler ep gradient S (Eppendorf, Hamburg, Germany) using DreamTaqTM as the mouse line was generated to have co-inheritance of both APP and PS1 gene. The laboratory materials, which are not listed here, were bought from Janvier, France.

\begin{tabular}{|c|c|c|c|}
\hline \multicolumn{4}{|c|}{ Genotyping PCR forAPPPS1-21 mice } \\
\hline Step & Temperature & Time & Number of cycles \\
\hline Initial denaturation & $95^{\circ} \mathrm{C}$ & $5 \mathrm{~min}$ & $1 \mathrm{x}$ \\
\hline Amplification & $95^{\circ} \mathrm{C}$ & $10 \mathrm{~s}$ & $30 \mathrm{x}$ \\
& $60^{\circ} \mathrm{C}$ & $30 \mathrm{~s}$ & \\
& $72^{\circ} \mathrm{C}$ & $1 \mathrm{~s}$ & $1 \mathrm{x}$ \\
\hline Cooling & $40^{\circ} \mathrm{C}$ & $30 \mathrm{~s}$ & \\
\hline
\end{tabular}

\subsection{Implantation of microcannulae and in vivo intrahippocampal manipulations}

In order to implant microcannulae, mice were provided at least 3 days before operation with water containing $3 \mathrm{ml} / \mathrm{L}$ of Sodium metamizol. The mice were anaesthetised with a cocktail of $120 \mathrm{mgkg}^{-1} / 8 \mathrm{mgkg}^{-1}$ of ketamine/xylazine. The coordinates for drilling holes were determined based on the position of the target region according to the Mouse Brain Atlas (Paxinos and Franklin). The head of mice were fixed in a Benchmark stereotaxic Instrument. The skin and the connective tissue above the skull were carefully removed. The exposed skull was then cleaned with PBS. Using a clean 0.5 driller, two holes $2 \mathrm{~mm}$ apart $(1 \mathrm{~mm}$ from on each side from the medial line ) were bilaterally drilled in the mice skull $(-1.70 \mathrm{~mm}$ posterior relative to bregma). Any bleeding was cleaned with a cotton swab soaked in PBS and $1.5 \mathrm{~mm}$ microcannula was carefully mounted on the skull. The microcannulae were fixed with dental cement. The head was kept fixed until the cement hardened and the microcannula was adequately fixed. Upon solidification of the dental cement, the mouse was wrapped up in a soft paper towel and warmed on a warm plate $\left(37^{\circ} \mathrm{C}\right)$ for $10 \mathrm{~min}$ and finally returned to its home cage. Mice implanted with microcannulae were individually housed and observed for a week before commencement of experiments. During the administration of drugs, mice were anesthetized with Isoflurane. $0.5 \mathrm{~mL}$ of Isoflurane was pipetted on a small tissue paper, which was placed in $0.5 \mathrm{~L}$ beaker. The mice were place in the beaker until they were anesthetized. The drugs were bilaterally injected for one minute into the hippocampus by using a $1.5 \mathrm{~mm}$ injector. After one minute, the injector remained in the microcannulae for additional 10 second. After the injection, the dummy was placed in the microcannulae and the mice were carefully returned to their home cages. 


\subsection{Protein lyses, Sub-cellular fractionation and Immunoblotting}

The hippocampus tissue was isolated and prepared as previously described (Fischer et al., 2007) and was immediately kept in liquid nitrogen. The frozen tissue was kept at $-80^{\circ} \mathrm{C}$ at all times until usage. Brain tissue was homogenized in TX-buffer $(50 \mathrm{mM}$ Tris $\mathrm{HCl}, 150 \mathrm{mM}$ $\mathrm{NaCl}, 2 \mathrm{mM}$ EDTA,1\% Triton-100, 1\% NP-40, 0,1\% SDS), subjected to the Bioruptor (Diagenode) for $15 \mathrm{~min}$ (High; 30 seconds ON, 30 seconds OFF). Next, the lysate was centrifuged at $12000 \mathrm{rpm}$ for $10 \mathrm{~min}$. The supernatant was used for immunobloting. Another method for protein isolation was Subcellular fractionation of hippocampus, which was made by using the Proteo Extract. Subcellular Proteome Extraction Kit (Calbiochem) to isolate cytosolic, membrane and nucleus protein fractions from Hippocampus tissue. $500 \mu \mathrm{L}$ of ice cold Extraction buffer I with 2,5 $\mu \mathrm{L}$ Protease Inhibitor Cocktail were added to the tissue, which was homogenized with a sterile stroke and incubated for $10 \mathrm{~min}$ at $4{ }^{\circ} \mathrm{C}$ with gentle agitation on an a shaker. Lysate was pellet by centrifugation at $4^{\circ} \mathrm{C}$ at $750 \mathrm{rcf}$ for $10 \mathrm{~min}$. Supernatant, containing the cytosolic fraction (Fraction I) was removed and stored on ice. Pellet was re-suspended with $500 \mu$ ice cold Extraction Buffer II and $2.5 \mu \mathrm{L}$ Protease Inhibitor Cocktail. After incubation at $4^{\circ} \mathrm{C}$ for $30 \mathrm{~min}$ by gentle agitation, insoluble material was pelleted at $5500 \mathrm{rcf}$ for $10 \mathrm{~min}$. Supernatant containing the membrane fraction (Fraction II) were removed and stored on ice. Pellet were re-suspended by gentle flicking the tube with $250 \mu \mathrm{L}$ Extraction Buffer III and $2.5 \mu \mathrm{L}$ Benzonase Nuclease and incubated for $10 \mathrm{~min}$ at $4^{\circ} \mathrm{C}$ by gentle agitation. Next the sample was centrifuged at $8500 \mathrm{rcf}$ for $10 \mathrm{~min}$. The supernatant containing the nuclear fraction (Fraction III) was removed and stored on ice. The protein concentration was determined using Bradford protein assay (Bradford, 1976). In brief $3 \mu \mathrm{L}$ of sample was mix with $997 \mu \mathrm{l}$ of 1x Bradford dye (Bradford stock solution 5x). The dilution was made with PBS $7.0 \mathrm{pH}$ ). The mixture was incubated for $5 \mathrm{~min}$. Next, the concentration was measured in a spectrometer. The desired sample fraction was then mixed with $5 \mathrm{x}$ loading dye and was heated for $5 \mathrm{~min}$ in $95^{\circ} \mathrm{C}$. Samples $(40 \mu \mathrm{g}$ of the total lysate or $10-20 \mu \mathrm{g}$ of nuclear fraction lysate) were loaded on 12\% acreylamide gel (Laemmli, 1970; performed as in (Fischer et al., 2007) for total of $2.5 \mathrm{~h} \mathrm{(45} \mathrm{min} \mathrm{60V} \mathrm{followed} \mathrm{by} 105 \mathrm{~min} \mathrm{120V})$. The protein was then transferred onto a nitrocellulose membrane and then blocked with $5 \%$ milk powder in TBST for $1 \mathrm{~h}$. Next, the membranes were incubated with first antibody for 1-2 days. Membranes were incubated for 45 min with fluorescent secondary antibodies $(1: 15,000$ in $0.5 \%$ milk in TBST), and then washed with TBST 3x 10 min. Before quantification using an Odyssey Infra-red Imager (Li-Cor), the membranes were washed with PBS briefly. It was made sure that responses were within the linear range. 


\subsection{Immunoprecipitation}

\subsubsection{Chromatin Immunoprecipitation (ChIP)}

Basically two ChIP processes have been performed. Native ChIP was employed for post mortem tissues described below and one day ChIP for the mouse samples. For (Jackson, 1978; Solomon, 1988; modified for whole tissue experiments by Diagenode company and our lab) the DNA-shearing Kit and One-Day ChIP Kit protocol from Diagenode (Diagenode, Belgium) was used according to the manufacturer's protocol. The following modifications were made to optimize the procedure for hippocampal tissue. Tissue was homogenized with twice the amount of the different buffers indicated during pre-shearing. DNA shearing was performed the Bioruptor (Diagenode) with the following settings ( $25 \mathrm{~min}$ in total, High, $30 \mathrm{~s}$ ON, $30 \mathrm{~s}$ OFF). Sheared chromatin samples were incubated for $60 \mathrm{~min}$ with $4 \mu 1$ of antibody in ultra sonic bath. Subsequently, the antibody-antigen complex was further incubated with pre-blocked beads and an extra of $500 \mu \mathrm{l}$ of ChIP buffer for $60 \mathrm{~min}$. Rather than recommended the beads were washed twice. The antibody-beads complex was incubated for $45 \mathrm{~min}$ in the presence of Proteinase K. Purified DNA was analyzed on a Bioanalyzer (Agilent) using pico-RNA chip. For native ChIP employed in the processing of post mortem tissues. Adjusted volume of Dounce buffer (Section 2.1.4) is added according to the weight of brain tissue. The tissue was then homogenized with 5 strokes and appropriate volume of $0.5 \mathrm{u} / \mu 1$ Micrococcal Nuclease (MNase) added followed by EDTA to a final concentration of $10 \mathrm{mM}$ to stop the reaction. The lysed tissue was hypotonized using $0.2 \mathrm{mM}$ EDTA and 0.2 $\mathrm{M}$ Benzamidine added and PMSF and incubated for $1 \mathrm{~h}$ with vortexing at regular intervals of $10 \mathrm{~min}, 3 \mathrm{M}$ DTT (1/2000) was then added and the solution centrifuged at $4000 \mathrm{rpm}$ for 10 $\min$ at $4^{\circ} \mathrm{C} .500 \mu \mathrm{l}$ of the supernatant was then taken for immuno-selection and $200 \mu \mathrm{l}$ used as input. Immuno-selection was performed by adding fresh 1/10 sample volume of 10x FSB buffer (Section 2.1.4). Appropriate antibody was then added and vortexed at medium power. The mixture was then incubated for $1 \mathrm{~h}$ in ultrasonic bath. Meanwhile protein G-Agarose beads was washed with $1.4 \mathrm{ml}$ FSB buffer and blocked with $15 \mu 1$ of Salmon sperm DNA (10 $\mathrm{mg} / \mathrm{ml}$ ) for $20 \mathrm{~min}$ at $4^{\circ} \mathrm{C}$ on a rotating wheel. Supernatant was removed after centrifugation at $2500 \mathrm{rpm}$ for $3 \mathrm{~min}$. Then $200 \mu \mathrm{l}$ of FSB per sample was added and the beads equally distributed in new microfuge tubes. This was achieved by comparing the levels after centrifuging at $1500 \mathrm{rpm}$ for $1 \mathrm{~min}$. The antibody-chromatin complex was then added to the beads and incubated on a wheel for $1 \mathrm{~h} 4^{\circ} \mathrm{C}$. Unbound protein was removed by centrifuging at $1500 \mathrm{rpm}$ for $3 \mathrm{~min}$ and supernatant discarded. Washing of the complex was performed 
sequentially using low and high salt buffers, lithium chloride and TE buffer (section). Fresh $250 \mu \mathrm{l}$ of Elution buffer was added at RT and vortexed at medium power and rotated for 15 min at RT. Supernatant was collected after centrifugation at $2500 \mathrm{rpm}$ for $2 \mathrm{~min}$. This step is repeated and the eluate pooled. Then $10 \mu \mathrm{l}$ of $0.5 \mathrm{M}$ EDTA and $25 \mu \mathrm{l}$ of $0.8 \mathrm{M}$ Tris- $\mathrm{HCl}, \mathrm{pH}$ 6.5 were added. Proteinase K (1/200) was added and incubated at $52^{\circ} \mathrm{C}$ for at least $2.5 \mathrm{~h}$. Phenol- $\mathrm{CHCl}_{3}$ purification was performed with $500 \mu \mathrm{l}$ and incubated at RT for $5 \mathrm{~min}$. Aqueous phase was transferred to a new tube after centrifugation for $5 \mathrm{~min}$ at $13000 \mathrm{rpm}$. A mixture of glycogen, $2 \mu \mathrm{l}$ and $50 \mu \mathrm{l}$ of $5 \mathrm{M}$ Sodium acetate was added and $1.375 \mu \mathrm{l}$ of $100 \%$ ethanol added and vortexed vigorously. The samples were then incubated at $-80^{\circ} \mathrm{C}$ over-night. The next day, the samples were centrifuged at $13000 \mathrm{rpm}$ for $25 \mathrm{~min}$ at $4{ }^{\circ} \mathrm{C}$. The pellet was then washed with ice cold $75 \%$ ethanol and centrifuge at $14000 \mathrm{rpm}$ for $10 \mathrm{~min} 4{ }^{\circ} \mathrm{C}$. The supernatant was discarded and the pellet air-dried and then dissolved in $50 \mu 1$ of $_{2} \mathrm{O}$.

\subsubsection{Co-immunoprecipitation}

Whole hippocampal tissue was lysed using the lysis buffer including $0.25 \mathrm{mM}$ of sodium orthovanadate. Hundred microlitres of lysate was taken and diluted in $100 \mu$ l of lysis buffer. An input of $40 \mu \mathrm{l}$ of the diluted sample was taken and stored at $-20^{\circ} \mathrm{C}$. For immuno-selection, $2.5 \mu \mathrm{l}$ of SphK2 (Abcam 92607) was added and incubated at $4^{\circ} \mathrm{C}$ for $2-3 \mathrm{~h}$ on a rotating wheel. During the incubation, protein A beads were washed, $100 \mu 1$ per sample with $200 \mu 1$ of lysis buffer. The beads were centrifuged at $5000 \mathrm{rpm}$ at RT for $1 \mathrm{~min}$ and supernatant discarded. The washing was repeated once. After the incubation, the complex was spun briefly and transferred to the beads. This was then further incubated for $2-3 \mathrm{~h}$ at $4^{\circ} \mathrm{C}$ on a rotating wheel. Unbound protein was removed after the incubation step by collecting the supernatant into a new microfuge tube after centrifugation at $5000 \mathrm{rpm}$ for $1 \mathrm{~min}$. The complex was then washed sequentially with buffer I and II and supernatant discarded. Sixty microlitres of $2 \mathrm{x}$ Laemlli buffer was then added and boiled at $95^{\circ} \mathrm{C}$ for $5 \mathrm{~min}$. The mixture was centrifuged at RT for $1 \mathrm{~min}$ at $5000 \mathrm{rpm}$ and the supernatant collected and used for western-blot.

\subsubsection{Methylated DNA Immunoprecipitation}

Two-5 $\mu \mathrm{g}$ of isolated DNA (using the phenol- $\mathrm{ChCl}_{3}$ ) dissolved in $200 \mu \mathrm{l}$ of TE buffer was used for methylated DNA immunoprecipitation. The DNA was sheared by sonication to 
Materials and methods Assessment of Epigenetic profile in Alzheimer's disease

obtain 200-500 bps. Approximately, $4 \mu \mathrm{g}(\cong 160 \mu \mathrm{l})$ of sonicated DNA and volume adjusted to $450 \mu \mathrm{l}$. The DNA was denatured at $95^{\circ} \mathrm{C}$ and immunoselected for $5 \mathrm{mC}$ antibody for $2 \mathrm{~h}$ on a rotating wheel at $4^{\circ} \mathrm{C}$ after addition of $51 \mu 1$ of $10 \mathrm{x}$ IP buffer. Meanwhile dynabeads are washed during the incubation step with PBS-BSA $0.1 \%$ for 5 min. The beads were collected with magnetic rack and re-suspended in $40 \mu \mathrm{l}$ per sample IP buffer and then added to the mixture. The mixture was incubated for $2 \mathrm{~h}$ at $4{ }^{\circ} \mathrm{C}$. Afterwards, the beads were collected using a magnetic rack and washed with $700 \mu 1$ 1x IP buffer at RT for 10 min with shaking at $800 \mathrm{rpm}$. Washing was repeated twice. The beads were then collected and re-suspended in $250 \mu 1$ Proteinase $\mathrm{K}$ digestion buffer and $3.5 \mu \mathrm{l}$ Proteinase $\mathrm{K}$ and incubated for $3 \mathrm{~h}$ at $50^{\circ} \mathrm{C}$. The DNA was then cleaned with phenol- $\mathrm{CHCl}_{3}$-isoamylalcohol 25:24:1. The DNA was precipitated with $400 \mathrm{mM} \mathrm{NaCl}$ and $1 \mu \mathrm{l}$ of glycogen. Two volumes of Ethanol was added and incubated at $-20^{\circ} \mathrm{C}$ for $20 \mathrm{~min}$ and centrifuged for $25 \mathrm{~min}$ at $13000 \mathrm{rpm}$ at $4{ }^{\circ} \mathrm{C}$. Supernatant was removed and washing step repeated with $500 \mu \mathrm{l}$ of $70 \%$ Ethanol and finally obtained DNA was dissolved in $40 \mu 1$ of TE buffer. qPCR was then run on the samples and loaded on a $2 \%$ agarose gel for $40 \mathrm{~min}$.

\subsection{Antibodies}

\begin{tabular}{|c|c|c|c|c|c|}
\hline \multicolumn{7}{|c|}{ Antibodies } & Company & Dilutions & Antibodies & Company & Dilutions \\
\hline \multicolumn{7}{|c|}{ Primary antibodies } \\
\hline Sphk2(Rb) & Abcam & $1: 1000$ & $\beta$-Actin $(\mathrm{Ms})$ & Santa-Cruz & $1: 2000$ \\
\hline Sphk1 & Abcam & $1: 1000$ & Hdac1 $(\mathrm{Rb})$ & Santa cruz & $1: 1000$ \\
\hline Ac-H3K9 $(\mathrm{Rb})$ & Millipore & $1: 5000$ & Hdac2 $(\mathrm{Ms})$ & Abcam & $1: 1000$ \\
\hline Ac-H3K14 $(\mathrm{Rb})$ & Millipore & $1: 2500$ & Hdac2 $(\mathrm{Rb})$ & Santa cruz & $1: 1000$ \\
\hline Ac-H4K5 $(\mathrm{Rb})$ & Millipore & $1: 2000$ & Hdac3 (Rb) & Santa cruz & $1: 1000$ \\
\hline Ac-H4K8 $(\mathrm{Rb})$ & Millipore & $1: 1000$ & Hdac8 $(\mathrm{Rb})$ & Santa cruz & $1: 1000$ \\
\hline Ac-H4K12 $(\mathrm{Rb})$ & Abcam & $1: 5000$ & Hdac10 $(\mathrm{Rb})$ & Santa cruz & $1: 500$ \\
\hline Ac-H4K16 $(\mathrm{Rb})$ & Millipore & $1: 2000$ & H4 & Abcam & $1: 500$ \\
\hline Dnmt3a $(\mathrm{Rb})$ & Cell Signalling & $1: 1000$ & Akt1 $(\mathrm{Ms})$ & Abcam & $1: 1000$ \\
\hline Dnmt1 $(\mathrm{Rb})$ & Cell Signalling & $1: 1000$ & IGFBP7 (Rb) & Abcam & $1: 1000$ \\
\hline Dnmt3b $(\mathrm{Rb})$ & Cell Signalling & $1: 1000$ & p-Akt(308) & Abcam & $1: 1000$ \\
\hline Prkcd $(\mathrm{Rb})$ & Santa cruz & $1: 500$ & GAPDH $(\mathrm{Ms})$ & Chemicon & $1: 1000$ \\
\hline 5mC & Eurogentec & $5 \mu 1$ per IP & DAPI & Vectashield & $1: 10000$ \\
\hline
\end{tabular}

\section{Secondary antibodies}

\begin{tabular}{|c|c|c|c|}
\hline Antibodies & Company & Dilutions & Host \\
\hline Anti rabbit IgG $800 \mathrm{~nm}$ & Li-COR & $1: 15000$ & Goat \\
\hline Anti rabbit IgG $680 \mathrm{~nm}$ & Li-COR & $1: 15000$ & Goat \\
\hline Anti mouse IgG $800 \mathrm{~nm}$ & Li-COR & $1: 15000$ & Goat \\
\hline Anti mouse IgG $680 \mathrm{~nm}$ & Li-COR & $1: 15000$ & Donkey \\
\hline Alexa 488 anti mouse & Invitrogen & $1: 500$ & Goat \\
\hline Cy3 anti rabbit & Jackson immunoreseach & $1: 500$ & \\
\hline
\end{tabular}




\subsection{HAT/HDAC Activity}

To specifically measure activity of HATs and HDACs in the nucleus, sub-cellular fractionation of hippocampal was performed using the Calbiochem Kit (ProteoExtract ${ }^{\circledR}$ Subcellular Proteome Extraction, Calbiochem 539790-1KIT). Nuclear fractions were then used in the determination of activity of the enzymes. HAT assay was performed using the HAT Assay Kit (BioVision, K332-100) according to the manufactures protocol. HDAC assay was performed using the Fluorometric HDAC assay kit (BioVision, k330-100) according to the manufactures protocol. Briefly, $120 \mu \mathrm{g}$ of nuclear extract were incubated for $4 \mathrm{~h}$ with the assay mix in Greiner $96 \mathrm{U}$ Bottom Transparent Polystyrol plate. Analysis was performed using a TECAN Infinite 200 Elisa plate reader and all determinations were performed at 430 $\mathrm{nm}$.

\subsection{Perfusion and Immunohistochemistry}

In order to implant microcannulae, mice were anesthetized with $0.1 \mathrm{mg} / \mathrm{kg}$ of Temgesic. Mice were anesthetized with a sub-cutaneously injection of $0.1 \mathrm{mg} / \mathrm{kg}$ of Temgesic dissolved in $\mathrm{NaCl}$ and then perfused by transcardial injection with ice-cold PBS followed by $4 \%$ PFA. Brain samples were then dissected out and kept in $30 \%$ sucrose solution for at least three days and then cryo-sectioned. For immunohistochemistry the brain sections were washed three times with PBS for 5 min each and then permeabilized with $0.2 \%$ Triton-X for $30 \mathrm{~min}$ at $4^{\circ} \mathrm{C}$. The sections were then washed three times with PBS for 5 min and incubated in 5\% BSA for $1 \mathrm{hr}$ at RT and then washed again for three times with PBS for $5 \mathrm{~min}$. The brain sections were then incubated with primary antibody (2.1.12) at RT for $2 \mathrm{~h}$ in $2 \%$ BSA solution. The slides were washed after the primary antibody incubation with PBS three times for $15 \mathrm{~min}$ and incubated in secondary antibody (2.1.12) for $2 \mathrm{~h}$ at RT in $1 \%$ BSA solution. Sections were afterwards incubated in DAPI $(1: 10000)$ for $20 \mathrm{~min}$. The sections were then mounted coverslips and sealed with Mowiol.

\subsubsection{Confocal microscopy and Image acquisition}

Fluorescence pictures were acquired and later quantified using Leica SP2 AOBS confocal microscope with Leica confocal Software (LCS). Gain and background settings were identical to all groups compared per experiments. In addition, all pictures per experiment containing all the groups compared were taken in the same microscope session without 
Materials and methods Assessment of Epigenetic profile in Alzheimer's disease

switching off the laser or changing any settings. Prior to the beginning of the pictures acquisition, the laser was allowed to heat up and proximally 30 blank picture slices were taken to achieve optimal laser power. A multi-line Argon laser and two Helium Neon lasers were used in the microscope. Two sequential images (lambda scan) were acquired by exciting fluorochromes. Images were acquired with identical parameters: pixel time $8 \mu \mathrm{s} /$ pixel (time acquisition $10 \mathrm{sec}$ ), 1024 pixels x 1024 pixels resolution, pinhole: 1 airy unit for 496-508 nm emission wavelengths.

\subsection{Bioinformatics and Statistical Analysis (Computer analysis)}

Sequences obtained from Seqlab were aligned using program BLAST and other programs from National Centre for Biotechnology Information (NCBI) (www.ncbi.nlm.nih.gov). For restriction analysis of DNA sequence NEBcutter V2.0 program was used (http://tools.neb.com/NEBcutter2/index.php. For densitometric quantification of gel pictures Image $\mathbf{J}$ software (http://rsb.info.nih.gov/ij/) was used. Levels of MeDIP DNA were measured using the Image $\mathbf{J}$ software. The promoter was analysed using the TRED (http://rulai.cshl.edu/cgi-bin/TRED/tred.cgi?process=home). $\mathrm{CpG}$ islands were identified using the software (http://www.uscnorris.com/cpgislands2/cpg.aspx) and methylated DNA primers on promoters were designed (http://www.urogene.org/methprimer/index1.html). TargetScan and miRanda were used for computational prediction of miRNA targets (www.targetscan.com/release 5.1) and (www.miRanda.org). Data of qPCR, western blotting and behavioral studies are expressed as mean \pm s.e.m (standard error mean) unless stated otherwise significance was defined performing student's t-test and ANOVA. Methylation of DNA was modelled with ChemSketch (http://www.acdlabs.com/resources/freeware/chemsketch/). 
Results Assessment of Epigenetic profile in Alzheimer's disease

\section{Results}

\section{Part I}

\subsection{The role of DNA methylation in Aging and Alzheimer's disease}

DNA methylation has been implicated with memory function but its role in AD is less well defined. The starting point to this project was a previous finding by our lab showing that IGFBP7 is dynamically regulated during fear extinction, a model for post-traumatic stress disorder (PTSD) (Agis-Balboa et al., 2011). Here elevated levels of IGFBP7 were associated with PTSD-like phenotypes in mice. Our unpublished data show that during fear extinction IGFBP7 levels are regulated via dynamic DNA-methylation, which is in line with differential DNA-methylation of IGFBP7 in cancer cells (Kanemitsu et al., 2000; Lin et al., 2007; Wang et al., 2008a). Moreover, increased serum levels of IGFBP7 have been observed in diabetic patients and insulin resistance (IR) (Kutsukake et al., 2008; Lopez-Bermejo et al., 2006) and AD patients (unpublished). This is interesting; since IR is a risk factor for AD and deregulated insulin/IGFs signalling has been implicated with AD pathogenesis. Considering the fact that in addition to altering insulin signalling, PTSD is a severe risk factor for developing AD at old age (Yaffe et al., 2010) it is tempting to hypothesize that environmental stressors affect DNA-methylation of IGFBP7 which in turn lead to elevated IGFBP7 levels, may contribute to AD pathogenesis. A role for IGFBPs has so far not been tested in AD and the following experiments were designed to test this hypothesis.

\subsubsection{Aberrant IGFBP7 expression in Alzheimer's disease}

It was first set out to determine the expression of IGFBPs levels in human AD patients. Post mortem samples from the prefrontal cortex of age-matched individuals with a similar postmortem delay were chosen for analysis (Fig. 3.1.1A and B). Determination of the levels of IGFBP1-7 via qPCR was first done. No difference in expression was detected for IGFBP1-6 in $\mathrm{AD}$ patients relative to the control group (Fig. 3.1.1C). In contrast, IGFBP7 was found to increase significantly in AD samples relative to controls (Fig. 3.1.1C, p=0.0092). Elevated levels of mRNA translated into increased amount of protein i.e. increased IGFBP7 levels was observed in the AD samples by immunoblot analysis (Fig. 3.1.1D, p=0.0003). A key pathway activated by insulin/IGFs to maintain cellular integrity is the Akt/PI3K-pathway (Cheng et al., 2010; Sesti, 2006). When the total level of Akt was determined no significant difference was observed between control and AD patients however, the level of p-Akt, a mark for Akt 
activation, was found to be significantly reduced in patients compared to the control samples (Fig. 3.1.1E, p=0.0358).
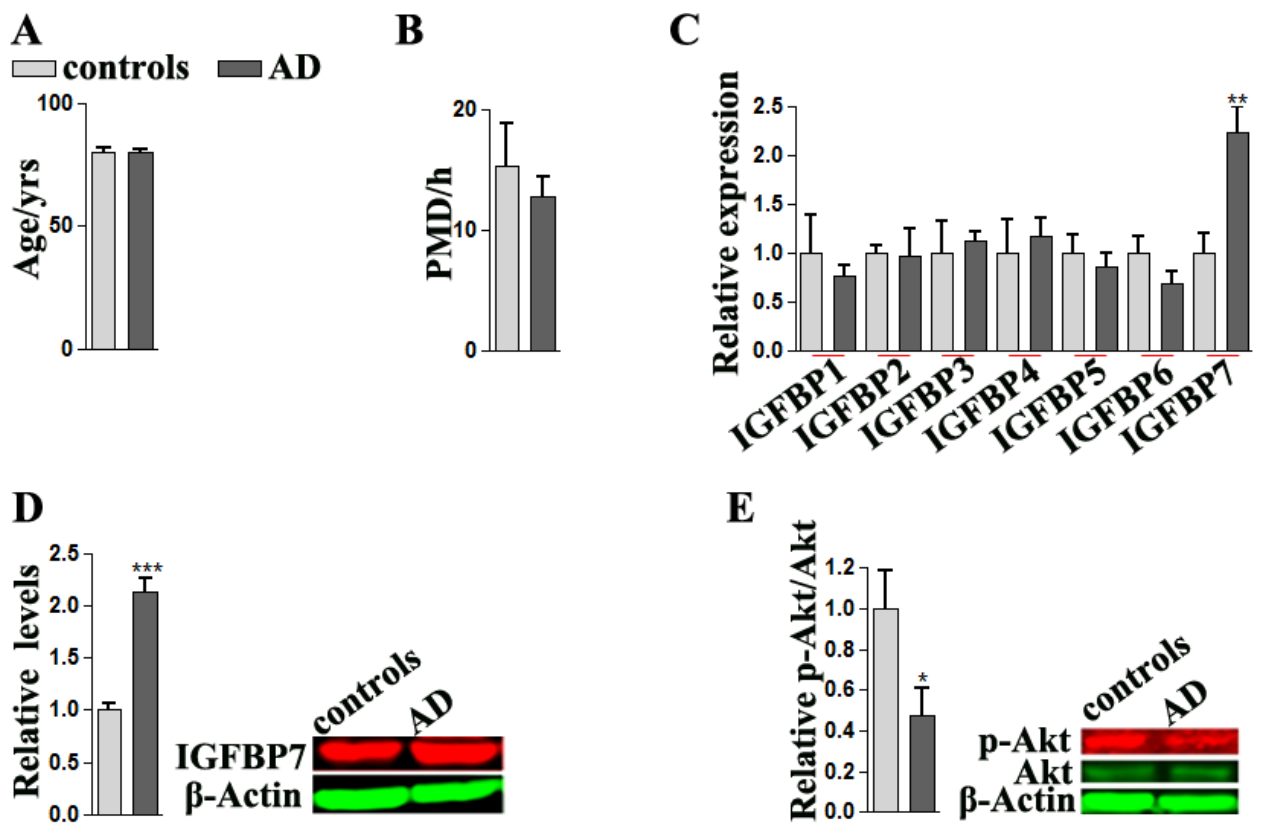

Fig. 3.1.1: Comparison of IGFBPs levels between controls and AD patients. A: Age of patients used for post mortem analysis. B: Post mortem delay in individuals used showing no significant difference between controls and AD patients. C: qPCR analysis shows that IGFBP7 mRNA was significantly increased in AD patients. D: Left panel shows immunoblot analysis of IGFBP7 protein levels significantly increased in AD patients and right panel shows representative immunoblot E: Left panel shows immunoblot analysis of reduced p-Akt levels in AD patients. Right panel shows representative immunoblot images of reduced activation of Akt in AD patients. Data was normalized to $\beta$-Actin. No. of controls $=7$ and $\mathrm{AD}=14$. Error bars indicate s.e.m. $(* \mathrm{p}<0.05$, **p<0.01 and $* * * \mathrm{p}<0.001)$.

In sum these data show that IGFBP7 levels are increased in AD patients which correlates with reduced Akt signalling, the major downstream pathway activated by the insulin/IGF cascade.

\subsubsection{CpG Methylation on the Promoter IGFBP7 was lower than controls}

Published (Nakae et al., 2001; Wajapeyee et al., 2010) as well as unpublished data from our group demonstrate the regulation of IGFBP7 by dynamic DNA methylation. Therefore methylated DNA immunoprecipitation (MeDIP) was performed to study the impact of DNAmethylation on deregulated IGFBP7 levels in AD. Assessment of methylated cytosine levels within the promoter of $I G F B P 7$ revealed a significant reduction in AD compared to controls but not within the promoters of IGFBP2 and IGFBP4 (Fig 3.1.2A, p=0.0333) suggesting that 
decreased DNA methylation contributes to elevated IGFBP7 levels. DNA methylation is regulated by DNA methyltransferases (Bird and Macleod, 2004; Goll and Bestor, 2005). Thus the enrichment of the DNA methyltransferases DNMT1 and DNMT3a at the IGFBP7 promoter using ChIP analysis was determined (Fig. 3.1.2B and C). Reduced levels of DNMT1 (Fig. 3.1.2B, p=0.0065) and DMNT3a (Fig. 3.1.2C, p=0.0085) at the IGFBP7 promoter in AD patients were observed. This effect was specific since similar levels of DNMT1 and DMNT3a were detected at the promoter regions of IGFBP2 and IGFBP4 (Fig 3.1.2 B and C).
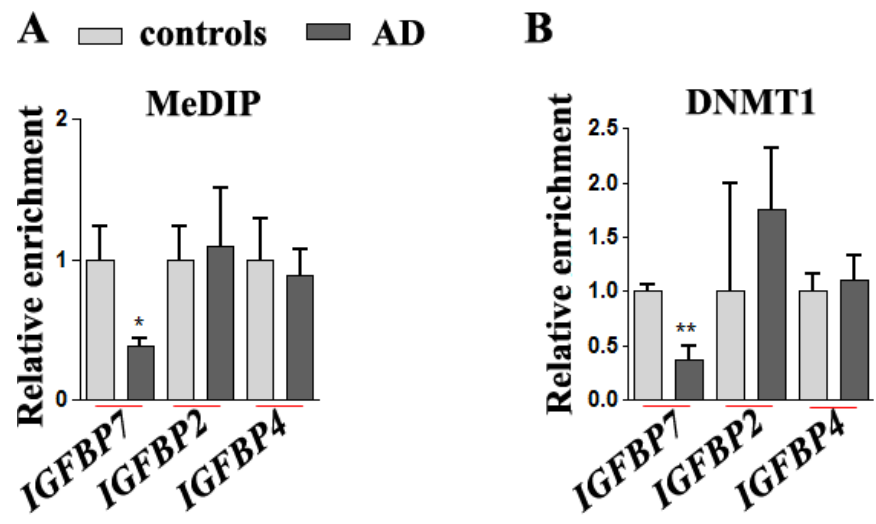

C

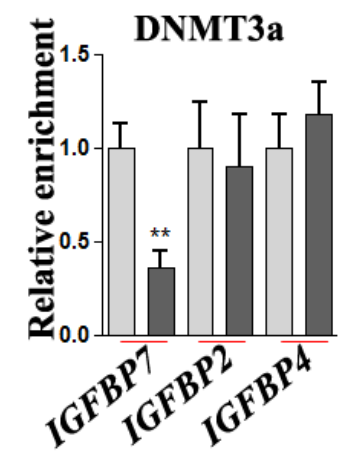

Fig. 3.1.2: Aberrant expression of IGFBP7 in post mortem tissue correlates with altered methylation pattern. A: MeDIP analysis revealed reduced levels of methylated cytosine at the promoter of the IGFBP7. No significant difference was observed on the promoters of IGFBP2 and IGFBP4. B: ChIP analysis revealed reduced enrichment of DNMT1 on the promoter of IGFBP7 and no difference on the promoter of IGFBP4. C: ChIP analysis revealed reduced enrichment of DNMT3a on the promoter of IGFBP7 and no difference on the promoter of IGFBP2 and IGFBP4. $\mathrm{N}=5$ and error bars indicate s.e.m (*p $<0.05$ and $* * \mathrm{p}<0.01)$.

\subsubsection{Characterization of 4-5 month in APPPS1-21 mice}

Post-mortem analysis of human brain tissue is suitable as an initial experiment to test our hypothesis on the role of IGFBP7 in AD pathogenesis. To perform further mechanistic studies, the APPPS1-21 mouse (Radde et al., 2006) that is characterized by an early onset of amyloid pathogenesis was used. The aim was to investigate IGFBP7 regulation during the longitudinal course of pathogenesis, especially memory disturbances. Thus, we first set our experiments to detect the earliest time point of memory disturbances in APPPS1-21 mice. Four to 8 month old mice were subjected to a battery of behavioural tests. Obtained data show that explorative behaviour measured via the open field test was similar in 4 month old APPPS1-21 and wild type/control mice. Basal anxiety was measured as the percentage of 
time spent in the corners vs. the centre region of the open field arena. No difference was found amongst groups (Fig.3.1.3A). However, when mice were subjected to the elevated plus maze test (EPM), which is a more sensitive test for basal anxiety, APPPS1-21 mice were observed to show reduced anxiety levels indicated by the fact that APPPS1-21 mice spent more time in the open arms of the maze when compared to control mice $(p=0.0001$, Fig.3.1.3B). Next, memory formation was assessed. First the novel object recognition test that depends on the hippocampus and cortical regions was employed. When tested for LTM there was no significant difference amongst groups. However, while wild type control mice showed a preference to the novel object that was significantly above chance level, APPPS121 mice did not perform better than chance, suggesting the novel object recognition learning was mildly impaired in 4-5 month old APPPS1-21 mice (Fig.3.1.1C). The mice were then tested for associative memory task using the contextual fear conditioning paradigm. There was no difference in activity during the training and in response to the electric foot shock amongst groups. Freezing behaviour, which indicates associative memory, was measured $24 \mathrm{~h}$ later in a memory test. There was no difference amongst groups, showing that associative memory is intact in 4 month-old APPPS1-21 mice (Fig. 3.1.3D). Next mice were subjected to the hippocampus-dependent Morris water maze test, a common measure for spatial memory. The escape latency throughout the training was similar amongst groups (Fig.3.1.3E). There was also no difference in the swimming speed (Fig.3.1.3G). However, when subjected to the probe test in order to measure spatial memory retrieval, control mice spent more time in the target quadrant when compared to APPPS1-21 mice (Fig.3.1.1F). In fact, only control mice showed a significant preference for the target quadrant when compared to the other quadrants $(\mathrm{p}=0.0001)$. Latency to target quadrant and target platform were increased in APPPS1-21 mice compared to controls (Fig.3.1.3I and J). 


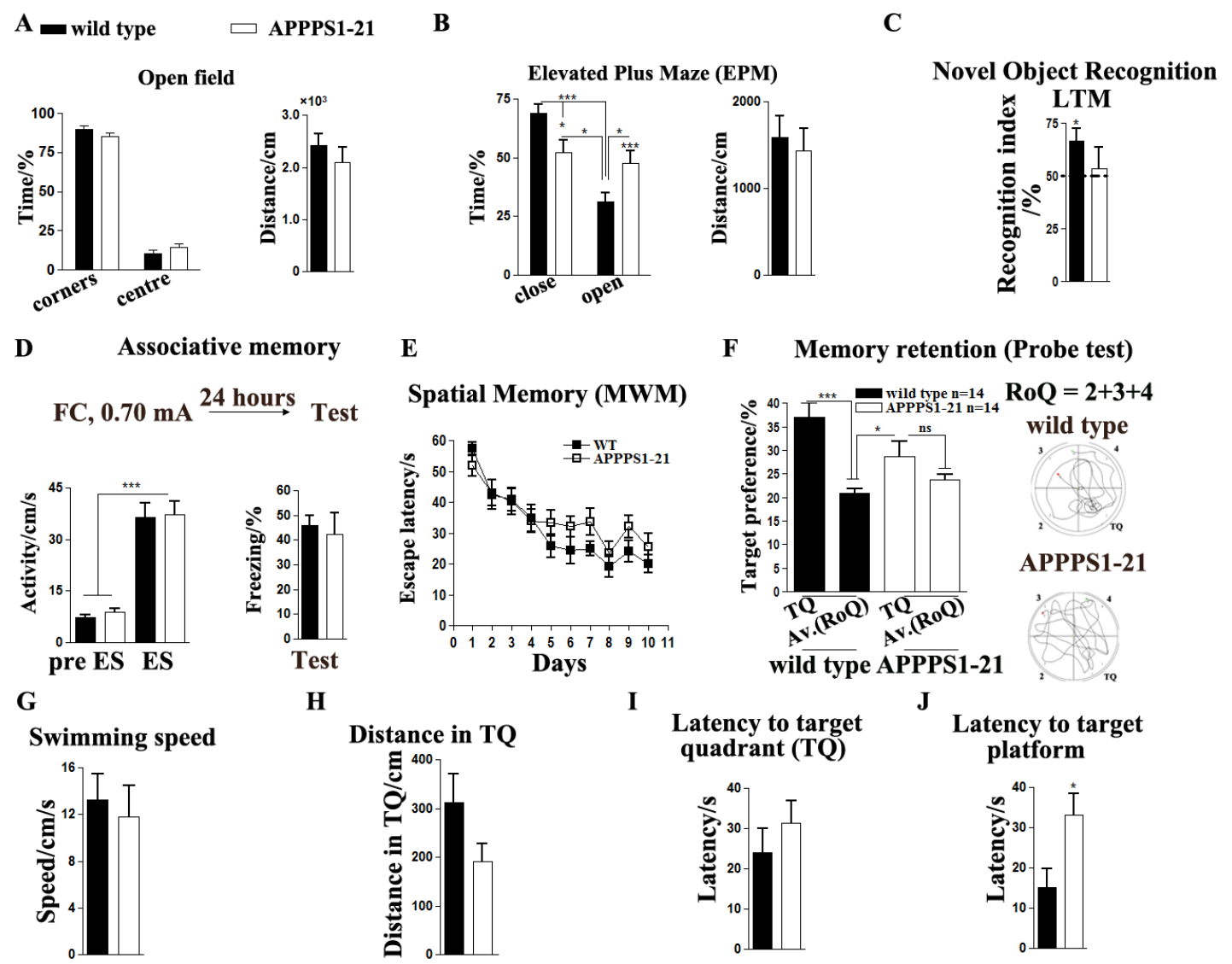

Fig.3.1.3: Behavioural characterization revealed earliest deficit in 4-5 month old APPPS1-21 mice. A: Open field showed similar motor activity in WT and APPPS1-21 mice. B: Elevated plus maze revealed reduced anxiety in APPPS1-21 relative to controls. Left panel shows no difference in activity as distance covered was the same for both groups. C: Controls mice showed significant preference in LTM in N.O.R test relative to chance levels whilst the transgenic mice did not. D: Fear conditioning revealed no difference between the two groups. Right panel shows activity during pre electric shock (ES) and ES while right panel shows memory assessed $24 \mathrm{~h}$ post ES. E: Spatial memory acquisition showed nearly no difference between the two groups. F: Memory retention was observed to be significantly different between control and APPPS1-21 mice. Left panel shows analysis of probe test in 4-5 month old mice and right panel shows representative trace pattern of swimming in control and APPPS1-21 mice in the pool. G: Swimming speed was not different between WT and APPPS1-21 mice H: Latency to TQ was also not different. I: Latency to target platform was observed to be significantly different between WT and APPPS1-21 mice. J: More distance was covered by the wild type than APPPS1-21 mice in target quadrant. $(\mathrm{n}=14)\left({ }^{*} \mathrm{p}<0.05, * * \mathrm{p}<0.01\right.$ and $\left.* * * \mathrm{p}<0.001\right)$.

In conclusion these data suggest that 4-5 month old APPPS1-21 mice exhibit mild cognitive deficit in memory tasks. These mice also show anxiety phenotype.

\subsubsection{Age dependent Cognitive deterioration in APPPS1-21 mice}

The data shown in fig. 3.1.3 demonstrated that 4-5 month old APPPS-21 mice show early signs of memory impairments that recapitulate the situation observed in MCI and AD patients 
Results Assessment of Epigenetic profile in Alzheimer's disease

where spatial navigation is amongst the first cognitive domains to be impaired while associative memory is relatively intact. Here we tested a memory function in 8-9 month old APPPS1-21 and control mice. When subjected to the open field test, explorative behaviour was similar amongst groups (Fig. 3.1.4A). Basal anxiety measured in the open field test by centre vs. corner activity was also similar amongst groups. When anxiety was measured in the more sensitive EPM test APPPS1-21 mice showed reduced anxiety. Thus, APPPS1-21 mice spent more time in the open arms when compared to the control group (Fig. 3.1.4B, $\mathrm{p}=0.0089$ ). Associative memory was tested using the contextual fear conditioning paradigm. The explorative behaviour during the training was similar amongst groups. Interestingly, APPPS-21 mice showed an increased response to the electric foot-shock (Fig. 3.1.4C). In spite of this finding, in comparison to the control group APPPS1-21 mice showed significantly reduced freezing behaviour during the memory test indicating impaired associative memory formation in 8 month old APPPS1-21 mice (Fig. 3.1.4C, p=0.0115). Spatial memory was tested using the Morris water maze test. There was a non-significant trend for reduced escape latency in APPPS1-21 mice (Fig. 3.1.4D). During the probe test, APPPS1-21 mice showed a severely impaired preference for the target quadrant indicating impairment in spatial memory (Fig. 3.1.4E). These data show that in 8-9 month old APPPS121 mice, associative and spatial memory function were impaired. Based on this observation, we decided to choose 4-6 month old APPPS1-21 mice to further test the role of IGFBP7, since these mice serve as a model for an early phase of the disease. 
Results Assessment of Epigenetic profile in Alzheimer's disease
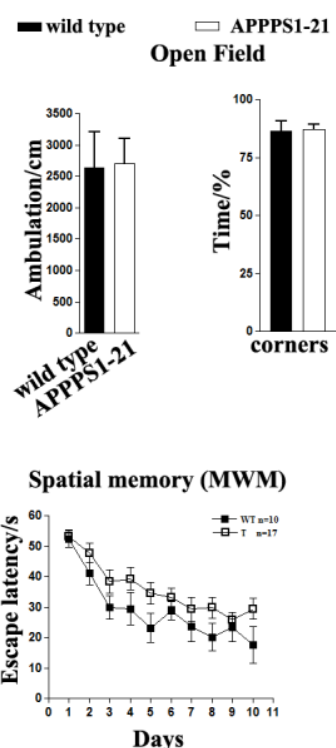

F Swimming speed

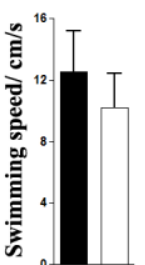

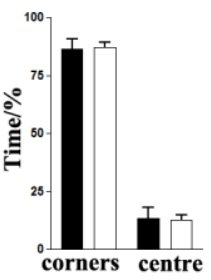

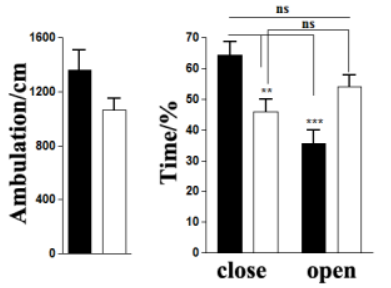

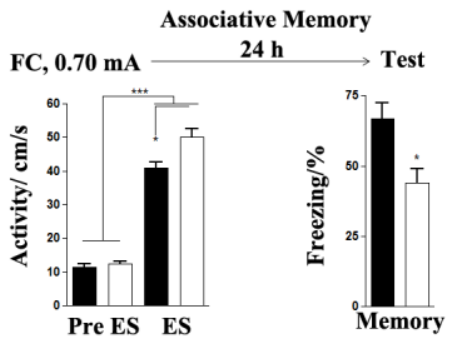

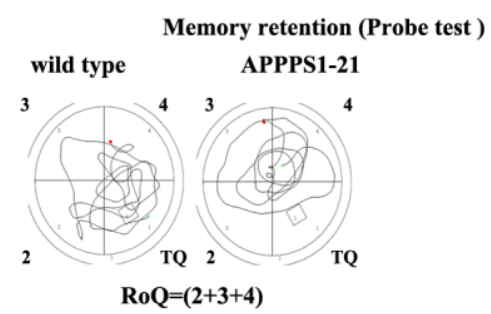

$\mathbf{H}$

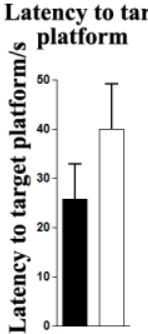

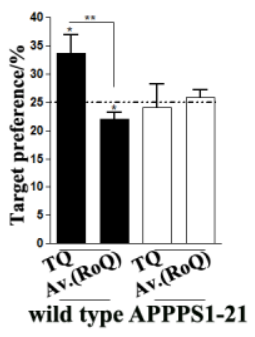

Distance in TQ

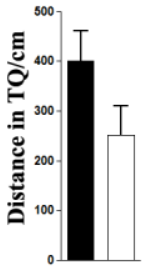

Fig.3.1.4: Behavioural characterization revealed earliest deficit in 8 month old APPPS1-21 mice. A: Open field showed similar motor activity in WT and APPPS1-21 mice. B: Elevated plus maze showed difference between WT and APPPS1-21. Right panel shows activity in the maze which was not different between the groups. Left panel shows reduced anxiety in APPPS1-21 mice relative to controls. C: Fear conditioning revealed impaired learning in APPPS1-21 compared to WT mice. Right panel shows activity of mice prior and during the ES. Left panel shows memory test assessed $24 \mathrm{~h}$ post ES. D: Learning curve showed non-significant difference in the memory acquisition between WT and APPPS1-21 mice. E: Left panel: Representative swim trace during the probe test: Right panel: Analysis of probe test (memory retention) was observed to be significantly impaired in APPPS1-21 mice compared to controls. F: Swimming speed showed no difference between the two groups of mice. G: Latency to TQ was not different between the groups however there is a trend toward protracted time by the APPPS1-21 mice to get to the TQ. H: A non-significant trend towards increased latency to the target platform by the APPPS1-21 mice was observed although. I: A non-significant distance covered in the TQ was observed between the WT compared to the APPPS1-21 mice $\left({ }^{*} \mathrm{p}<0.05\right.$, $* * \mathrm{p}<0.01$ and $\left.{ }^{* * *} \mathrm{p}<0.001\right)$.

\subsubsection{IGFBP7 levels in APPPS1-21 mice}

Firstly, longitudinal characterization of 4-6 month-old mice was done to determine change in methylation. MeDIP was performed and assessment of methylated cytosine enrichment within the promoter of Igfbp7 revealed a significant reduction in 6 month old APPPS1-21 mice compared to 4 month APPPS1-21 mice (Fig 3.1.5A, p=0.0375) indicating deregulation 
of DNA-methylation starting in 6 month APPPS1-21 mice. Then the mRNA levels of IGFBP1-7 in 6-month old APPPS1-21 and control mice were measured. While the levels of IGFBP1-6 were similar amongst groups, a mild yet significant increase in IGFBP7 mRNA was detected in the hippocampus of APPPS1-21 mice (Fig. 3.1.5B). Next IGFBP7 protein levels were analysed. In line with this datum, a robust increase in IGFBP7 protein in APPPS1-21 mice was detected (Fig.3.1.5C). Having established that IGFBP7 levels increase in APPPS1-21 mice, enrichment of DNMTs at the IGFBP7 promoter was determined. ChIP analysis revealed a significant decrease of DNMT3a at the IGFBP7 promoter (Fig. 3.1.5D, $* \mathrm{p}<0.05$, one-way ANOVA) and a trend was observed for DNMT1 (Fig. 3.1.5E). Assessment of enrichment of DNMT3a and DNMT1 showed no difference on the promoter of both $I G F B P 2$ and IGFBP4 (Fig. 3.1.5D and E).

A
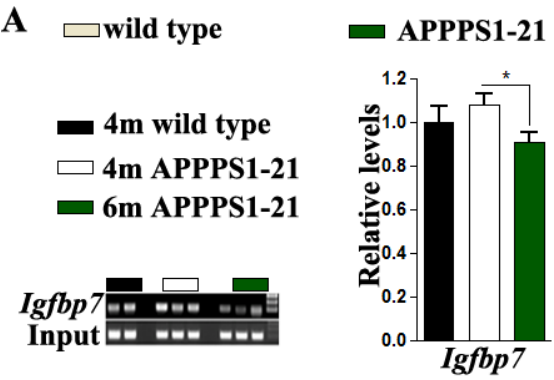

B

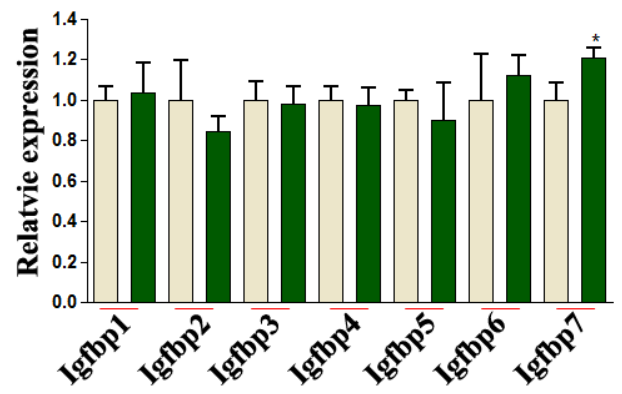

C
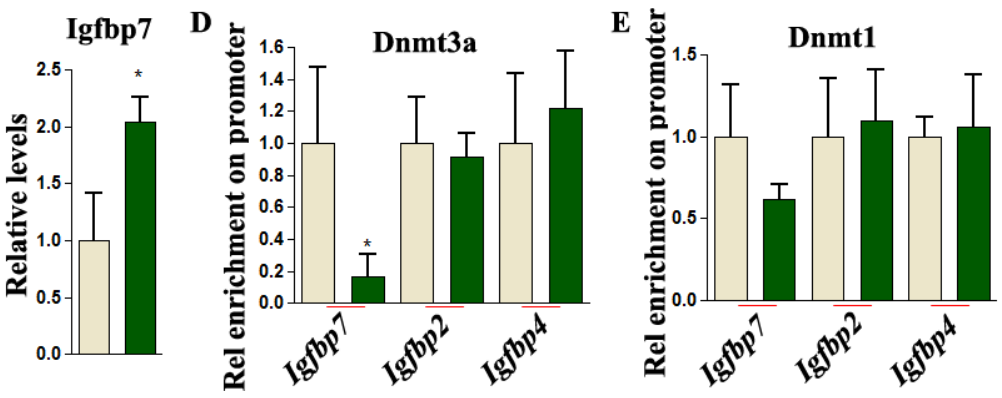

Fig.3.1.5: Deregulation of methylation in 6-month old APPPS1-21 mice. MeDIP revealed a significant change between 4- and 6-month old APPPS1-21 mice. Left and right panels show gel image and quantification of methylated cytosine enrichment on the promoter of $\operatorname{Igfbp} 7$ respectively. B: Evaluation of mRNA of Igfbps revealed an increase in the Igfbp7 in APPPS1-21 compared to wild type at 6 month of age. C: Immunoblot of Igfbp7. Left panel: showing representative image of Igfbp7 in control and APPPS1-21 mice. Right panel: showing quantification of the levels of Igfbp7 and normalized to $\beta$-Actin. D: Significant reduction of DNMT3a using ChIP on the promoter of Igfbp7 (one way ANOVA, Kruskal Wallis test $* \mathrm{p}<0.05$ ) in APPPS1-21 mice relative to controls with no difference on Igfbp2 and Igfbp4. E: Decreased level of DNMT1 enrichment on the promoter of Igfbp7 with no difference on Igfbp2 and Igfbp4 in 6 month old APPPS1-21 mice was observed. $(\mathrm{n}=3)$. Error bars indicate s.e.m. $(* \mathrm{p}<0.05)$. 
Results Assessment of Epigenetic profile in Alzheimer's disease

In fact, impairment in associative memory and spatial memory was observed in 6-month old in APPPS1-21 mice relative to controls (See appendix, Fig. 4).

\subsubsection{Recombinant IGFBP7 impairs memory formation in-vivo}

So far our data suggest that IGFBP7 levels increase early in AD patients and in AD mouse models. However, a role for IGFBP7 in memory function has not been tested so far. To analyse if IGFBP7 plays a role in memory formation mice were implanted with microcannulae into the dorsal hippocampus and injected one hour prior to fear conditioning training with recombinant IGFBP7 ( $1 \mu 1$ of $0.25 \mu \mathrm{g} / \mu 1$ per hemisphere). Associative memory was analysed $1 \mathrm{~h}$ later. When compared to the vehicle group, IGFBP7 treated mice showed a severely reduced freezing behaviour ( $\mathrm{p}=0.0026$, Fig. 3.1.6B) indicating impaired associative memory formation. When tissue from CA1 region of the hippocampus was analysed, it was observed that IGFBP7-treated mice showed reduced p-Akt levels (Fig.3.1.6C, p=0.0157) confirming that IGFBP7 administration had a direct impact on hippocampal signalling. To further test the effect of IGFBP7 on spatial memory, mice were implanted with microcannulae and then subjected to open field exploratory test to assess their motor function. No difference was observed in time spent in corners vs. centre of the open field arena (Fig. 3.1.6D). The mice were then divided into two groups and subjected to spatial memory test. The mice were administered with mouse-IgG (Santa cruz, CA) and IGFBP7 directly after the last training section. When compared to the vehicle group, IGFBP7 treated mice showed an increased latency to find the hidden platform (Fig. 3.1.6E, two way ANOVA showed treatment effect on memory acquisition) indicating impaired spatial memory formation. Analysis of probe test showed that both groups learnt beyond chance levels but IgG-treated mice spent significantly more time in TQ compared to IGFBP7-treated mice (Fig. 3.1.6F, $\mathrm{p}=0.0001$ ). Comparison of time spent in TQ by IgG- to IGFBP7-treated mice also showed significant difference between the groups (Fig. 3.1.6F, $\mathrm{p}=0.0347$ ). 
A

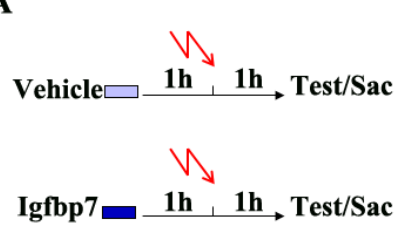

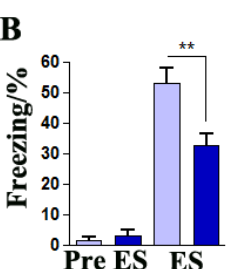

$\mathbf{E}$

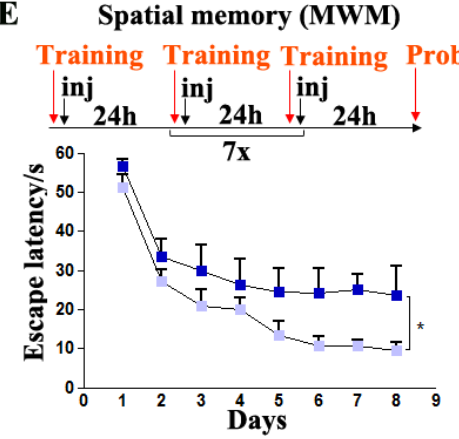

C
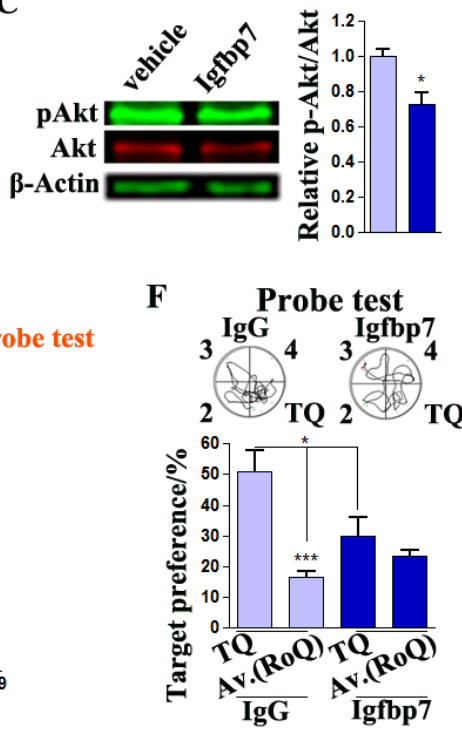

Fig.3.1.6: Over-expression of recombinant IGFBP7 impairs associative memory. A: Scheme of injection and behavioural experiments B: Intra-hippocampal injection of recombinant IGFBP7 impairs fear memory. C: Administration of IGFBP7 an hour before fear conditioning led to reduced levels of p-Akt assessed an hour after FC compared to vehicle group. Left panel shows representative images of immunoblot and right panel shows relative levels of p-Akt to Akt. Data was normalized to $\beta$-Actin. (Vehicle, $n=5$ and Igfbp7, $n=6$ ). D: Open field evaluation of motor function of mice implanted with microcannulae for intra-hippocampal injections. E: Upper panel shows experimental paradigm for intra-hippocampal administration of IGFBP7 and IgG during the training session of the Morris water maze test. Injection was repeated throughout all 8 training sessions. Lower panel shows spatial learning curve. F: Probe test shows the target preference during the test performed $24 \mathrm{~h}$ after the last training session. Note that IGFBP7-treated mice showed impaired target preference indicative of impaired spatial consolidation $(\mathrm{n}=10,9)$. Upper and lower panels show analysis and representative traces respectively. Error bars indicate s.e.m. $\left({ }^{*} \mathrm{p}<0.05, * * \mathrm{p}<0.01\right.$ and $\left.* * * \mathrm{p}<0.001\right)$.

\subsubsection{Increased levels of IGFBP7 affect cell viability}

Since IGFBP7 is a known inhibitor of cell proliferation (Lin et al., 2007; Ruan et al., 2006; Tomimaru et al., 2012; Wajapeyee et al., 2010) we wondered whether elevated IGFBP7 levels would affect cellular viability of neuronal cells. Thus we treated primary hippocampal neurons that were in culture for 21 days with IGFBP7 $(0.5 \mu \mathrm{g} / \mu \mathrm{l})$. Subsequently we performed an MTT assay (Cayman, Ann Arbor MI Catalog No. 10009365). The optical density was then measured to assess the number of viable cells. From the absorbance measurement at $570 \mathrm{~nm}$, it was observed that viability was reduced in a dose dependent manner suggesting that elevated IGFBP7 levels exhibits detrimental effect on neuronal cells. 
Results Assessment of Epigenetic profile in Alzheimer's disease

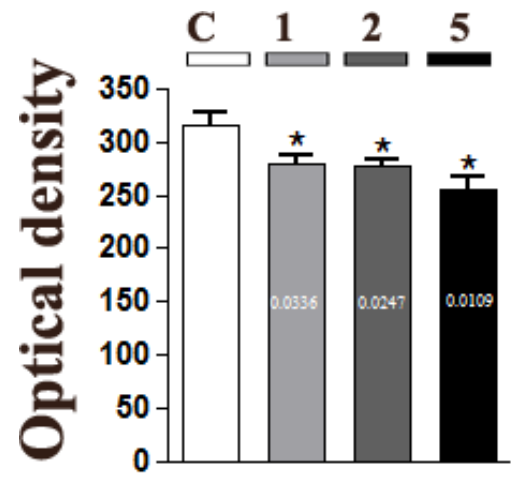

Fig. 3.1.7: Reduction of cell survival upon exposure to recombinant IGFBP7 treatment. Primary neuronal cells aged 21d.i.v. were treated with recombinant Igfbp7 for $24 \mathrm{~h}$. Cells were then collected for viability assay $(n=5)$. Error bars indicate s.e.m. $\mathrm{c}=\mathrm{control}$ and 1,2 and 5 corresponding to volume of IGFBP7 used. $(* \mathrm{p}<0.05)$.

\subsubsection{Immunization ameliorates Cognitive deficit.}

Based on the findings described above, it was hypothesized that inhibiting IGFBP7 function could be a suitable strategy to treat memory impairment in AD. To test this possibility, microcanulae was implanted into the hippocampus of 6 month-old APPPS1-21 mice. Upon recovery, over the time course of $48 \mathrm{~h}$, mice received two injections of an antibody against IGFBP7 or vehicle (PBS) spaced at $24 \mathrm{~h}$ intervals (Fig. 3.1.8A). The mice were then subjected to contextual fear conditioning training and tested for associative memory function after $24 \mathrm{~h}$ (Fig. 3.1.8A). Wild type mice that received PBS injection were used as an additional control group. The activity during the training and the response to the foot-shock was similar in all the three groups (Fig. 3.1.8B). Interestingly, when memory test was performed 24h later it was found that APPPS1-21 mice treated with the IGFBP7ab displayed significantly increased memory function when compared to the vehicle group (Fig. 3.1.8C). In line with this data we detected impaired p-Akt levels in vehicle treated APPPS1-21 mice when compared to vehicle treated wild type mice. This effect was rescued in IGFBP7ab treated APPPS1-21 mice. In sum these data suggested that re-establishing insulin/IGFs to the wild type levels might be beneficial and help to ameliorate cognitive impairment. It however, remained to be established if it does affect other forms of memory like spatial memory. 

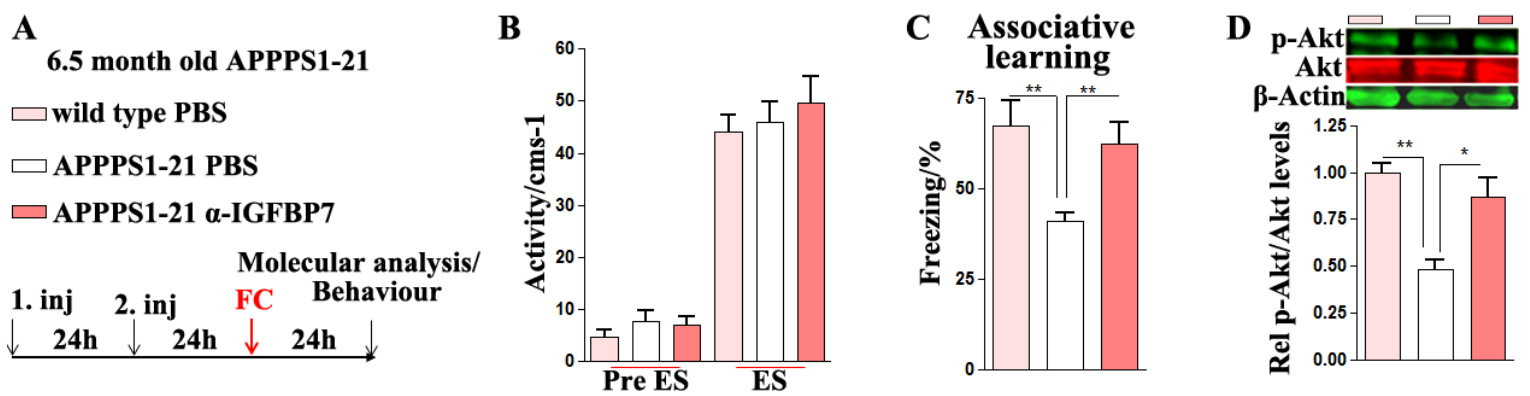

Fig.3.1.8: Intra-hippocampal immunization against IGFBP7 ameliorates associative memory. A: Scheme of antibody immunization against IGFBP7 before fear conditioning and memory test assessed $24 \mathrm{~h}$ later. B: Activity of mice pre and post shock showed no difference amongst the groups. C: Administering of antibody against Igfbp7 reinstates fear memory in APPPS1-21 mice. (Behavioural analysis WT, $n=7$, APPPS1-21 with PBS, $n=8$ and APPPS1-21 with antibody against Igfbp7, $n=9$ ). D: The level of p-Akt modification in APPPS121 mice immunized with antibody against Igfbp7 was restored, comparable to WT levels. Upper panel shows representative image of immunoblot of Akt and p-Akt and lower panel shows relative quantification of p-Akt to Akt. (For western blot $\mathrm{n}=3$ was used for all three conditions and normalized to $\beta$-Actin). Error bars indicate s.e.m. $(* \mathrm{p}<0.05$ and $* * \mathrm{p}<0.01)$. 
Results Assessment of Epigenetic profile in Alzheimer's disease

\section{Part II}

\subsection{Reduced Nuclear Sphingosine kinase 2 activity underlies altered ac-H4K12 acetylation in Alzheimer's disease.}

Previous data from our laboratory has suggested that changes in histone-acetylation, especially deregulated acetylation of H4K12, marks the onset of memory disturbances in the aging brain (Peleg et al., 2012). The aim of the following experiments was to test if deregulated histone-acetylation can also be detected in early stages of Alzheimer's disease and to elucidate the underlying mechanisms.

\subsubsection{Decreased ac-H4K12 in APPPS1-21 mice at 4-5 month old}

Our data described in section 3.1.3 have shown that cognitive deficits can first be observed in 4-5 month old APPPS1-21 mice (See Fig. 3.1.3). Thus we isolated hippocampal tissue from 4 month old APPPS1-21 mice and control littermates and performed quantitative immunoblot analysis to measure the bulk acetylation of H3K9, H3K14, H4K5, H4K8, H4K12 and H4K16. Only H4K12 acetylation was significantly reduced in 4 month-old APPPS1-21 mice when compared to wild type control ( $\mathrm{p}=0.0390$, Fig.3.2.1A and B). To further confirm that bulk changes in H4K12 acetylation translate into altered chromatin structure we analysed Prkcd gene which is deregulated in the aging brain and in AD pathogenesis (Hsiao et al., 2011; Peleg et al., 2010). First qPCR analysis revealed a significant reduction of Prkcd expression in the hippocampus of APPPS1-21 mice when compared to controls $(p=0.0002$, Fig. 3.2.1C). In line with these data, quantitative immunoblot analysis showed that the protein levels of Prkcd were significantly reduced in APPPS1-21 mice compared to WT ( $\mathrm{p}=0.0286$, Fig. 3.2.1D). Next we measured ac-H3K9 and ac-H4K12 levels along the Prkcd gene via ChIP analysis. Unlike H3K9 acetylation which showed no difference using a partial genomic walking ChIP-qPCR approach, H4K12 acetylation showed a gradual decrease along the coding region while levels at the promoter site were unaffected (Fig. 3.2.1E). This is in agreement with previous findings showing that deregulation of ac-H4K12 is linked to the coding region of genes and is implicated with disturbed transcriptional elongation (Peleg et al., 2010; Wang et al., 2008b). These data suggest that ac-H4K12 is amongst the first histonemodifications to be deregulated in the hippocampus of APPPS1-21 mice at the onset of memory dysfunction. 


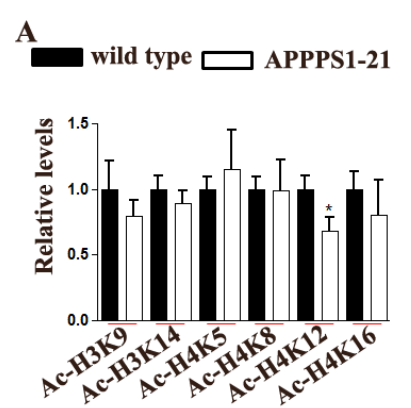

E

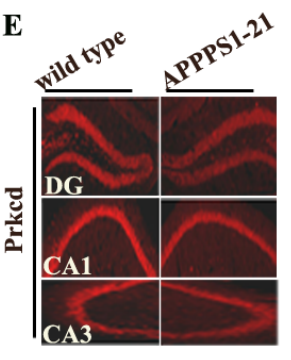

$\mathbf{B}$

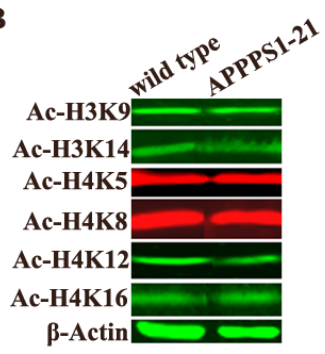

G

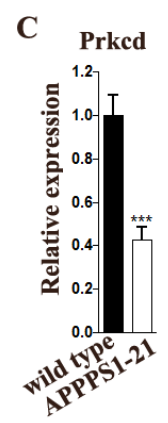

$\mathbf{H}$
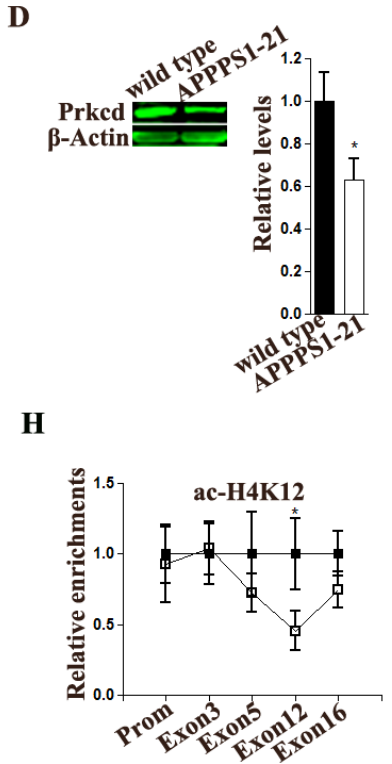

Fig.3.2.1: Reduced level of Prkcd paralleled reduced ac-H4K12 levels on bulk level. A: Quantification of acetylation on specific lysine residues on histones $\mathrm{H} 3$ and $\mathrm{H} 4$ showed reduction inac-H4K12. B: Representative images of immunoblot of acetylated lysine residues on histones H3 and H4. C: A reduced mRNA level of Prkcd was observed in APPPS1-21 mice. D: Quantitative immunoblot revealed reduction in Prkcd levels in APPPS121 mice with left and right panels showing representative image and quantification respectively. E: Immunohistochemical analysis showed reduced fluorescence intensity (F.I.) of Prkcd in APPPS1-21 compared to WT mice. F: Quantification of immunohistochemistry showing reduced levels of Prkcd in APPPS1-21 compared to WT. G: ChIP analysis of enrichment on genomic locations on Prkcd. Partial genomic walking showing no difference on the enrichment of ac-H3K9 on Prkcd and H: Partial genomic walking showing gradual decrease of ac-H4K12 along the coding regions of Prkcd with significant reduction on exon12 and no change on the proximal part of the gene. Scale bar: $500 \mu \mathrm{m}$. Error bars indicate s.e.m. $\left({ }^{*} \mathrm{p}<0.05\right.$ and $* * * p<0.001)$.

\subsubsection{Increased HDAC activity in APPPS1-21 mice}

To evaluate the mechanisms that underlie decreased H4K12 acetylation in APPPS1-21 mice, we measured the expression of HATs via qPCR analysis. None of the HATs investigated were differentially regulated in the hippocampus of APPPS1-21 when compared to the control group (Fig. 3.2.2A). Since mRNA levels not always correlate with protein production we also measured the total HAT activity. No difference in hippocampal HAT activity was found amongst groups (Fig. 3.2.2B). The deficit in H4K12 acetylation might also be attributed to increased HDAC activity. Indeed, hippocampal HDAC activity was increased in APPPS1-21 mice when compared to the control group, although it was borderline significant. (Fig. 3.2.2C, $\mathrm{p}=0.0832$ ). The HDAC activity assay does not distinguish amongst individual 
HDACs. Thus, we analysed whether distinct HDACs would be up-regulated in APPPS1-21 mice. The levels of all 11 zinc-dependent HDACs were measured via qPCR and a significant increase in HDAC2 mRNA was observed when compared to the control group. Subsequently, HDAC protein levels were analysed. No difference was observed amongst groups. The finding that despite an increase in HDAC2 mRNA levels, HDAC2 protein was not increased in APPPS1-21 mice, was further confirmed using two different HDAC2 antibodies (Fig. 3.2.2E).
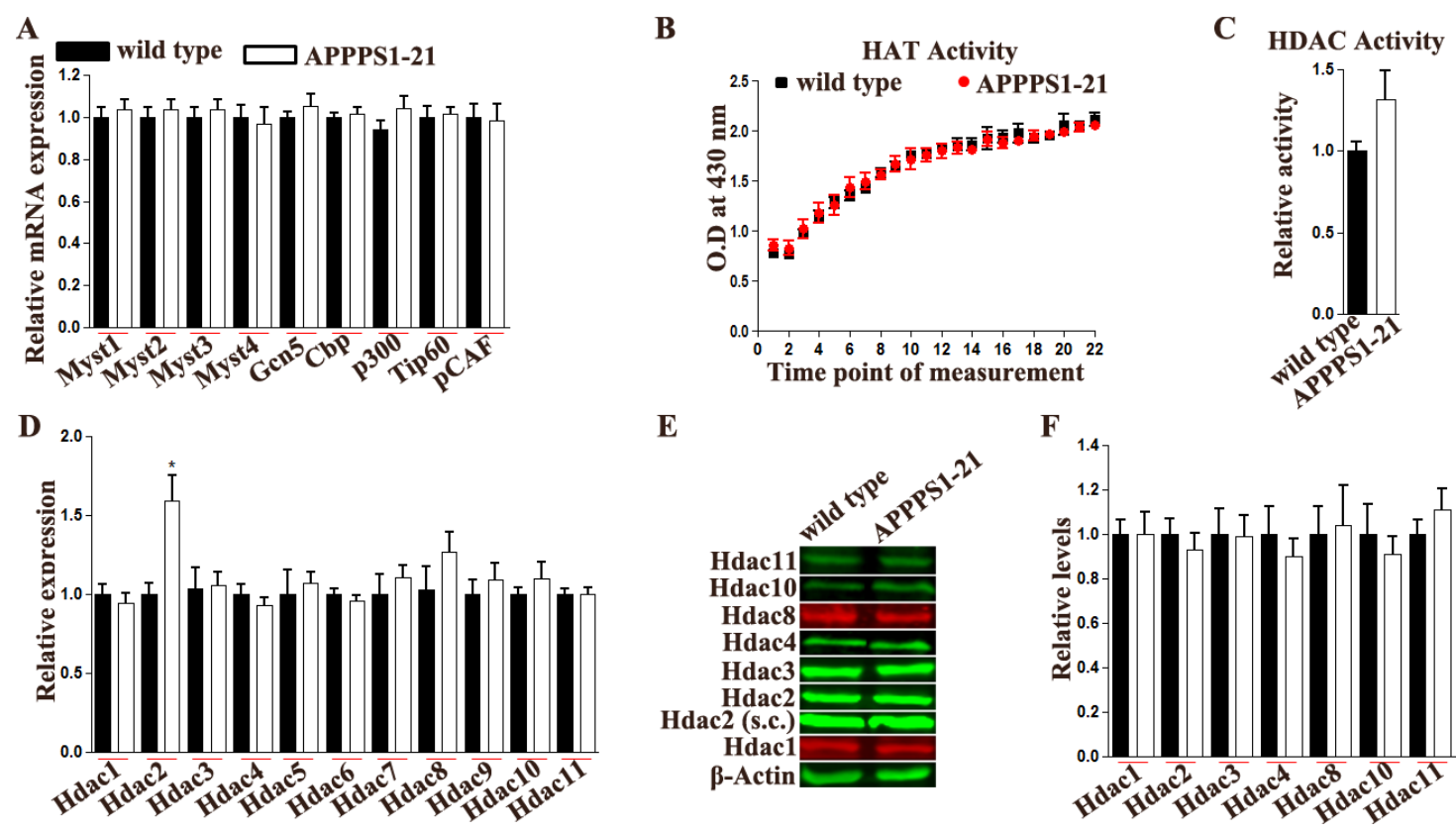

Fig.3.2.2: Molecular characterization of 4 month old APPPS1-21 mice revealed increased Hdac activity. A: mRNA of HATs evaluated showed no difference between WT and APPPS1-21 mice. B: In-vitro HAT assay performed with nuclear fraction of hippocampal lysates showed no difference also between the two groups. C: In-vitro Hdac activity measured with nuclear fraction of hippocampal lysates showed a non-significant increase in APPPS1-21 mice compared to WT. D: Analysis of mRNA of HDACs showed a significant increase in Hdac2 compared to the WT whilst the remaining other 10 HDACs did not change significantly. All expression analysis was normalized to Hprt1. E: Representative image of protein levels of HDACs evaluated with quantification showing no difference between the two groups. Data normalized to $\beta$-Actin. F: Analysis of immunoblots of Hdacs level in mice. The blots were normalized to $\beta$-Actin. Error bars indicate s.e.m. $\left({ }^{*} p<0.05\right)$.

\subsubsection{Sphingosine kinase levels mediate increased HDAC activity in APPPS1-21 mice}

The finding that HDAC activity was increased in APPPS1-21 mice despite the fact that none of the HDACs was altered on the protein level was puzzling. The finding that HDAC2 mRNA levels increase without affecting the total HDAC2 protein levels might indicate that 
HDAC2 mRNA changes present part of an early compensatory response. Since HDAC2 has been implicated with H4K12 acetylation in the context of memory formation (Guan et al., 2009; Yamaguchi et al., 2010) we speculated that other mechanisms may affect HDAC activity, especially HDAC2 in APPPS1-21 mice. A recent study reported that HDAC2 activity is inhibited by the natural occurring Sphingosine-1 phosphate (S1P) which is generated by SphK1 and 2 (Hait et al., 2009). Thus, we hypothesized that S1P function might contribute to decreased H4K12 acetylation and memory disturbances in APPPS1-21 mice. First we measured the levels of SphK1, SphK2 and the Sphingosine phosphatase Sgpp1 and Spgg1 in the hippocampus of APPPS1-21 and control mice. SphK1 and SphK2 mRNA levels were decreased in the hippocampus of APPPS1-21 mice. In addition the levels of sphingosine-1-phosphate phosphatase 2 (Sgpp2) were increase in APPPS1-21 mice. Quantitative immunoblot analysis confirmed a decrease in both SphK1 and SphK2 protein level in APPPS1-21 mice. However, only SphK2 down-regulation in APPPS1-21 mice reached significance (Fig. 3.2.3B). So far our data suggest the intriguing possibility that the increased HDAC activity observed in 4 month old APPPS1-21 mice might be due to reduced S1P signalling which acts as a natural inhibitor of HDAC function. Previous data showed that SphK2 associates with HDAC2 (Hait, et al., 2009). To further test this hypothesis that reduced SphK2 levels contribute to increased HDAC activity we measured SphK2 binding to HDAC2 via CoIP in nuclear lysates obtained from APPPS1-21 and control mice. Our data showed that the interaction of Hdac2 with SphK2 was significantly reduced in APPPS1-21 mice when compared to WT ( $\mathrm{p}=0.0417$, Fig. 3.2.3C).
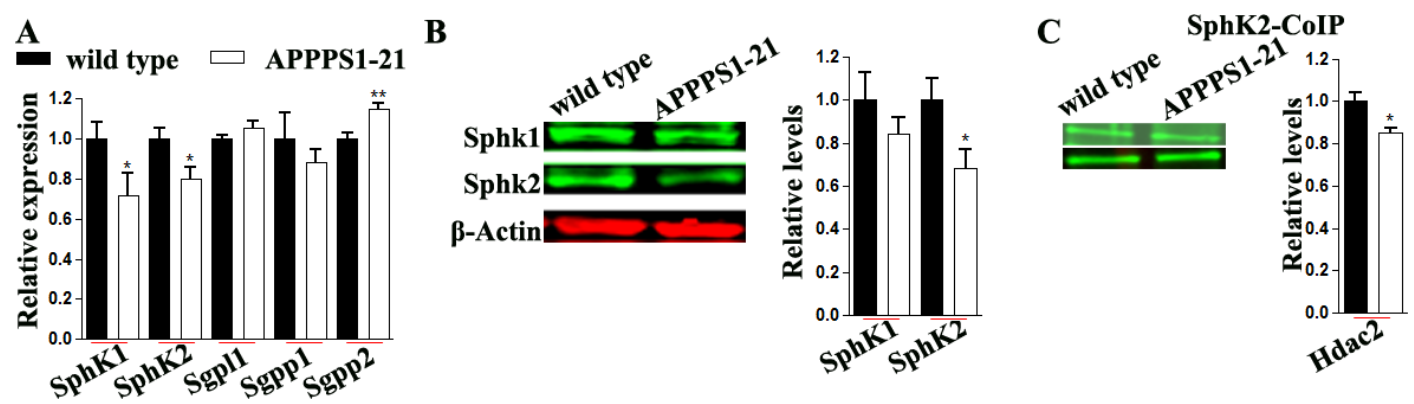

Fig.3.2.3: A reduced level of SphK2 mRNA in 4 month old APPPS1-21mice is not regulated by histone acetylation. A: qPCR showing reduced mRNA levels SphK1 and SphK2 and an increase in Sgpp2 levels. B: Protein levels showed a significant reduction in SphK2. Left panel showing representative immunoblot images of SphK1 and SphK2. Right panel: showing quantification of immunoblot. C: CoIP showing reduction in the amount of bound Hdac2 protein with SphK2. Left panel showing representative immunoblot images of Hdac2 binding to SphK2. Right panel shows quantification of immunoblot. Error bars indicate s.e.m. $\left({ }^{*} \mathrm{p}<0.05\right.$ and $* * \mathrm{p}<0.01)$. 
To investigate whether down-regulation of SphK2 itself could be due to altered histoneacetylation as part of a feed-back mechanism we used ChIP-qPCR to measure hippocampal ac-H3K9 and ac-H4K12 acetylation within the Sphk2 gene. No difference was found amongst APPPS1-21 and control mice (Fig 3.2.3i).

Sphk2

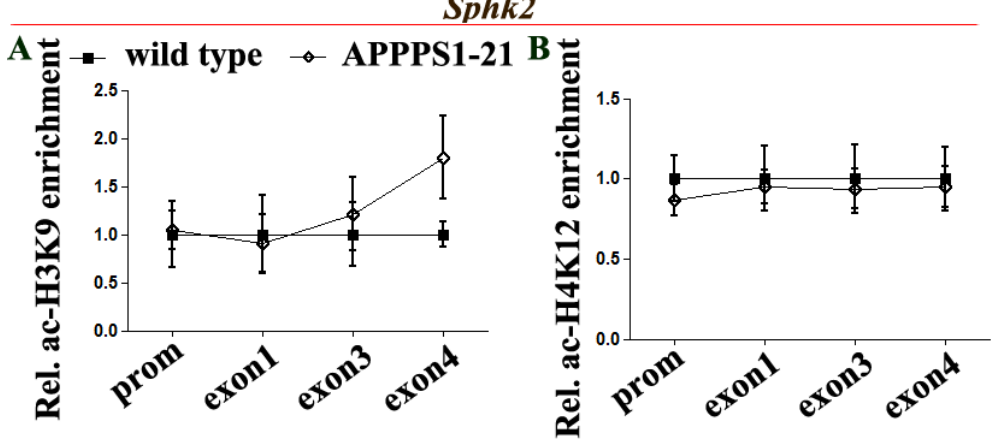

Fig. 3.2.3i: A: qPCR of ChIP DNA showed no difference between WT and APPPS1-21 mice on promoter and exons 1 and 3 but with an increase on exon4 on Sphk2 in the APPPS1-21 mice. B: Ac-H4K12 showed no difference in the enrichment on probed genomic locations on Sphk2. Error bars indicate s.e.m.

\subsubsection{Reduced Sphingonsine signalling in human AD patients}

To correlate observed difference in mice in post-mortem tissues, Braak and Braak classification done posthumously based on the advancement of the disease, was used and stages I-III stages of disease were selected on the premises of disease onset and progression being dynamic and take place over time. It is conceivable therefore that insults culminating in decreased acetylated histones with time become so pronounced at late stages of the disease or heavily compensated. To test this, we first determined bulk changes by immunoblot on acH3K9 and ac-H4K12. Quantitative analysis revealed altered ac-H3K9 and ac-H4K12, which suggested a temporal effect and progressive deterioration of acetylated histone (Fig. 3.2.4A). Then the expression of PRKCD was determined and a perfect overlap of observed effect in mice was obtained (Fig. 3.2.4B, $\mathrm{p}=0.0052$ ), a reduction in $\mathrm{AD}$ patients compared to nondemented people. The protein level of PRKCD was also found to be significantly reduced in the AD patients (Fig. 3.2.4C, p=0.0455). Furthermore ChIP of the above mentioned histone modifications revealed pronounced decrease of enrichment of these sites along the whole gene i.e. PRKCD promoter and coding regions (Fig 3.2.4D and E). 

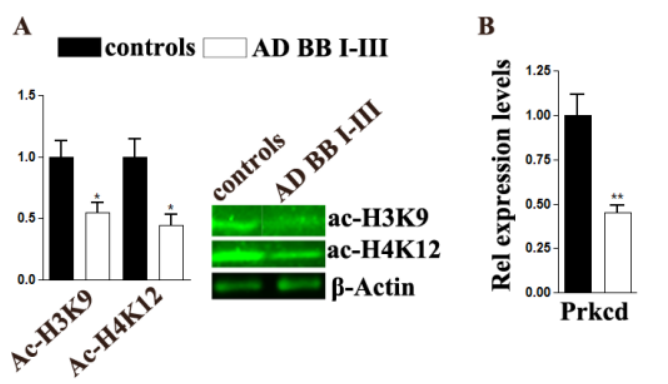

C

D
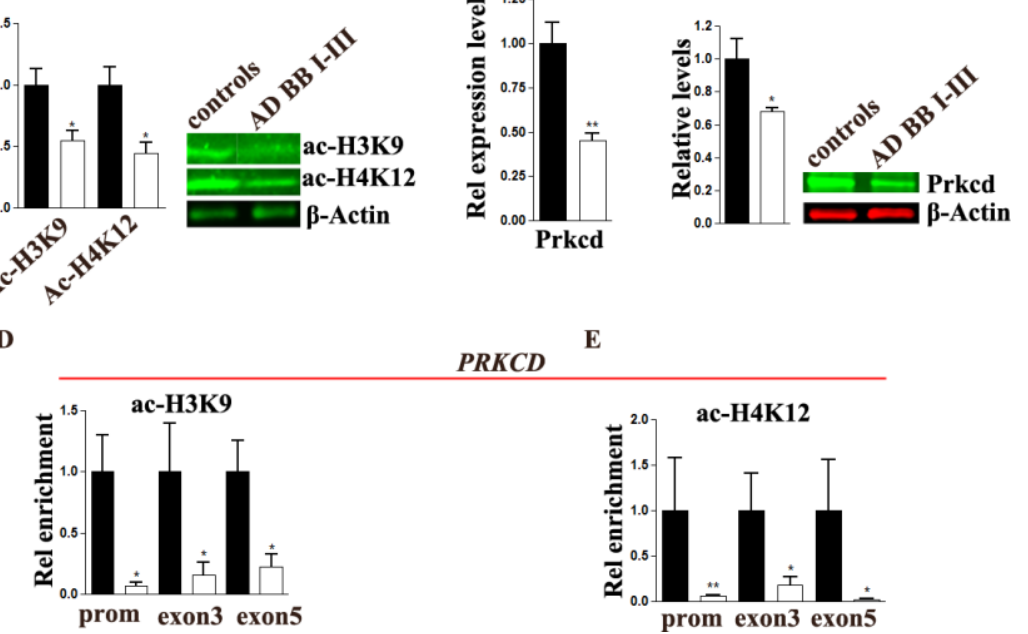

$\mathbf{E}$

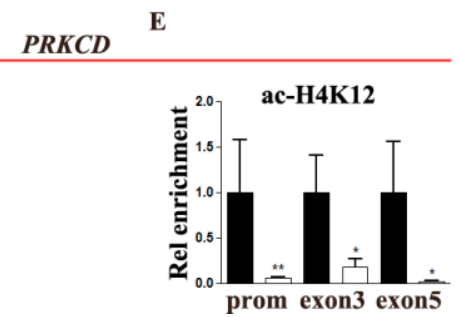

Fig. 3.2.4: Gene expression levels in $A D$ compared to controls A: Western blot with ac-H3K9 and ac-H4K12 showed significant difference between control and demented samples. Right and left panels show quantification and representative images of ac-H3K9 and ac-H4K12 respectively. B: PRKCD level is significantly reduced in AD patients. C: Immunoblot revealed reduction in the levels of Prkcd in AD patients. Right and left panels show quantification and representative images of Prkcd respectively. D: ChIP performed with ac-H3K9 on genomic locations probed and E: Analysis of ac-H4K12 ChIP also showed significant reduction of both modifications on different genomic sites. Error bars indicate s.e.m. $(* \mathrm{p}<0.05$ and $* * \mathrm{p}<0.01)$.

To elucidate further in the human samples, the levels of HDACs were analyzed by qPCR. Again it was found that all the HDACs looked at did not change significantly except for HDAC6 which might mean a compensatory response. On the other hand until now HDAC6 seems not to be located in the nucleus and therefore the observed effect could be cytoplasmic. The levels of SPHK2 and its isozymes and metabolizing proteins were then analyzed. It was found that unlike SPHK1 which showed no significant decrease in between the groups, SPHK2 mRNA was significantly reduced (Fig.3.2.5C) and the protein level was also significantly reduced (Fig.3.2.5, $\mathrm{p}=0.0233$ ). It was also observed that the levels of S1PR1, one of the $\mathrm{G}$ protein coupled receptors through which S1P act was observed to increase significantly which could be interpreted as a compensatory process. SGPL1, a lyase which irreversibly cleaves the S1P to generate phosphoethanolamine and hexadecenal was also observed to show significant reduction (Fig.3.2.5C, p=0.0270), again pointing out to a compensatory mechanism possibly as a result of a deficit in SPHK2 activity. Since BB I-III is quite an advance stage of the disease, it was decided to check if the SPHK2 was regulated by histone acetylation. qPCR on ChIP samples immunoprecipitated with ac-H3K9 showed only reduction on the promoter of $S P H K 2$ and not the other genomic locations looked at 
(Fig.3.2.5F). On the contrary, ac-H4K12 did not show difference on the promoter of SPHK2 however, a further look into the coding regions namely exons 1 and 2 showed significant reduction on the enrichment of ac-H4K12 on these positions (Fig. 3.2.5E).

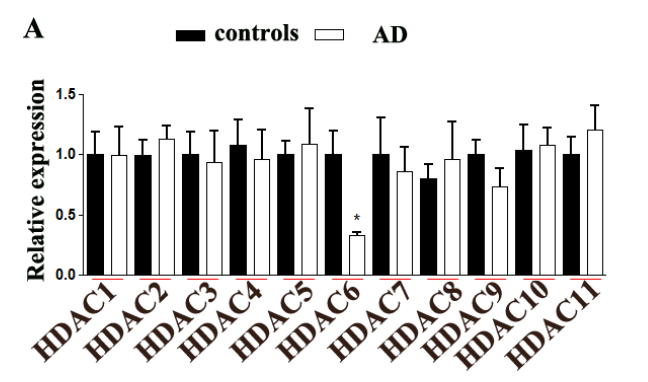

B

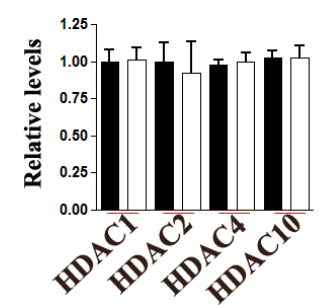

C

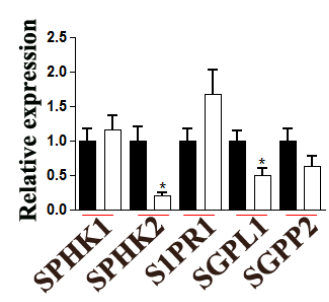

D

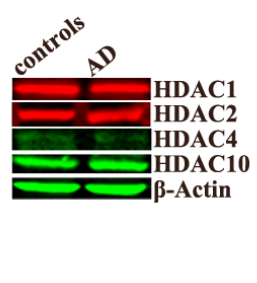

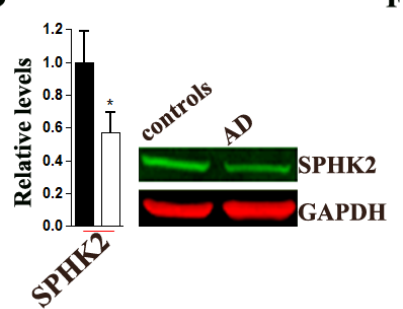

$\mathbf{E}$

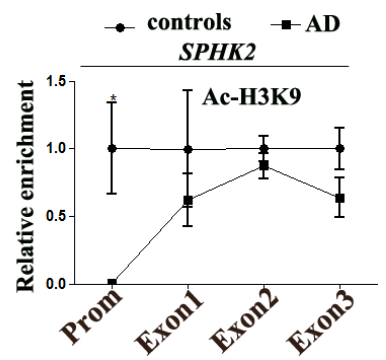

F

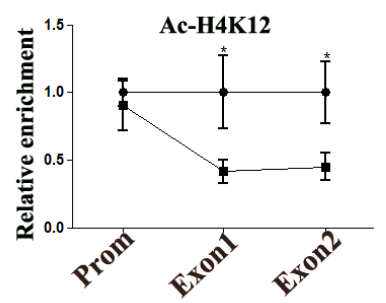

Fig.3.2.5: Expression of HDAC mRNA in controls and AD samples. A: No differential expression of HDACs except for HDAC6 mRNA was observed in AD compared to controls. B: Protein levels showed no changes in HDAC1, 2, 4 and 10 levels. Right and left panels show quantification and representative images of HDACs respectively and data normalized to $\beta$-Actin. C: Reduced levels of SPHK2 and SGPL1 levels observed in demented patient and S1PR1 was observed to increase in AD indicating a compensatory response. D: Protein levels of SPHK2 showed significant reduction. Right and left panels show quantification and representative images of SPHK2 respectively. Data was normalized to GAPDH and E: ChIP with ac-H3K9 and ac-H4K12 showed differential enrichment on probed genomic locations on SPHK2. Error bars indicate s.e.m. $(* \mathrm{p}<0.05)$.

\subsubsection{SphK2 is differentially expressed during memory consolidation}

The findings described above prompted us to speculate whether SphK2 mediated sphingosine signalling would play a role in memory formation under physiological conditions. Previous data established that fear conditioning training leads to a transient up-regulation of hippocampal histone-acetylation $1 \mathrm{~h}$ afterwards. To elucidate the involvement of SphK2 in the mechanism leading to increased histone acetylation upon fear conditioning, mRNA was extracted from hippocampal tissues from naïve and fear conditioned mice $(1 \mathrm{~h})$ after fear conditioning training. qPCR analysis showed that SphK2 but not SphK1 levels were increased in fear conditioned mice when compared to the control group (Fig. 3.2.6A, $\mathrm{p}=0.0406$ ). Elevated SphK2 mRNA levels were accompanied by significantly increased SphK2 protein levels when measured $1 \mathrm{~h}$ after the training (Fig. 3.2.6A, $\mathrm{p}=0.0074$ ). It has 
been shown that Hdac2 negatively regulates memory formation (Guan et al., 2009) and SphK2 binds both Hdac1 and Hdac2 and its activity remodels chromatin by phosphorylating sphingolipid which then binds to Hdac1 and Hdac2 and dissociates them from the chromatin (Hait et al., 2009). In light of this we performed Co-IP with SphK2 and found less interaction of Sphk2 with Hdac2. Implication of this result is dissociation of Hdac2 from the complex and corresponding increase in histone acetylation. This might however, mediate nuclear export of Hdac2. To address this question, immunoblot was performed with cytoplasmic fraction of mice subjected to fear condition and naïve ones. Quantification revealed a trend of increased Hdac2 in the cytoplasmic fraction of fear conditioned mice (Fig. 3.2.6C). On the contrary, Hdac1 level was however, found to increase (Fig.3.2.6D). This indicated a possible eviction of Hdac2 from the complex upon binding with Sphingosine-1 phosphate. However, a pronounced nuclear export was not observed suggesting that there is an appreciable nuclear retention of Hdac2 but not associated with the complex hence increased histone acetylation.
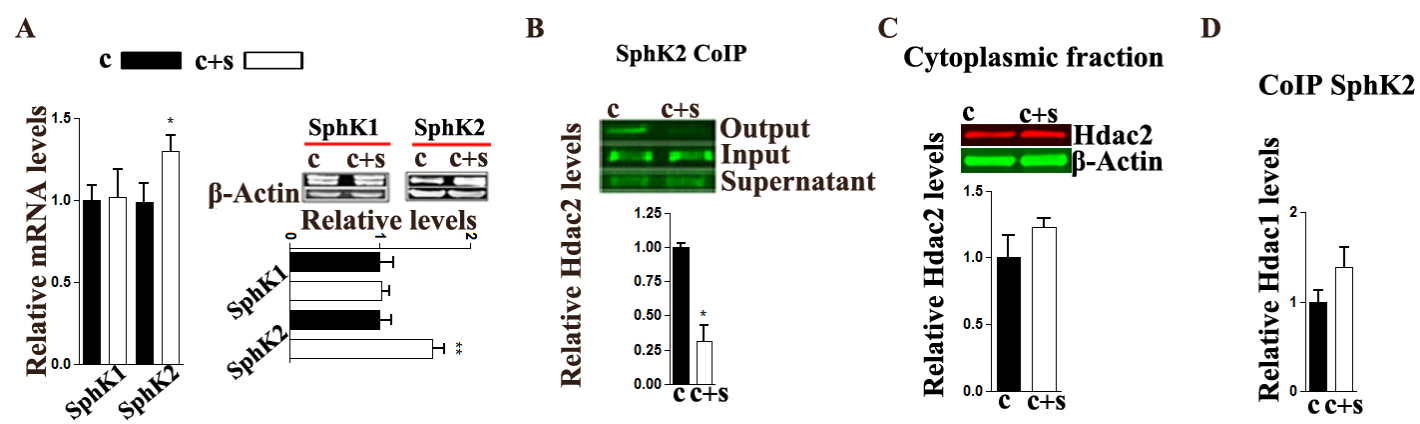

Fig.3.2.6: Fear conditioning of mice led to increased expression of SphK2 in mRNA and protein levels. A: Right panel indicates analysis of mRNA by qPCR showing increase in the levels of SphK2 upon fear conditioning but not SphK1. Left panel shows immunoblot of increased levels of SphK2 protein 1h after fear conditioning. B: CoIP of SphK2 revealed interaction of the SphK2 and Hdac2. Note reduced level of interaction of SphK2 with Hdac2 upon fear learning, an indication of nuclear exit. C: Relative cytoplasmic levels of Hdac2 1h after fear conditioning training showed only a trend which suggest possible nuclear retention but not associated with the complex. Upper and lower panels show representative immunoblot images and quantification respectively. D: CoIP of SphK2 revealed non-significant increase in the level of Hdac1 associated with SphK2 upon fear conditioning suggesting a possible complex composition change upon eviction of Hdac2. $(* \mathrm{p}<0.05$ and $* * \mathrm{p}<0.01)$. 


\section{Discussions}

\subsubsection{The role of DNA Methylation in Alzheimer's disease}

Due to the involvement of methylation in multiple biological processes it is reasoned that the slightest perturbation could lead to a disease condition. In this part of the work we have studied the role of DNA methylation in AD pathogenesis by specifically investigating a gene known as natural inhibitor of cell proliferation and survival, IGFBP7. The expression profile of IGFBP7 was significantly increased in both AD and APPPS1-21 mice (our data), a finding supported by the work of Kutsukake showing increased levels of IGFBP7 in diabetic patients (Kutsukake et al., 2008). Published data in cancer research have shown that IGFBP7 is regulated by methylation (Lin et al., 2007; Wang et al., 2008a). Enrichment of DNMTs on the promoter of IGFBP7 in AD patients is significantly reduced compared to controls although there was only a trend towards reduction in APPPS1-21 mice compared to controls. The finding that $\mathrm{AD}$ brains have reduced methylation profile is highly important as work by Mastroeni and colleagues showed compromised DNA methylation profile in identical twins who are nearly $100 \%$ genetically identical mediates the development of dementia/AD (Mastroeni et al., 2010). Furthermore, an inverse correlation of age and DNA methylation has been observed (Bishop et al., 2010; Heyn et al., 2012) suggesting that altered DNA methylation might underlie age-related cognitive decline. This was further substantiated by work of others highlighting the importance of DNA methylation in not only repressing genes that negatively impact on cognition (our study), but also specific non-promoter enrichment involving transcription of gene essential for learning and neurogenesis (Oliveira et al., 2012; $\mathrm{Wu}$ et al., 2010). In fact, methylation is highly important by virtue of its involvement in a number of cognitive-related diseases like Rett syndrome and ICF (Amir et al., 1999; Hansen et al., 1999). In addition, we also observed up-regulation of Dnmt3a and Dnmt3b upon associative learning (Appendix Fig.1) thus confirming the observation of Miller and colleagues. Nucleoside based inhibitor were used in their study to demonstrate impairment of memory upon inhibition of methylation (Miller et al., 2010; Miller and Sweatt, 2007) indicating that indeed DNA methylation is essential not only for organogenesis and their maintenance but rather it is also important for memory formation as well. Thus our study specifically linked differential enrichment of DNMTs on the promoter of IGFBP7 leading to altered levels in AD. 
Discussions Assessment of Epigenetic profile in Alzheimer's disease

\subsubsection{Regulation of DNMTs in APPPS1-21 mice}

Profiling of the enrichment of methylation on the promoter of Igfbp7 using ChiP-qPCR showed decreased enrichment of both DNMT1 and DNMT3a indicating that deregulation of Igfbp7 in APPPS1-21 and AD is mediated through altered promoter methylation levels. The deregulation in APPPS1-21 mice was observed not to be due to transcription as the mRNA of the Dnmts was not significantly different at this age. Some known miRNAs involved in posttranscriptional regulation of Dnmt1 and 3a were then assessed. We observed a differential expression of the miR-29 family (Appendix Fig.2). While miR-29a was unexpectedly decreased significantly in APPPS1-21 mice, miR-29b was significant increased in APPPS121 mice. Previous findings showed down-regulation of miR-29 as underlying cause of increased BACE levels in AD (Boissonneault et al., 2009; Hebert et al., 2008). In addition, miR-29b has also been linked with regulation of DNMTs (Fabbri et al., 2007; Meunier et al., 2012). Our data therefore suggest that miR-29a might be more involved in regulating BACE levels whilst miR-29b regulates the level of DNMTs. The observed result also showed that the regulation of Dnmts was through inhibition of translation rather than degradation of mRNA (Filipowicz et al., 2008) since the mRNA of the DNMTs were not different in APPPS1-21 mice compared to controls. Differential expression of miRNAs in AD or APPPS1-21 mice is further supported by recently published work which showed deregulation of the miRNAoame upon exposure to $A \beta$-peptides (Schonrock et al., 2010) suggesting that amyloid might exert its effect by destabilizing the miRNAoame of an organism.

\subsubsection{Altered insulin signalling exacerbates AD like pathology}

In this study, we employed a biased approach based on previous work published from our group showing regulation of IGFBP7 is necessary for fear extinction (Agis-Balboa et al., 2011) and further asked if IGFBP7 affects insulin/IGF function in AD due to similarity between signalling cascades affected in diabetic patients and AD. To test the role of IGFBP7 in learning we mimicked increased levels of IGFBP7 in AD by administering IGFBP7 intrahippocampally to wild type mice. Upon testing on associative memory task and spatial memory tasks, IGFBP7 treated mice showed impaired memory formation relative to vehicle (PBS/IgG) treated group, an indication of increased IGFBP7 negatively impacts on memory formation. This finding further highlights the essential role of insulin/IGFs signalling in memory formation. Published work showed AD-like pathologies ( $\beta$-amyloidosis and tauopathy) and negative effects on memory are exacerbated with selective depletion of 
Discussions Assessment of Epigenetic profile in Alzheimer's disease

insulin producing pancreatic $\beta$-cells using streptozotocin (STZ) in the 5XFAD and the pR5 mice that express P301L mutant human tau mouse model (Devi et al., 2012; Ke et al., 2009) which suggested that altered insulin function can affect both amyloidosis and tauopathy. Hence decreasing insulin/IGFs levels can lead to SAD. Therefore IGFBP7 negatively impact on cognitive functions.

\subsubsection{IGFBP7 impairs memory formation in by dampening activation of Akt}

Insulin/IGFs signalling are evolutionary conserved pathway and act through a number of downstream cascades and notable amongst them is the Akt/PI3K pathway known to be antiapoptotic and critical for the survival of cells and signalling in the brain (Brazil et al., 2004; Cheng et al., 2010; Kim and Feldman, 2012; Sesti, 2006). In the study, activated Akt was decreased in both AD patients and APPPS1-21 mice relative to controls. Administration of IGFBP7 to wild type mice also dampened level of p-Akt. Both impaired spontaneous alternation behaviour upon administration of $A \beta-1-42$ and reduced adult "neurogenesis" were linked with reduced activation of Akt (Gang et al., 2011; Knobloch and Mansuy, 2008; Li et al., 2008; Pearson-Leary and McNay, 2012; Wang et al., 2004). Besides, Akt could also forestall other effects like apoptosis and tau hyperphosphorylation by inhibition of BAD, a Bcl family member involved in apoptosis, GSK3 $\alpha / \beta$ (Datta et al., 1997; Phiel et al., 2003; Zhao et al., 2006). The evidence presented further suggests that activation of Akt is neuroprotective and inhibition of IGFBP7 to avail insulin/IGFs could have a therapeutic effect on AD. Recently, the involvement of IGF-II was documented in both fear learning and extinction (Agis-Balboa et al., 2011; Chen et al., 2011) further strengthening the involvement of insulin/IGFs signalling in cognition and AD.

\subsubsection{Targeting of IGFBP7 to restore insulin signalling}

Intra-hippocampal inhibition of IGFBP7 ameliorates contextual fear learning in APPPS1-21 mice. Control and anti-IGFBP7 treated APPPS1-21 (six month-old) mice showed enhance associative memory compared to vehicle treated APPPS1-21 mice. No statistical difference was observed between control and anti-IGFBP7-treated mice. This finding is highly interesting suggesting that targeting IGFBP7 could serve as a therapeutic treatment for AD. The finding is in agreement with data obtained by inducing experimentally diabetes using STZ which exacerbates AD-like pathology (Devi et al., 2012; Ke et al., 2009) and cause 
Discussions Assessment of Epigenetic profile in Alzheimer's disease

impairment in spatial memory (Shingo et al., 2012) suggesting the involvement of insulin signalling in AD. Furthermore, intranasal spray of insulin enhances verbal memory and working memories in both animals and human (Benedict et al., 2011; Craft et al., 2012; Dominguez et al., 2012). Rodriguez-Rivera and colleagues also reported that insulin sensitizing drug like rosiglitazone improved fear memory in Tg2576 mouse model (Rodriguez-Rivera et al., 2011) supporting our data that targeting IGFBP7 to increase availability of insulin/IGFs to their receptors could have a beneficial effect on cognitive functions. Besides these observations, insulin receptor $\beta$-Subunit haplo-insufficiency impairs both hippocampal LTP and recognition memory in mice (Nistico et al., 2012). Synaptogenesis and neurogenesis are other possible means by which inhibition of IGFBP7 could also facilitate memory formation by affecting in APPPS1-21 in an Akt dependent manner however, the brevity of the protocol favoured direct effect. Nevertheless availability of insulin/IGFs might help in deciding the fate of developing new-born neurons. A possible impact of Insulin/IGFs in the brain on transcription and translation (Shi et al., 2003) might also have been overlooked. In a nutshell altered insulin/IGFs function in the brain does negatively affect neuronal integrity and cognitive function and enhancing insulin/IGFs function might intervene therapeutically.

\subsubsection{Conclusions and summary}

In this study, we found altered IGFBP7 expression in post-mortem AD patient and APPPS121 mice. This finding correlated with altered DNMTs expression and reduced DNAmethylation profile of the IGFBP7 promoter in APPPS1-21 mice and AD brain. As a consequence, altered activation of Akt was observed in $\mathrm{AD}$ when compared to control situations. Mimicking increased levels of IGFBP7 in wild type mice showed a similar effect on Akt activation and impaired memory function in wild type mice. To evaluate the therapeutic potential of IGFBP7 inhibition, an antibody approach was used. APPPS1-21 mice treated with anti-IGFBP7 showed improved associative memory formation compared to vehicle treated APPPS1-21 mice. No significant difference was observed between control and anti-IGFBP7 treated mice. These data are highly interesting and suggest that targeting IGFBP7 could have a therapeutic effect on AD. 
Discussions Assessment of Epigenetic profile in Alzheimer's disease

\section{Chapter II}

\subsection{Role of Sphingosine kinase 2 in AD}

An in depth analysis involving a longitudinal study of APPPS1-21 mouse model revealed several changes at different time points indicating that there is indeed deterioration with time and therefore the need for early therapeutic intervention. To follow up on the early cognitive deficit observed at 4 months of age led us to identify increased HDAC activity due to low levels of SphK2 expression.

\subsubsection{Impaired spatial memory in 4-5 months old APPPS1-21 mice}

Impaired spatial navigation of the early deficits observed in AD (Iachini et al., 2009; Laczo et al., 2010) and can be tested in rodents using the Morris water maze test. Our data showed that 4-5 months old APPPS1-21 mice showed first impairments in this test. Specifically, retrieval of consolidated long term memories was impaired at this time point. Impairment in spatial memory became more pronounced in 8-9 months old APPPS1-21 indication progression of the disease. This indicates that deterioration of spatial memory occurs early in APPPS1-21 mice and deteriorates temporally. It also shows the facial validity of the disease since spatial memory is one of the earliest forms of memory impaired in AD patients usually preceding other forms of memory impairments such as associative learning (Hamann et al., 2002; Laczo et al., 2010). In line with this, associative learning was intact in 4-5 month old APPPS1-21 mice and only impaired in 8-9 month old mice. Another behavioural trait observed to be significantly different between controls and 4-5 months old APPPS1-21 mice is anxiety. This was not pursued further as it is largely a complex trait involving different cortical regions like hippocampus, amygdala, medial prefrontal cortex (Bannerman et al., 2004; Bertoglio et al., 2006; LeDoux, 2000; Muller et al., 1997; Petrovich et al., 2001) and eventually converging on the hypothalamus (LeDoux, 2000; Maren and Fanselow, 1995). The findings of this work therefore showed impaired spatial memory in APPPS1-21 mice.

\subsubsection{Four month old APPPS1-21 mice showed reduction in ac-H4K12}

Evaluation of hippocampal histone-acetylation in 4-month old APPPS1-21 and control mice revealed decreased ac-H4K12 while other histone-modifications were unaffected at the bulk level. Post-mortem AD brains also revealed significant reduction in ac-H4K12. Altered 
chromatin modification has been implicated in AD. In fact previous work either showed global change with pan acetylated histone antibodies, 50\% response of ac-H4 in APP/PS1 mice upon associative learning (Francis et al., 2009) and reduced ac-H4 in CA3 region of the hippocampus in $\operatorname{Tg} 2576$ mice (Ricobaraza et al., 2009). Advanced age analysis of APPPS121 mice revealed global deregulation of histone modifications (Govindarajan et al., 2011). This was supported by the findings in post-mortem AD brain that also showed altered acH3K9 compared to controls. In light of this our study therefore specifically identified acH4K12 as the earliest site to be changing in APPPS1-21 mice and is associated with spatial memory decline. While I failed to detect deregulation of HDAC proteins that would correlate with altered H4K12 acetylation, deregulation of SphK2 paralleled ac-H4K12 in the APPPS121 mouse model. However, at terminal stages as observed in AD patients, a global deregulation of histone-acetylation was observed. The finding of this work is not only important for diagnosis but also suggests that there might be a specific enzyme or enzyme complex mediating the effect and its modulation would be necessary to stall the progression and ameliorate it. As a transcriptional read-out of altered ac-H4K12 in 4-months old APPPS1-21 mice, we evaluated the expression profile of Prkcd. We found a pronounced reduction in Prkcd mRNA which translated into reduced protein levels. "Partial genomic walking" revealed that this was ac-H4K12 dependent since significant difference on exon 12 was observed but not at the promoter while ac-H3K9 was not different on all probed genomic locations in APPPS1-21 mice indicating that ac-H4K12 is essential for elongation and aids the traversal of RNAPII (Peleg et al., 2010; Wang et al., 2008b). The cleavage of p35 to p25 is regulated by Prkcd (Hsiao et al., 2008; Patrick et al., 1999; Tseng et al., 2002; Zhao et al., 2009). In spite of beneficial effect of short-lived activity of p25 on memory formation, prolonged effects due to accumulation of p25 has been shown to be toxic (Fischer et al., 2005; Hsiao et al., 2008; Patrick et al., 1999; Tseng et al., 2002). Another study showed that altered ac-histones in AD and attributed the changes to Hdac2. In fact, Hdac2 activity could be inhibited by Prkcd as it also phosphorylates Sp1 which then binds to Hdac2 leading to its nuclear exit (Tsai et al., 2011) thereby suggesting Prkcd as a molecular target in addressing both increased Hdac activity as well as regulation of p25 levels. The data suggest that restoring Prkcd to controls levels might help in mitigating molecular and behavioural changes observed in APPPS1-21 mice and in AD. Frail cognitive performance in APPPS1-21 mice could also be an indication of altered Prkcd function. It is known that Prkcd levels are altered upon social isolation and this results in impaired memory abilities (Hsiao et al., 2011). In a nutshell, an altered level of Prkcd in APPPS-21 mice and AD patients is observed due to 
Discussions Assessment of Epigenetic profile in Alzheimer's disease

deregulated epigenome hence either failure to transcribe or stalling of RNAPII after initiation.

\subsubsection{Targeting Sphingosine kinase 2 to reinstate histone acetylation in AD}

My data showed that HDAC activity increased in APPPS1-21 mice when compared to controls. HAT activity remained unchanged. This finding is in line with recent data showing that HDAC inhibitors administered both acutely and chronically ameliorate cognitive decline in AD-like mouse models namely: Ckp25, APPPS1-21, APPPS1/ $\Delta 9$ and Tg-2576 (Fischer et al., 2007; Francis et al., 2009; Govindarajan et al., 2011; Kilgore et al., 2010; Ricobaraza et al., 2009) and supports the view that HDACs are causatively involved in AD pathogenesis. Despite increased HDAC activity I failed to detect significant differences in HDAC expression in APPPS1-21 and control mice using immunoblot suggesting that the increase in activity is not due to altered protein levels. There is evidence that especially H4K12 acetylation is affected by HDAC2 (Graff et al., 2012; Guan et al., 2009; Yamaguchi et al., 2010). However, the relative amount of HDAC2 did not change based on our immunoblot data using two different antibodies. These data prompted me to analyse the expression of Sphk2, which was recently described as a natural inhibitor of Hdac1/2 (Hait et al., 2009) and expression profile in the mouse brain from Allen brain atlas (http://www.brain-map.org/) revealed high levels in the hippocampus (Appendix Fig.3). Expression analysis of SphK2 in AD patients showed a significant decrease compared to controls. This finding is quite interesting as SphK2 and it product, S1P were reported to be decreased in AD (He et al., 2010). The isoenzyme SphK1 was also observed to be down-regulated in APPPS1-21. Interestingly knockdown of SphK1 has been reported to impair LTP in hippocampal slice and deficit in spatial memory (Kanno et al., 2010). In sum altered levels of SphKs were observed in our experimental conditions and likely the cause of increased HDAC activity in APPPS121 mice.

To present further evidence that increased activity of HDACs in APPPS1-21 mice is possibly due to SphK2-mediated increase in Hdac2 activity, we carried out a CoIP from nuclear lysates of APPPS1-21 mice and mice subjected FC where increased histones acetylation have been observed since SphK2 is known to interact with the chromatin (Hait et al., 2009). Interestingly, our data showed that reduced SphK2 levels in APPPS1-21 mice translate into less interaction of Hdac2 and SphK2. This would lead to reduced generation of S1P, hence 
Discussions $\quad$ Assessment of Epigenetic profile in Alzheimer's disease

increased activity of Hdac2 in APPPS1-21 mice. This is supported by our finding that subjecting mice to associative learning led to a reduced interaction between HDAC2 and SphK2 and on the contrary, increased interaction with Hdac1. A possible explanation for this observation could be that Hdac2 underwent nuclear/chromatin exit upon chromatin remodelling due to S1P meanwhile Hdac1 does not exit the nucleus. Based on these data we argue that inhibition of Hdac2 would have a therapeutic effect on $\mathrm{AD}$ due to the following reasons. First of all, Prkcd which was found in our study to be down-regulated was reported to have a potential inhibitory effect on Hdac2 inducing its nuclear exit (Tsai et al., 2011). Secondly, SphK2 also found in our study do inhibit the activity of Hdac2 by inducing its nuclear exit. Our observations are further supported by previous publications showing that manipulation of S1P by a knock-out approach of SphK1 led to impairment of spatial memory and LTP in hippocampal slices (Kanno et al., 2010). Also S1P has been shown to be deregulated in $\mathrm{AD}$ (He et al., 2010). In our study, a self perpetuating effect of SphK2 was observed increasing its mRNA and protein significantly upon fear conditioning which was unexpected if it regulates learning. These data suggest a scenario in which SphK2 can exert its effect in a more pronounced fashion thus inhibiting Hdac2 and enhancing de-condensation of chromatin and more access to RNAPII hence transcription. In addition, SphK2 is activated and act as protective manner upon ischemic damages (Pfeilschifter et al., 2011).

\subsubsection{Conclusions}

In this part of the work I identify a specific enzyme involved in reduced histone acetylation in AD. I found that ac-H4K12 is the first histone-modification to be altered in 4 month old APPPS1-21 mice and that this change is not explained by altered HDAC or HAT levels but rather correlated with altered SphK2 levels which affect HDAC2 activity. 


\section{Summary}

$\mathrm{AD}$ is caused by multivariate factors with a convergent insult to neuronal integrity leading to cognitive decline and neurodegeneration. To develop an efficient therapeutic strategy for treatment of $\mathrm{AD}$ calls for a deeper understanding of the biochemical mechanisms that leads to neuronal dysfunction and cell death. The data presented here further support the view that epigenetic factors are involved in AD pathogenesis.

In a first approach I was able to show that memory dysfunction in APPPS1-21 mice is linked to elevated DNA-methylation of IGFBP7, a critical regulator of insulin and IGF signalling. Similar data was observed in human AD patients. Moreover, mimicking elevated levels IGFBP7 in wild type mice resulted in memory impairment. In turn, targeting IGFBP7 reinstated memory function APPPS1-21 mice. Thus, my data shows that epigenetic regulation of IGFBP7 contributes to the pathogenesis of AD and that targeting IGFBP7 could be a novel therapy to treat AD. Furthermore, IGFBP7 could be a suitable biomarker to detect disease onset and progression, a possibility that has been suggested before and is currently further investigated by our laboratory.

In the second part of my thesis I show that altered hippocampal histone acetylation correlates with memory impairment in APPPS1-21 mice. Especially ac-H4K12 acetylation was amongst the earliest histone-marks that were decreased. In contrast to my initial hypothesis I found that deregulated sphingosine-signalling - that affects HDAC activity - rather than changes in HDAC protein levels itself, are likely to be responsible for this effect.

In conclusion, my data show that epigenetic mechanisms are affected in $\mathrm{AD}$ pathogenesis and that specifically epigenetic regulation of IGFBP7 and SphK2-mediated histone-modifications could lead to the development if suitable biomarker and novel therapeutic strategies. 


\section{References}

Aarsland, D., Kurz, M. W., 2010. The epidemiology of dementia associated with Parkinson disease. J Neurol Sci. 289, 18-22.

Aarsland, D., Zaccai, J., Brayne, C., 2005. A systematic review of prevalence studies of dementia in Parkinson's disease. Mov Disord. 20, 1255-63.

Affholter, J. A., Hsieh, C. L., Francke, U., Roth, R. A., 1990. Insulin-degrading enzyme: stable expression of the human complementary DNA, characterization of its protein product, and chromosomal mapping of the human and mouse genes. Mol Endocrinol. 4, 1125-35.

Agis-Balboa, R. C., Arcos-Diaz, D., Wittnam, J., Govindarajan, N., Blom, K., Burkhardt, S., Haladyniak, U., Agbemenyah, H. Y., Zovoilis, A., Salinas-Riester, G., Opitz, L., Sananbenesi, F., Fischer, A., 2011. A hippocampal insulin-growth factor 2 pathway regulates the extinction of fear memories. EMBO J. 30, 4071-83.

Aguado, F., Sanchez-Franco, F., Rodrigo, J., Cacicedo, L., Martinez-Murillo, R., 1994. Insulin-like growth factor I-immunoreactive peptide in adult human cerebellar Purkinje cells: colocalization with low-affinity nerve growth factor receptor. Neuroscience. 59, 641-50.

Amir, R. E., Van den Veyver, I. B., Wan, M., Tran, C. Q., Francke, U., Zoghbi, H. Y., 1999. Rett syndrome is caused by mutations in X-linked MECP2, encoding methyl-CpG-binding protein 2. Nat Genet. 23, 185-8.

Andrieu-Abadie, N., Levade, T., 2002. Sphingomyelin hydrolysis during apoptosis. Biochim Biophys Acta. 1585, 126-34.

Avvakumov, N., Cote, J., 2007. The MYST family of histone acetyltransferases and their intimate links to cancer. Oncogene. 26, 5395-407.

Ayer-le Lievre, C., Stahlbom, P. A., Sara, V. R., 1991. Expression of IGF-I and -II mRNA in the brain and craniofacial region of the rat fetus. Development. 111, 105-15.

Bach, M. A., Shen-Orr, Z., Lowe, W. L., Jr., Roberts, C. T., Jr., LeRoith, D., 1991. Insulin-like growth factor I mRNA levels are developmentally regulated in specific regions of the rat brain. Brain Res Mol Brain Res. 10, 43-8.

Backstrom, J. R., Lim, G. P., Cullen, M. J., Tokes, Z. A., 1996. Matrix metalloproteinase-9 (MMP-9) is synthesized in neurons of the human hippocampus and is capable of degrading the amyloidbeta peptide (1-40). J Neurosci. 16, 7910-9.

Bannerman, D. M., Rawlins, J. N., McHugh, S. B., Deacon, R. M., Yee, B. K., Bast, T., Zhang, W. N., Pothuizen, H. H., Feldon, J., 2004. Regional dissociations within the hippocampus--memory and anxiety. Neurosci Biobehav Rev. 28, 273-83.

Baura, G. D., Foster, D. M., Kaiyala, K., Porte, D., Jr., Kahn, S. E., Schwartz, M. W., 1996. Insulin transport from plasma into the central nervous system is inhibited by dexamethasone in dogs. Diabetes. 45, 86-90.

Benedict, C., Brede, S., Schioth, H. B., Lehnert, H., Schultes, B., Born, J., Hallschmid, M., 2011. Intranasal insulin enhances postprandial thermogenesis and lowers postprandial serum insulin levels in healthy men. Diabetes. 60, 114-8.

Benson, L. J., Phillips, J. A., Gu, Y., Parthun, M. R., Hoffman, C. S., Annunziato, A. T., 2007. Properties of the type B histone acetyltransferase Hat1: $\mathrm{H} 4$ tail interaction, site preference, and involvement in DNA repair. J Biol Chem. 282, 836-42.

Berchtold, N. C., Cotman, C. W., 1998. Evolution in the conceptualization of dementia and Alzheimer's disease: Greco-Roman period to the 1960s. Neurobiol Aging. 19, 173-89.

Bertoglio, L. J., Joca, S. R., Guimaraes, F. S., 2006. Further evidence that anxiety and memory are regionally dissociated within the hippocampus. Behav Brain Res. 175, 183-8.

Bertram, L., 2008. The genetics of Alzheimer's disease. Handb Clin Neurol. 89, 223-32.

Bhaskara, S., Chyla, B. J., Amann, J. M., Knutson, S. K., Cortez, D., Sun, Z. W., Hiebert, S. W., 2008. Deletion of histone deacetylase 3 reveals critical roles in $\mathrm{S}$ phase progression and DNA damage control. Mol Cell. 30, 61-72. 
Bird, A., 2002. DNA methylation patterns and epigenetic memory. Genes Dev. 16, 6-21.

Bird, A., Macleod, D., 2004. Reading the DNA methylation signal. Cold Spring Harb Symp Quant Biol. $69,113-8$

Bishop, N. A., Lu, T., Yankner, B. A., 2010. Neural mechanisms of ageing and cognitive decline. Nature. 464, 529-35.

Blanchard, R. J., Blanchard, D. C., 1969. Crouching as an index of fear. J Comp Physiol Psychol. 67, 370-5.

Boissonneault, V., Filali, M., Lessard, M., Relton, J., Wong, G., Rivest, S., 2009. Powerful beneficial effects of macrophage colony-stimulating factor on beta-amyloid deposition and cognitive impairment in Alzheimer's disease. Brain. 132, 1078-92.

Bourc'his, D., Xu, G. L., Lin, C. S., Bollman, B., Bestor, T. H., 2001. Dnmt3L and the establishment of maternal genomic imprints. Science. 294, 2536-9.

Braak, H., Braak, E., 1995. Staging of Alzheimer's disease-related neurofibrillary changes. Neurobiol Aging. 16, 271-8; discussion 278-84.

Brazil, D. P., Yang, Z. Z., Hemmings, B. A., 2004. Advances in protein kinase B signalling: AKTion on multiple fronts. Trends Biochem Sci. 29, 233-42.

Brookmeyer, R., Gray, S., Kawas, C., 1998. Projections of Alzheimer's disease in the United States and the public health impact of delaying disease onset. Am J Public Health. 88, 1337-42.

Burks, D. J., Font de Mora, J., Schubert, M., Withers, D. J., Myers, M. G., Towery, H. H., Altamuro, S. L., Flint, C. L., White, M. F., 2000. IRS-2 pathways integrate female reproduction and energy homeostasis. Nature. 407, 377-82.

Buxbaum, J. D., Thinakaran, G., Koliatsos, V., O'Callahan, J., Slunt, H. H., Price, D. L., Sisodia, S. S., 1998. Alzheimer amyloid protein precursor in the rat hippocampus: transport and processing through the perforant path. J Neurosci. 18, 9629-37.

Cannon-Carlson, S. V., Gokhale, H., Teebor, G. W., 1989. Purification and characterization of 5hydroxymethyluracil-DNA glycosylase from calf thymus. Its possible role in the maintenance of methylated cytosine residues. J Biol Chem. 264, 13306-12.

Castellucci, V. F., Blumenfeld, H., Goelet, P., Kandel, E. R., 1989. Inhibitor of protein synthesis blocks long-term behavioral sensitization in the isolated gill-withdrawal reflex of Aplysia. J Neurobiol. 20, 1-9.

Castro, B. M., Silva, L. C., Fedorov, A., de Almeida, R. F., Prieto, M., 2009. Cholesterol-rich fluid membranes solubilize ceramide domains: implications for the structure and dynamics of mammalian intracellular and plasma membranes. J Biol Chem. 284, 22978-87.

Chang, S., McKinsey, T. A., Zhang, C. L., Richardson, J. A., Hill, J. A., Olson, E. N., 2004. Histone deacetylases 5 and 9 govern responsiveness of the heart to a subset of stress signals and play redundant roles in heart development. Mol Cell Biol. 24, 8467-76.

Chao, H. T., Zoghbi, H. Y., Rosenmund, C., 2007. MeCP2 controls excitatory synaptic strength by regulating glutamatergic synapse number. Neuron. 56, 58-65.

Chawla, S., Vanhoutte, P., Arnold, F. J., Huang, C. L., Bading, H., 2003. Neuronal activity-dependent nucleocytoplasmic shuttling of HDAC4 and HDAC5. J Neurochem. 85, 151-9.

Chen, B., Cepko, C. L., 2009. HDAC4 regulates neuronal survival in normal and diseased retinas. Science. 323, 256-9.

Chen, D. Y., Stern, S. A., Garcia-Osta, A., Saunier-Rebori, B., Pollonini, G., Bambah-Mukku, D., Blitzer, R. D., Alberini, C. M., 2011. A critical role for IGF-II in memory consolidation and enhancement. Nature. 469, 491-7.

Cheng, Z., Tseng, Y., White, M. F., 2010. Insulin signaling meets mitochondria in metabolism. Trends Endocrinol Metab. 21, 589-98.

Clarke, C. J., Snook, C. F., Tani, M., Matmati, N., Marchesini, N., Hannun, Y. A., 2006. The extended family of neutral sphingomyelinases. Biochemistry. 45, 11247-56.

Corder, E. H., Woodbury, M. A., 1993. Genetic heterogeneity in Alzheimer's disease: a grade of membership analysis. Genet Epidemiol. 10, 495-9. 
Corkin, S., 2002. What's new with the amnesic patient H.M.? Nat Rev Neurosci. 3, 153-60.

Costa-Mattioli, M., Sonenberg, N., 2008. Translational control of gene expression: a molecular switch for memory storage. Prog Brain Res. 169, 81-95.

Craft, S., Baker, L. D., Montine, T. J., Minoshima, S., Watson, G. S., Claxton, A., Arbuckle, M., Callaghan, M., Tsai, E., Plymate, S. R., Green, P. S., Leverenz, J., Cross, D., Gerton, B., 2012. Intranasal insulin therapy for Alzheimer disease and amnestic mild cognitive impairment: a pilot clinical trial. Arch Neurol. 69, 29-38.

Crang, A. J., Jacobson, W., 1982. The relationship of myelin basic protein (arginine) methyltransferase to myelination in mouse spinal cord. J Neurochem. 39, 244-7.

Crusio, W. E., Schwegler, H., 2005. Learning spatial orientation tasks in the radial-maze and structural variation in the hippocampus in inbred mice. Behav Brain Funct. 1, 3.

Cupers, P., Orlans, I., Craessaerts, K., Annaert, W., De Strooper, B., 2001. The amyloid precursor protein (APP)-cytoplasmic fragment generated by gamma-secretase is rapidly degraded but distributes partially in a nuclear fraction of neurones in culture. J Neurochem. 78, 1168-78.

Datta, S. R., Dudek, H., Tao, X., Masters, S., Fu, H., Gotoh, Y., Greenberg, M. E., 1997. Akt phosphorylation of BAD couples survival signals to the cell-intrinsic death machinery. Cell. 91, 231-41.

Day, J. J., Sweatt, J. D., 2010. DNA methylation and memory formation. Nat Neurosci. 13, 1319-23.

de la Monte, S. M., 2009. Insulin resistance and Alzheimer's disease. BMB Rep. 42, 475-81.

Devi, L., Alldred, M. J., Ginsberg, S. D., Ohno, M., 2012. Mechanisms underlying insulin deficiencyinduced acceleration of beta-amyloidosis in a mouse model of Alzheimer's disease. PLoS One. 7, e32792.

Dominguez, R. O., Marschoff, E. R., Gonzalez, S. E., Repetto, M. G., Serra, J. A., 2012. Type 2 diabetes and/or its treatment leads to less cognitive impairment in Alzheimer's disease patients. Diabetes Res Clin Pract.

Eichenbaum, H., 2001. The hippocampus and declarative memory: cognitive mechanisms and neural codes. Behav Brain Res. 127, 199-207.

Ellenbogen, J. M., Payne, J. D., Stickgold, R., 2006. The role of sleep in declarative memory consolidation: passive, permissive, active or none? Curr Opin Neurobiol. 16, 716-22.

Espinosa, R., 3rd, Lemons, R. S., Perlman, R. K., Kuo, W. L., Rosner, M. R., Le Beau, M. M., 1991. Localization of the gene encoding insulin-degrading enzyme to human chromosome 10, bands q23----q25. Cytogenet Cell Genet. 57, 184-6.

Fabbri, M., Garzon, R., Cimmino, A., Liu, Z., Zanesi, N., Callegari, E., Liu, S., Alder, H., Costinean, S., Fernandez-Cymering, C., Volinia, S., Guler, G., Morrison, C. D., Chan, K. K., Marcucci, G., Calin, G. A., Huebner, K., Croce, C. M., 2007. MicroRNA-29 family reverts aberrant methylation in lung cancer by targeting DNA methyltransferases 3A and 3B. Proc Natl Acad Sci U S A. 104, 15805-10.

Farrer, M. J., Crayton, L., Davies, G. E., Oliver, C., Powell, J., Holland, A. J., Kessling, A. M., 1997. Allelic variability in D21S11, but not in APP or APOE, is associated with cognitive decline in Down syndrome. Neuroreport. 8, 1645-9.

Farris, W., Mansourian, S., Chang, Y., Lindsley, L., Eckman, E. A., Frosch, M. P., Eckman, C. B., Tanzi, R. E., Selkoe, D. J., Guenette, S., 2003. Insulin-degrading enzyme regulates the levels of insulin, amyloid beta-protein, and the beta-amyloid precursor protein intracellular domain in vivo. Proc Natl Acad Sci U S A. 100, 4162-7.

Farris, W., Mansourian, S., Leissring, M. A., Eckman, E. A., Bertram, L., Eckman, C. B., Tanzi, R. E., Selkoe, D. J., 2004. Partial loss-of-function mutations in insulin-degrading enzyme that induce diabetes also impair degradation of amyloid beta-protein. Am J Pathol. 164, 1425-34.

Feng, J., Zhou, Y., Campbell, S. L., Le, T., Li, E., Sweatt, J. D., Silva, A. J., Fan, G., 2010. Dnmt1 and Dnmt3a maintain DNA methylation and regulate synaptic function in adult forebrain neurons. Nat Neurosci. 13, 423-30. 
Ferri, C. P., Prince, M., Brayne, C., Brodaty, H., Fratiglioni, L., Ganguli, M., Hall, K., Hasegawa, K., Hendrie, H., Huang, Y., Jorm, A., Mathers, C., Menezes, P. R., Rimmer, E., Scazufca, M., 2005. Global prevalence of dementia: a Delphi consensus study. Lancet. 366, 2112-7.

Fielenbach, N., Antebi, A., 2008. C. elegans dauer formation and the molecular basis of plasticity. Genes Dev. 22, 2149-65.

Filipcik, P., Cente, M., Krajciova, G., Vanicky, I., Novak, M., 2009. Cortical and hippocampal neurons from truncated tau transgenic rat express multiple markers of neurodegeneration. Cell Mol Neurobiol. 29, 895-900.

Filipowicz, W., Bhattacharyya, S. N., Sonenberg, N., 2008. Mechanisms of post-transcriptional regulation by microRNAs: are the answers in sight? Nat Rev Genet. 9, 102-14.

Finnin, M. S., Donigian, J. R., Cohen, A., Richon, V. M., Rifkind, R. A., Marks, P. A., Breslow, R., Pavletich, N. P., 1999. Structures of a histone deacetylase homologue bound to the TSA and SAHA inhibitors. Nature. 401, 188-93.

Fischer, A., Sananbenesi, F., Mungenast, A., Tsai, L. H., 2010. Targeting the correct HDAC(s) to treat cognitive disorders. Trends Pharmacol Sci. 31, 605-17.

Fischer, A., Sananbenesi, F., Pang, P. T., Lu, B., Tsai, L. H., 2005. Opposing roles of transient and prolonged expression of p25 in synaptic plasticity and hippocampus-dependent memory. Neuron. 48, 825-38.

Fischer, A., Sananbenesi, F., Wang, X., Dobbin, M., Tsai, L. H., 2007. Recovery of learning and memory is associated with chromatin remodelling. Nature. 447, 178-82.

Foster, N. L., Wilhelmsen, K., Sima, A. A., Jones, M. Z., D'Amato, C. J., Gilman, S., 1997. Frontotemporal dementia and parkinsonism linked to chromosome 17: a consensus conference. Conference Participants. Ann Neurol. 41, 706-15.

Francis, Y. I., Fa, M., Ashraf, H., Zhang, H., Staniszewski, A., Latchman, D. S., Arancio, O., 2009. Dysregulation of histone acetylation in the APP/PS1 mouse model of Alzheimer's disease. J Alzheimers Dis. 18, 131-9.

Gang, B., Yue, C., Han, N., Xue, H., Li, B., Sun, L., Li, X., Zhao, Q., 2011. Limited hippocampal neurogenesis in SAMP8 mouse model of Alzheimer's disease. Brain Res. 1389, 183-93.

Garofalo, R. S., 2002. Genetic analysis of insulin signaling in Drosophila. Trends Endocrinol Metab. $13,156-62$.

Gavin, D. P., Sharma, R. P., Chase, K. A., Matrisciano, F., Dong, E., Guidotti, A., 2012. Growth arrest and DNA-damage-inducible, beta (GADD45b)-mediated DNA demethylation in major psychosis. Neuropsychopharmacology. 37, 531-42.

Giannakopoulos, P., Herrmann, F. R., Bussiere, T., Bouras, C., Kovari, E., Perl, D. P., Morrison, J. H., Gold, G., Hof, P. R., 2003. Tangle and neuron numbers, but not amyloid load, predict cognitive status in Alzheimer's disease. Neurology. 60, 1495-500.

Goelet, P., Castellucci, V. F., Schacher, S., Kandel, E. R., 1986. The long and the short of long-term memory--a molecular framework. Nature. 322, 419-22.

Gold, M., Hausmann, R., Maitra, U., Hurwitz, J., 1964. The Enzymatic Methylation of Rna and DNA. 8. Effects of Bacteriophage Infection on the Activity of the Methylating Enzymes. Proc Natl Acad Sci U S A. 52, 292-7.

Goldgaber, D., Lerman, M. I., McBride, O. W., Saffiotti, U., Gajdusek, D. C., 1987. Characterization and chromosomal localization of a cDNA encoding brain amyloid of Alzheimer's disease. Science. 235, 877-80.

Goll, M. G., Bestor, T. H., 2005. Eukaryotic cytosine methyltransferases. Annu Rev Biochem. 74, 481514.

Goll, M. G., Kirpekar, F., Maggert, K. A., Yoder, J. A., Hsieh, C. L., Zhang, X., Golic, K. G., Jacobsen, S. E., Bestor, T. H., 2006. Methylation of tRNAAsp by the DNA methyltransferase homolog Dnmt2. Science. 311, 395-8.

Goto, T., Monk, M., 1998. Regulation of X-chromosome inactivation in development in mice and humans. Microbiol Mol Biol Rev. 62, 362-78. 
Govindarajan, N., Agis-Balboa, R. C., Walter, J., Sananbenesi, F., Fischer, A., 2011. Sodium butyrate improves memory function in an Alzheimer's disease mouse model when administered at an advanced stage of disease progression. J Alzheimers Dis. 26, 187-97.

Graff, J., Rei, D., Guan, J. S., Wang, W. Y., Seo, J., Hennig, K. M., Nieland, T. J., Fass, D. M., Kao, P. F., Kahn, M., Su, S. C., Samiei, A., Joseph, N., Haggarty, S. J., Delalle, I., Tsai, L. H., 2012. An epigenetic blockade of cognitive functions in the neurodegenerating brain. Nature. 483, 2226.

Grosgen, S., Grimm, M. O., Friess, P., Hartmann, T., 2010. Role of amyloid beta in lipid homeostasis. Biochim Biophys Acta. 1801, 966-74.

Grundman, M., Petersen, R. C., Ferris, S. H., Thomas, R. G., Aisen, P. S., Bennett, D. A., Foster, N. L., Jack, C. R., Jr., Galasko, D. R., Doody, R., Kaye, J., Sano, M., Mohs, R., Gauthier, S., Kim, H. T., Jin, S., Schultz, A. N., Schafer, K., Mulnard, R., van Dyck, C. H., Mintzer, J., Zamrini, E. Y., Cahn-Weiner, D., Thal, L. J., 2004. Mild cognitive impairment can be distinguished from Alzheimer disease and normal aging for clinical trials. Arch Neurol. 61, 59-66.

Guan, J. S., Haggarty, S. J., Giacometti, E., Dannenberg, J. H., Joseph, N., Gao, J., Nieland, T. J., Zhou, Y., Wang, X., Mazitschek, R., Bradner, J. E., DePinho, R. A., Jaenisch, R., Tsai, L. H., 2009. HDAC2 negatively regulates memory formation and synaptic plasticity. Nature. 459, 55-60.

Haass, C., Selkoe, D. J., 2007. Soluble protein oligomers in neurodegeneration: lessons from the Alzheimer's amyloid beta-peptide. Nat Rev Mol Cell Biol. 8, 101-12.

Haberland, M., Mokalled, M. H., Montgomery, R. L., Olson, E. N., 2009a. Epigenetic control of skull morphogenesis by histone deacetylase 8. Genes Dev. 23, 1625-30.

Haberland, M., Montgomery, R. L., Olson, E. N., 2009b. The many roles of histone deacetylases in development and physiology: implications for disease and therapy. Nat Rev Genet. 10, 3242.

Haggarty, S. J., Koeller, K. M., Wong, J. C., Grozinger, C. M., Schreiber, S. L., 2003. Domain-selective small-molecule inhibitor of histone deacetylase 6 (HDAC6)-mediated tubulin deacetylation. Proc Natl Acad Sci U S A. 100, 4389-94.

Hait, N. C., Allegood, J., Maceyka, M., Strub, G. M., Harikumar, K. B., Singh, S. K., Luo, C., Marmorstein, R., Kordula, T., Milstien, S., Spiegel, S., 2009. Regulation of histone acetylation in the nucleus by sphingosine-1-phosphate. Science. 325, 1254-7.

Hamann, S., Monarch, E. S., Goldstein, F. C., 2002. Impaired fear conditioning in Alzheimer's disease. Neuropsychologia. 40, 1187-95.

Hannun, Y. A., Obeid, L. M., 2002. The Ceramide-centric universe of lipid-mediated cell regulation: stress encounters of the lipid kind. J Biol Chem. 277, 25847-50.

Hansen, R. S., Wijmenga, C., Luo, P., Stanek, A. M., Canfield, T. K., Weemaes, C. M., Gartler, S. M., 1999. The DNMT3B DNA methyltransferase gene is mutated in the ICF immunodeficiency syndrome. Proc Natl Acad Sci U S A. 96, 14412-7.

He, X., Huang, Y., Li, B., Gong, C. X., Schuchman, E. H., 2010. Deregulation of sphingolipid metabolism in Alzheimer's disease. Neurobiol Aging. 31, 398-408.

Hebert, S. S., Horre, K., Nicolai, L., Papadopoulou, A. S., Mandemakers, W., Silahtaroglu, A. N., Kauppinen, S., Delacourte, A., De Strooper, B., 2008. Loss of microRNA cluster miR-29a/b-1 in sporadic Alzheimer's disease correlates with increased BACE1/beta-secretase expression. Proc Natl Acad Sci U S A. 105, 6415-20.

Herman, J. G., Baylin, S. B., 2003. Gene silencing in cancer in association with promoter hypermethylation. N Engl J Med. 349, 2042-54.

Heyn, H., Li, N., Ferreira, H. J., Moran, S., Pisano, D. G., Gomez, A., Diez, J., Sanchez-Mut, J. V., Setien, F., Carmona, F. J., Puca, A. A., Sayols, S., Pujana, M. A., Serra-Musach, J., Iglesias-Platas, I., Formiga, F., Fernandez, A. F., Fraga, M. F., Heath, S. C., Valencia, A., Gut, I. G., Wang, J., Esteller, M., 2012. Distinct DNA methylomes of newborns and centenarians. Proc Natl Acad Sci U S A. 109, 10522-7. 
Higuchi, M., Zhang, B., Forman, M. S., Yoshiyama, Y., Trojanowski, J. Q., Lee, V. M., 2005. Axonal degeneration induced by targeted expression of mutant human tau in oligodendrocytes of transgenic mice that model glial tauopathies. J Neurosci. 25, 9434-43.

Hobbs, C. A., Sherman, S. L., Yi, P., Hopkins, S. E., Torfs, C. P., Hine, R. J., Pogribna, M., Rozen, R., James, S. J., 2000. Polymorphisms in genes involved in folate metabolism as maternal risk factors for Down syndrome. Am J Hum Genet. 67, 623-30.

Hsiao, Y. H., Chen, P. S., Chen, S. H., Gean, P. W., 2011. The involvement of Cdk5 Activator p35 in social isolation-triggered onset of early Alzheimer's disease-related cognitive deficit in the transgenic mice. Neuropsychopharmacology. 36, 1848-58.

Hsiao, Y. H., Chen, P. S., Yeh, S. H., Lin, C. H., Gean, P. W., 2008. N-acetylcysteine prevents betaamyloid toxicity by a stimulatory effect on p35/cyclin-dependent kinase 5 activity in cultured cortical neurons. J Neurosci Res. 86, 2685-95.

Hu, E., Chen, Z., Fredrickson, T., Zhu, Y., Kirkpatrick, R., Zhang, G. F., Johanson, K., Sung, C. M., Liu, R., Winkler, J., 2000. Cloning and characterization of a novel human class I histone deacetylase that functions as a transcription repressor. J Biol Chem. 275, 15254-64.

Huang, Y. L., Lin, H. S., Chen, S. U., Lee, H., 2009. Tyrosine sulphation of sphingosine 1-phosphate 1 (S1P1) is required for S1P-mediated cell migration in primary cultures of human umbilical vein endothelial cells. J Biochem. 146, 815-20.

Hubbert, C., Guardiola, A., Shao, R., Kawaguchi, Y., Ito, A., Nixon, A., Yoshida, M., Wang, X. F., Yao, T. P., 2002. HDAC6 is a microtubule-associated deacetylase. Nature. 417, 455-8.

Huertas, D., Sendra, R., Munoz, P., 2009. Chromatin dynamics coupled to DNA repair. Epigenetics. 4, 31-42.

lachini, I., lavarone, A., Senese, V. P., Ruotolo, F., Ruggiero, G., 2009. Visuospatial memory in healthy elderly, AD and $\mathrm{MCl}$ : a review. Curr Aging Sci. 2, 43-59.

Inche, A. G., La Thangue, N. B., 2006. Chromatin control and cancer-drug discovery: realizing the promise. Drug Discov Today. 11, 97-109.

Ittner, L. M., Ke, Y. D., Delerue, F., Bi, M., Gladbach, A., van Eersel, J., Wolfing, H., Chieng, B. C., Christie, M. J., Napier, I. A., Eckert, A., Staufenbiel, M., Hardeman, E., Gotz, J., 2010. Dendritic function of tau mediates amyloid-beta toxicity in Alzheimer's disease mouse models. Cell. 142, 387-97.

Iwata, N., Tsubuki, S., Takaki, Y., Shirotani, K., Lu, B., Gerard, N. P., Gerard, C., Hama, E., Lee, H. J., Saido, T. C., 2001. Metabolic regulation of brain Abeta by neprilysin. Science. 292, 1550-2.

James, S. J., Pogribna, M., Pogribny, I. P., Melnyk, S., Hine, R. J., Gibson, J. B., Yi, P., Tafoya, D. L., Swenson, D. H., Wilson, V. L., Gaylor, D. W., 1999. Abnormal folate metabolism and mutation in the methylenetetrahydrofolate reductase gene may be maternal risk factors for Down syndrome. Am J Clin Nutr. 70, 495-501.

Jankovic, J., 2008. Parkinson's disease: clinical features and diagnosis. J Neurol Neurosurg Psychiatry. 79, 368-76.

Kandel, E. R., 2001. The molecular biology of memory storage: a dialogue between genes and synapses. Science. 294, 1030-8.

Kanemitsu, N., Kato, M. V., Miki, T., Komatsu, S., Okazaki, Y., Hayashizaki, Y., Sakai, T., 2000. Characterization of the promoter of the murine mac25 gene. Biochem Biophys Res Commun. 279, 251-7.

Kanno, T., Nishizaki, T., Proia, R. L., Kajimoto, T., Jahangeer, S., Okada, T., Nakamura, S., 2010. Regulation of synaptic strength by sphingosine 1-phosphate in the hippocampus. Neuroscience. 171, 973-80.

Karow, D. S., McEvoy, L. K., Fennema-Notestine, C., Hagler, D. J., Jr., Jennings, R. G., Brewer, J. B., Hoh, C. K., Dale, A. M., 2010. Relative capability of MR imaging and FDG PET to depict changes associated with prodromal and early Alzheimer disease. Radiology. 256, 932-42. 
Ke, Y. D., Delerue, F., Gladbach, A., Gotz, J., Ittner, L. M., 2009. Experimental diabetes mellitus exacerbates tau pathology in a transgenic mouse model of Alzheimer's disease. PLoS One. 4, e7917.

Kilgore, M., Miller, C. A., Fass, D. M., Hennig, K. M., Haggarty, S. J., Sweatt, J. D., Rumbaugh, G., 2010. Inhibitors of class 1 histone deacetylases reverse contextual memory deficits in a mouse model of Alzheimer's disease. Neuropsychopharmacology. 35, 870-80.

Kim, B., Feldman, E. L., 2012. Insulin resistance in the nervous system. Trends Endocrinol Metab. 23, 133-41.

Kim, J. J., Fanselow, M. S., 1992. Modality-specific retrograde amnesia of fear. Science. 256, 675-7.

Kimberly, W. T., Zheng, J. B., Guenette, S. Y., Selkoe, D. J., 2001. The intracellular domain of the betaamyloid precursor protein is stabilized by Fe65 and translocates to the nucleus in a notchlike manner. J Biol Chem. 276, 40288-92.

Klimasauskas, S., Weinhold, E., 2007. A new tool for biotechnology: AdoMet-dependent methyltransferases. Trends Biotechnol. 25, 99-104.

Knobloch, M., Mansuy, I. M., 2008. Dendritic spine loss and synaptic alterations in Alzheimer's disease. Mol Neurobiol. 37, 73-82.

Kohama, T., Olivera, A., Edsall, L., Nagiec, M. M., Dickson, R., Spiegel, S., 1998. Molecular cloning and functional characterization of murine sphingosine kinase. J Biol Chem. 273, 23722-8.

Kopelman, M. D., Thomson, A. D., Guerrini, I., Marshall, E. J., 2009. The Korsakoff syndrome: clinical aspects, psychology and treatment. Alcohol Alcohol. 44, 148-54.

Kosik, K. S., Joachim, C. L., Selkoe, D. J., 1986. Microtubule-associated protein tau (tau) is a major antigenic component of paired helical filaments in Alzheimer disease. Proc Natl Acad Sci U S A. 83, 4044-8.

Kotian, S., Liyanarachchi, S., Zelent, A., Parvin, J. D., 2011. Histone deacetylases 9 and 10 are required for homologous recombination. J Biol Chem. 286, 7722-6.

Kotzbauer, P. T., Trojanowsk, J. Q., Lee, V. M., 2001. Lewy body pathology in Alzheimer's disease. J Mol Neurosci. 17, 225-32.

Kouzarides, T., 2007. Chromatin modifications and their function. Cell. 128, 693-705.

Kowalska, A., Takahashi, K., Kozubski, W., Tabira, T., 2002. Microtubule associated protein (tau) gene variability in patients with frontotemporal dementia. Folia Neuropathol. 40, 1-5.

Kreitzer, A. C., 2009. Physiology and pharmacology of striatal neurons. Annu Rev Neurosci. 32, 12747.

Kriaucionis, S., Heintz, N., 2009. The nuclear DNA base 5-hydroxymethylcytosine is present in Purkinje neurons and the brain. Science. 324, 929-30.

Kurdistani, S. K., Tavazoie, S., Grunstein, M., 2004. Mapping global histone acetylation patterns to gene expression. Cell. 117, 721-33.

Kutsukake, M., Ishihara, R., Momose, K., Isaka, K., Itokazu, O., Higuma, C., Matsutani, T., Matsuda, A., Sasajima, K., Hara, T., Tamura, K., 2008. Circulating IGF-binding protein 7 (IGFBP7) levels are elevated in patients with endometriosis or undergoing diabetic hemodialysis. Reprod Biol Endocrinol. 6, 54.

Laczo, J., Andel, R., Vyhnalek, M., Vlcek, K., Magerova, H., Varjassyova, A., Tolar, M., Hort, J., 2010. Human analogue of the morris water maze for testing subjects at risk of Alzheimer's disease. Neurodegener Dis. 7, 148-52.

Lagger, G., O'Carroll, D., Rembold, M., Khier, H., Tischler, J., Weitzer, G., Schuettengruber, B., Hauser, C., Brunmeir, R., Jenuwein, T., Seiser, C., 2002. Essential function of histone deacetylase 1 in proliferation control and CDK inhibitor repression. EMBO J. 21, 2672-81.

Lammich, S., Kojro, E., Postina, R., Gilbert, S., Pfeiffer, R., Jasionowski, M., Haass, C., Fahrenholz, F., 1999. Constitutive and regulated alpha-secretase cleavage of Alzheimer's amyloid precursor protein by a disintegrin metalloprotease. Proc Natl Acad Sci U S A. 96, 3922-7.

LeDoux, J. E., 2000. Emotion circuits in the brain. Annu Rev Neurosci. 23, 155-84. 
Lee, D. Y., Hayes, J. J., Pruss, D., Wolffe, A. P., 1993. A positive role for histone acetylation in transcription factor access to nucleosomal DNA. Cell. 72, 73-84.

Lee, H., Rezai-Zadeh, N., Seto, E., 2004. Negative regulation of histone deacetylase 8 activity by cyclic AMP-dependent protein kinase A. Mol Cell Biol. 24, 765-73.

Lee, M. J., Van Brocklyn, J. R., Thangada, S., Liu, C. H., Hand, A. R., Menzeleev, R., Spiegel, S., Hla, T., 1998. Sphingosine-1-phosphate as a ligand for the $G$ protein-coupled receptor EDG-1. Science. 279, 1552-5.

Letenneur, L., Gilleron, V., Commenges, D., Helmer, C., Orgogozo, J. M., Dartigues, J. F., 1999. Are sex and educational level independent predictors of dementia and Alzheimer's disease? Incidence data from the PAQUID project. J Neurol Neurosurg Psychiatry. 66, 177-83.

Levenson, J. M., Roth, T. L., Lubin, F. D., Miller, C. A., Huang, I. C., Desai, P., Malone, L. M., Sweatt, J. D., 2006. Evidence that DNA (cytosine-5) methyltransferase regulates synaptic plasticity in the hippocampus. J Biol Chem. 281, 15763-73.

Levine, B., Turner, G. R., Tisserand, D., Hevenor, S. J., Graham, S. J., McIntosh, A. R., 2004. The functional neuroanatomy of episodic and semantic autobiographical remembering: a prospective functional MRI study. J Cogn Neurosci. 16, 1633-46.

Li, B., Carey, M., Workman, J. L., 2007. The role of chromatin during transcription. Cell. 128, 707-19.

Li, B., Yamamori, H., Tatebayashi, Y., Shafit-Zagardo, B., Tanimukai, H., Chen, S., Iqbal, K., GrundkeIqbal, I., 2008. Failure of neuronal maturation in Alzheimer disease dentate gyrus. J Neuropathol Exp Neurol. 67, 78-84.

Li, E., Beard, C., Jaenisch, R., 1993. Role for DNA methylation in genomic imprinting. Nature. 366, 362-5.

Li, E., Bestor, T. H., Jaenisch, R., 1992. Targeted mutation of the DNA methyltransferase gene results in embryonic lethality. Cell. 69, 915-26.

Lin, J., Lai, M., Huang, Q., Ma, Y., Cui, J., Ruan, W., 2007. Methylation patterns of IGFBP7 in colon cancer cell lines are associated with levels of gene expression. J Pathol. 212, 83-90.

Lisman, J., Schulman, H., Cline, H., 2002. The molecular basis of CaMKII function in synaptic and behavioural memory. Nat Rev Neurosci. 3, 175-90.

Litvan, I., Agid, Y., Calne, D., Campbell, G., Dubois, B., Duvoisin, R. C., Goetz, C. G., Golbe, L. I., Grafman, J., Growdon, J. H., Hallett, M., Jankovic, J., Quinn, N. P., Tolosa, E., Zee, D. S., 1996. Clinical research criteria for the diagnosis of progressive supranuclear palsy (SteeleRichardson-Olszewski syndrome): report of the NINDS-SPSP international workshop. Neurology. 47, 1-9.

Liu, H., Sugiura, M., Nava, V. E., Edsall, L. C., Kono, K., Poulton, S., Milstien, S., Kohama, T., Spiegel, S., 2000. Molecular cloning and functional characterization of a novel mammalian sphingosine kinase type 2 isoform. J Biol Chem. 275, 19513-20.

Lopez-Bermejo, A., Khosravi, J., Fernandez-Real, J. M., Hwa, V., Pratt, K. L., Casamitjana, R., GarciaGil, M. M., Rosenfeld, R. G., Ricart, W., 2006. Insulin resistance is associated with increased serum concentration of IGF-binding protein-related protein 1 (IGFBP-rP1/MAC25). Diabetes. $55,2333-9$.

Luco, R. F., Pan, Q., Tominaga, K., Blencowe, B. J., Pereira-Smith, O. M., Misteli, T., 2010. Regulation of alternative splicing by histone modifications. Science. 327, 996-1000.

Maren, S., Fanselow, M. S., 1995. Synaptic plasticity in the basolateral amygdala induced by hippocampal formation stimulation in vivo. J Neurosci. 15, 7548-64.

Mark, R. J., Lovell, M. A., Markesbery, W. R., Uchida, K., Mattson, M. P., 1997a. A role for 4hydroxynonenal, an aldehydic product of lipid peroxidation, in disruption of ion homeostasis and neuronal death induced by amyloid beta-peptide. J Neurochem. 68, 255-64.

Mark, R. J., Pang, Z., Geddes, J. W., Uchida, K., Mattson, M. P., 1997b. Amyloid beta-peptide impairs glucose transport in hippocampal and cortical neurons: involvement of membrane lipid peroxidation. J Neurosci. 17, 1046-54. 
Mastroeni, D., Grover, A., Delvaux, E., Whiteside, C., Coleman, P. D., Rogers, J., 2010. Epigenetic changes in Alzheimer's disease: decrements in DNA methylation. Neurobiol Aging. 31, 202537.

Matrisciano, F., Dong, E., Gavin, D. P., Nicoletti, F., Guidotti, A., 2011. Activation of group II metabotropic glutamate receptors promotes DNA demethylation in the mouse brain. Mol Pharmacol. 80, 174-82.

McKeith, I., Mintzer, J., Aarsland, D., Burn, D., Chiu, H., Cohen-Mansfield, J., Dickson, D., Dubois, B., Duda, J. E., Feldman, H., Gauthier, S., Halliday, G., Lawlor, B., Lippa, C., Lopez, O. L., Carlos Machado, J., O'Brien, J., Playfer, J., Reid, W., 2004. Dementia with Lewy bodies. Lancet Neurol. 3, 19-28.

McKeith, I. G., Dickson, D. W., Lowe, J., Emre, M., O'Brien, J. T., Feldman, H., Cummings, J., Duda, J. E., Lippa, C., Perry, E. K., Aarsland, D., Arai, H., Ballard, C. G., Boeve, B., Burn, D. J., Costa, D., Del Ser, T., Dubois, B., Galasko, D., Gauthier, S., Goetz, C. G., Gomez-Tortosa, E., Halliday, G., Hansen, L. A., Hardy, J., Iwatsubo, T., Kalaria, R. N., Kaufer, D., Kenny, R. A., Korczyn, A., Kosaka, K., Lee, V. M., Lees, A., Litvan, I., Londos, E., Lopez, O. L., Minoshima, S., Mizuno, Y., Molina, J. A., Mukaetova-Ladinska, E. B., Pasquier, F., Perry, R. H., Schulz, J. B., Trojanowski, J. Q., Yamada, M., 2005. Diagnosis and management of dementia with Lewy bodies: third report of the DLB Consortium. Neurology. 65, 1863-72.

McKeith, I. G., Galasko, D., Kosaka, K., Perry, E. K., Dickson, D. W., Hansen, L. A., Salmon, D. P., Lowe, J., Mirra, S. S., Byrne, E. J., Lennox, G., Quinn, N. P., Edwardson, J. A., Ince, P. G., Bergeron, C., Burns, A., Miller, B. L., Lovestone, S., Collerton, D., Jansen, E. N., Ballard, C., de Vos, R. A., Wilcock, G. K., Jellinger, K. A., Perry, R. H., 1996. Consensus guidelines for the clinical and pathologic diagnosis of dementia with Lewy bodies (DLB): report of the consortium on DLB international workshop. Neurology. 47, 1113-24.

McMillan, P. J., Kraemer, B. C., Robinson, L., Leverenz, J. B., Raskind, M., Schellenberg, G., 2011. Truncation of tau at E391 promotes early pathologic changes in transgenic mice. J Neuropathol Exp Neurol. 70, 1006-19.

Mejat, A., Ramond, F., Bassel-Duby, R., Khochbin, S., Olson, E. N., Schaeffer, L., 2005. Histone deacetylase 9 couples neuronal activity to muscle chromatin acetylation and gene expression. Nat Neurosci. 8, 313-21.

Meunier, L., Siddeek, B., Vega, A., Lakhdari, N., Inoubli, L., Bellon, R. P., Lemaire, G., Mauduit, C., Benahmed, M., 2012. Perinatal programming of adult rat germ cell death after exposure to xenoestrogens: role of microRNA miR-29 family in the down-regulation of DNA methyltransferases and Mcl-1. Endocrinology. 153, 1936-47.

Miller, C. A., Gavin, C. F., White, J. A., Parrish, R. R., Honasoge, A., Yancey, C. R., Rivera, I. M., Rubio, M. D., Rumbaugh, G., Sweatt, J. D., 2010. Cortical DNA methylation maintains remote memory. Nat Neurosci. 13, 664-6.

Miller, C. A., Sweatt, J. D., 2007. Covalent modification of DNA regulates memory formation. Neuron. $53,857-69$.

Montgomery, R. L., Davis, C. A., Potthoff, M. J., Haberland, M., Fielitz, J., Qi, X., Hill, J. A., Richardson, J. A., Olson, E. N., 2007. Histone deacetylases 1 and 2 redundantly regulate cardiac morphogenesis, growth, and contractility. Genes Dev. 21, 1790-802.

Moretti, P., Zoghbi, H. Y., 2006. MeCP2 dysfunction in Rett syndrome and related disorders. Curr Opin Genet Dev. 16, 276-81.

Moriue, T., Igarashi, J., Yoneda, K., Nakai, K., Kosaka, H., Kubota, Y., 2008. Sphingosine 1-phosphate attenuates $\mathrm{H} 2 \mathrm{O} 2$-induced apoptosis in endothelial cells. Biochem Biophys Res Commun. 368, 852-7.

Morris, R. G. M. (1981). Spatial localization does not require the presence of local cues. Learning and Motivation,12,239-260. 
Muller, J., Corodimas, K. P., Fridel, Z., LeDoux, J. E., 1997. Functional inactivation of the lateral and basal nuclei of the amygdala by muscimol infusion prevents fear conditioning to an explicit conditioned stimulus and to contextual stimuli. Behav Neurosci. 111,683-91.

Nakae, J., Kido, Y., Accili, D., 2001. Distinct and overlapping functions of insulin and IGF-I receptors. Endocr Rev. 22, 818-35.

Narlikar, G. J., Fan, H. Y., Kingston, R. E., 2002. Cooperation between complexes that regulate chromatin structure and transcription. Cell. 108, 475-87.

Neary, D., Snowden, J. S., Gustafson, L., Passant, U., Stuss, D., Black, S., Freedman, M., Kertesz, A., Robert, P. H., Albert, M., Boone, K., Miller, B. L., Cummings, J., Benson, D. F., 1998. Frontotemporal lobar degeneration: a consensus on clinical diagnostic criteria. Neurology. 51, 1546-54.

Nistico, R., Cavallucci, V., Piccinin, S., Macri, S., Pignatelli, M., Mehdawy, B., Blandini, F., Laviola, G., Lauro, D., Mercuri, N. B., D'Amelio, M., 2012. Insulin Receptor beta-Subunit Haploinsufficiency Impairs Hippocampal Late-Phase LTP and Recognition Memory. Neuromolecular Med.

Nukina, N., Ihara, Y., 1986. One of the antigenic determinants of paired helical filaments is related to tau protein. J Biochem. 99, 1541-4.

Oates, N. A., van Vliet, J., Duffy, D. L., Kroes, H. Y., Martin, N. G., Boomsma, D. I., Campbell, M., Coulthard, M. G., Whitelaw, E., Chong, S., 2006. Increased DNA methylation at the AXIN1 gene in a monozygotic twin from a pair discordant for a caudal duplication anomaly. Am J Hum Genet. 79, 155-62.

Okano, M., Bell, D. W., Haber, D. A., Li, E., 1999. DNA methyltransferases Dnmt3a and Dnmt3b are essential for de novo methylation and mammalian development. Cell. 99, 247-57.

Okano, M., Xie, S., Li, E., 1998. Dnmt2 is not required for de novo and maintenance methylation of viral DNA in embryonic stem cells. Nucleic Acids Res. 26, 2536-40.

Oliveira, A. M., Hemstedt, T. J., Bading, H., 2012. Rescue of aging-associated decline in Dnmt3a2 expression restores cognitive abilities. Nat Neurosci.

Palop, J. J., Chin, J., Mucke, L., 2006. A network dysfunction perspective on neurodegenerative diseases. Nature. 443, 768-73.

Palop, J. J., Mucke, L., 2010. Amyloid-beta-induced neuronal dysfunction in Alzheimer's disease: from synapses toward neural networks. Nat Neurosci. 13, 812-8.

Parthun, M. R., 2007. Hat1: the emerging cellular roles of a type B histone acetyltransferase. Oncogene. 26, 5319-28.

Patrick, G. N., Zukerberg, L., Nikolic, M., de la Monte, S., Dikkes, P., Tsai, L. H., 1999. Conversion of p35 to p25 deregulates Cdk5 activity and promotes neurodegeneration. Nature. 402, 615-22.

Pearson-Leary, J., McNay, E. C., 2012. Intrahippocampal administration of amyloid-beta(1-42) oligomers acutely impairs spatial working memory, insulin signaling, and hippocampal metabolism. J Alzheimers Dis. 30, 413-22.

Peleg, S., Sananbenesi, F., Zovoilis, A., Burkhardt, S., Bahari-Javan, S., Agis-Balboa, R. C., Cota, P., Wittnam, J. L., Gogol-Doering, A., Opitz, L., Salinas-Riester, G., Dettenhofer, M., Kang, H., Farinelli, L., Chen, W., Fischer, A., 2010. Altered histone acetylation is associated with agedependent memory impairment in mice. Science. 328, 753-6.

Perez, R. G., Zheng, H., Van der Ploeg, L. H., Koo, E. H., 1997. The beta-amyloid precursor protein of Alzheimer's disease enhances neuron viability and modulates neuronal polarity. J Neurosci. 17, 9407-14.

Petrovich, G. D., Canteras, N. S., Swanson, L. W., 2001. Combinatorial amygdalar inputs to hippocampal domains and hypothalamic behavior systems. Brain Res Brain Res Rev. 38, 24789.

Pfeilschifter, W., Czech-Zechmeister, B., Sujak, M., Mirceska, A., Koch, A., Rami, A., Steinmetz, H., Foerch, C., Huwiler, A., Pfeilschifter, J., 2011. Activation of sphingosine kinase 2 is an 
endogenous protective mechanism in cerebral ischemia. Biochem Biophys Res Commun. $413,212-7$.

Phiel, C. J., Wilson, C. A., Lee, V. M., Klein, P. S., 2003. GSK-3alpha regulates production of Alzheimer's disease amyloid-beta peptides. Nature. 423, 435-9.

Qiu, W. Q., Ferreira, A., Miller, C., Koo, E. H., Selkoe, D. J., 1995. Cell-surface beta-amyloid precursor protein stimulates neurite outgrowth of hippocampal neurons in an isoform-dependent manner. J Neurosci. 15, 2157-67.

Qiu, W. Q., Walsh, D. M., Ye, Z., Vekrellis, K., Zhang, J., Podlisny, M. B., Rosner, M. R., Safavi, A., Hersh, L. B., Selkoe, D. J., 1998. Insulin-degrading enzyme regulates extracellular levels of amyloid beta-protein by degradation. J Biol Chem. 273, 32730-8.

Radde, R., Bolmont, T., Kaeser, S. A., Coomaraswamy, J., Lindau, D., Stoltze, L., Calhoun, M. E., Jaggi, F., Wolburg, H., Gengler, S., Haass, C., Ghetti, B., Czech, C., Holscher, C., Mathews, P. M., Jucker, M., 2006. Abeta42-driven cerebral amyloidosis in transgenic mice reveals early and robust pathology. EMBO Rep. 7, 940-6.

Ratnavalli, E., Brayne, C., Dawson, K., Hodges, J. R., 2002. The prevalence of frontotemporal dementia. Neurology. 58, 1615-21.

Ricobaraza, A., Cuadrado-Tejedor, M., Perez-Mediavilla, A., Frechilla, D., Del Rio, J., Garcia-Osta, A., 2009. Phenylbutyrate ameliorates cognitive deficit and reduces tau pathology in an Alzheimer's disease mouse model. Neuropsychopharmacology. 34, 1721-32.

Roberson, E. D., Scearce-Levie, K., Palop, J. J., Yan, F., Cheng, I. H., Wu, T., Gerstein, H., Yu, G. Q., Mucke, L., 2007. Reducing endogenous tau ameliorates amyloid beta-induced deficits in an Alzheimer's disease mouse model. Science. 316, 750-4.

Rodriguez-Rivera, J., Denner, L., Dineley, K. T., 2011. Rosiglitazone reversal of Tg2576 cognitive deficits is independent of peripheral gluco-regulatory status. Behav Brain Res. 216, 255-61.

Rossi-Arnaud, C., Fagioli, S., Ammassari-Teule, M., 1991. Spatial learning in two inbred strains of mice: genotype-dependent effect of amygdaloid and hippocampal lesions. Behav Brain Res. $45,9-16$.

Rosso, S. M., Donker Kaat, L., Baks, T., Joosse, M., de Koning, I., Pijnenburg, Y., de Jong, D., Dooijes, D., Kamphorst, W., Ravid, R., Niermeijer, M. F., Verheij, F., Kremer, H. P., Scheltens, P., van Duijn, C. M., Heutink, P., van Swieten, J. C., 2003. Frontotemporal dementia in The Netherlands: patient characteristics and prevalence estimates from a population-based study. Brain. 126, 2016-22.

Roztocil, E., Nicholl, S. M., Davies, M. G., 2009. Mechanisms of sphingosine-1-phosphate-induced akt-dependent smooth muscle cell migration. Surgery. 145, 34-41.

Ruan, W. J., Lin, J., Xu, E. P., Xu, F. Y., Ma, Y., Deng, H., Huang, Q., Lv, B. J., Hu, H., Cui, J., Di, M. J., Dong, J. K., Lai, M. D., 2006. IGFBP7 plays a potential tumor suppressor role against colorectal carcinogenesis with its expression associated with DNA hypomethylation of exon 1. J Zhejiang Univ Sci B. 7, 929-32.

Sandberg, A. C., Engberg, C., Lake, M., von Holst, H., Sara, V. R., 1988. The expression of insulin-like growth factor I and insulin-like growth factor II genes in the human fetal and adult brain and in glioma. Neurosci Lett. 93, 114-9.

Sastre, M., Steiner, H., Fuchs, K., Capell, A., Multhaup, G., Condron, M. M., Teplow, D. B., Haass, C., 2001. Presenilin-dependent gamma-secretase processing of beta-amyloid precursor protein at a site corresponding to the S3 cleavage of Notch. EMBO Rep. 2, 835-41.

Sawamura, N., Ko, M., Yu, W., Zou, K., Hanada, K., Suzuki, T., Gong, J. S., Yanagisawa, K., Michikawa, M., 2004. Modulation of amyloid precursor protein cleavage by cellular sphingolipids. J Biol Chem. 279, 11984-91.

Saywell, N., Taylor, D., 2008. The role of the cerebellum in procedural learning--are there implications for physiotherapists' clinical practice? Physiother Theory Pract. 24, 321-8. 
Schonrock, N., Ke, Y. D., Humphreys, D., Staufenbiel, M., Ittner, L. M., Preiss, T., Gotz, J., 2010. Neuronal microRNA deregulation in response to Alzheimer's disease amyloid-beta. PLoS One. 5, e11070.

Schwegler, H., Crusio, W. E., 1995. Correlations between radial-maze learning and structural variations of septum and hippocampus in rodents. Behav Brain Res. 67, 29-41.

Scoville, W. B., Milner, B., 1957. Loss of recent memory after bilateral hippocampal lesions. J Neurol Neurosurg Psychiatry. 20, 11-21.

Selkoe, D. J., Podlisny, M. B., 2002. Deciphering the genetic basis of Alzheimer's disease. Annu Rev Genomics Hum Genet. 3, 67-99.

Sesti, G., 2006. Pathophysiology of insulin resistance. Best Pract Res Clin Endocrinol Metab. 20, 66579.

Shi, Y., Taylor, S. I., Tan, S. L., Sonenberg, N., 2003. When translation meets metabolism: multiple links to diabetes. Endocr Rev. 24, 91-101.

Shingo, A. S., Kanabayashi, T., Murase, T., Kito, S., 2012. Cognitive decline in STZ-3V rats is largely due to dysfunctional insulin signalling through the dentate gyrus. Behav Brain Res. 229, 37883.

Snowdon, D. A., 1997. Aging and Alzheimer's disease: lessons from the Nun Study. Gerontologist. 37, 150-6.

Spiegel, S., Milstien, S., 2003. Sphingosine-1-phosphate: an enigmatic signalling lipid. Nat Rev Mol Cell Biol. 4, 397-407.

Strahl, B. D., Allis, C. D., 2000. The language of covalent histone modifications. Nature. 403, 41-5.

Taipa, R., Pinho, J., Melo-Pires, M., 2012. Clinico-pathological correlations of the most common neurodegenerative dementias. Front Neurol. 3, 68.

Takiguchi, M., Achanzar, W. E., Qu, W., Li, G., Waalkes, M. P., 2003. Effects of cadmium on DNA(Cytosine-5) methyltransferase activity and DNA methylation status during cadmiuminduced cellular transformation. Exp Cell Res. 286, 355-65.

Takuwa, Y., Du, W., Qi, X., Okamoto, Y., Takuwa, N., Yoshioka, K., 2010. Roles of sphingosine-1phosphate signaling in angiogenesis. World J Biol Chem. 1, 298-306.

Tanzi, R. E., St George-Hyslop, P. H., Haines, J. L., Polinsky, R. J., Nee, L., Foncin, J. F., Neve, R. L., McClatchey, A. I., Conneally, P. M., Gusella, J. F., 1987. The genetic defect in familial Alzheimer's disease is not tightly linked to the amyloid beta-protein gene. Nature. 329, 1567.

Tarnow, E., 2009. Short term memory may be the depletion of the readily releasable pool of presynaptic neurotransmitter vesicles of a metastable long term memory trace pattern. Cogn Neurodyn. 3, 263-9.

Tatar, M., Bartke, A., Antebi, A., 2003. The endocrine regulation of aging by insulin-like signals. Science. 299, 1346-51.

Taunton, J., Hassig, C. A., Schreiber, S. L., 1996. A mammalian histone deacetylase related to the yeast transcriptional regulator Rpd3p. Science. 272, 408-11.

Tissenbaum, H. A., Ruvkun, G., 1998. An insulin-like signaling pathway affects both longevity and reproduction in Caenorhabditis elegans. Genetics. 148, 703-17.

Tomimaru, Y., Eguchi, H., Wada, H., Kobayashi, S., Marubashi, S., Tanemura, M., Umeshita, K., Kim, T., Wakasa, K., Doki, Y., Mori, M., Nagano, H., 2012. IGFBP7 downregulation is associated with tumor progression and clinical outcome in hepatocellular carcinoma. Int J Cancer. 130, 319-27.

Tsai, P. F., Lin, S. J., Weng, P. L., Tsai, S. C., Lin, J. H., Chou, Y. C., Tsai, C. H., 2011. Interplay between PKCdelta and Sp1 on histone deacetylase inhibitor-mediated Epstein-Barr virus reactivation. J Virol. 85, 2373-85.

Tseng, H. C., Zhou, Y., Shen, Y., Tsai, L. H., 2002. A survey of Cdk5 activator p35 and p25 levels in Alzheimer's disease brains. FEBS Lett. 523, 58-62. 
Tully, T., Quinn, W. G., 1985. Classical conditioning and retention in normal and mutant Drosophila melanogaster. J Comp Physiol A. 157, 263-77.

Tulving E and Donaldson W (1972) Episodic and semantic memory. Organization of memory. New York: Academic Press. 1972. p. 381-403.

Turner, P. R., O'Connor, K., Tate, W. P., Abraham, W. C., 2003. Roles of amyloid precursor protein and its fragments in regulating neural activity, plasticity and memory. Prog Neurobiol. 70, 132.

Ullman, M. T., 2004. Contributions of memory circuits to language: the declarative/procedural model. Cognition. 92, 231-70.

Vaquero, A., Loyola, A., Reinberg, D., 2003. The constantly changing face of chromatin. Sci Aging Knowledge Environ. 2003, RE4.

Vassar, R., Citron, M., 2000. Abeta-generating enzymes: recent advances in beta- and gammasecretase research. Neuron. 27, 419-22.

Verdel, A., Curtet, S., Brocard, M. P., Rousseaux, S., Lemercier, C., Yoshida, M., Khochbin, S., 2000. Active maintenance of mHDA2/mHDAC6 histone-deacetylase in the cytoplasm. Curr Biol. 10, 747-9.

Wajapeyee, N., Serra, R. W., Zhu, X., Mahalingam, M., Green, M. R., 2010. Role for IGFBP7 in senescence induction by BRAF. Cell. 141, 746-7.

Walker, F. O., 2007. Huntington's disease. Lancet. 369, 218-28.

Wang, R., Dineley, K. T., Sweatt, J. D., Zheng, H., 2004. Presenilin 1 familial Alzheimer's disease mutation leads to defective associative learning and impaired adult neurogenesis. Neuroscience. 126, 305-12.

Wang, Y., Zhang, D., Zheng, W., Luo, J., Bai, Y., Lu, Z., 2008a. Multiple gene methylation of nonsmall cell lung cancers evaluated with 3-dimensional microarray. Cancer. 112, 1325-36.

Wang, Z., Zang, C., Rosenfeld, J. A., Schones, D. E., Barski, A., Cuddapah, S., Cui, K., Roh, T. Y., Peng, W., Zhang, M. Q., Zhao, K., 2008b. Combinatorial patterns of histone acetylations and methylations in the human genome. Nat Genet. 40, 897-903.

Weingarten, M. D., Lockwood, A. H., Hwo, S. Y., Kirschner, M. W., 1975. A protein factor essential for microtubule assembly. Proc Natl Acad Sci U S A. 72, 1858-62.

Wenk, G. L., 2003. Neuropathologic changes in Alzheimer's disease. J Clin Psychiatry. 64 Suppl 9, 710.

Wischik, C. M., Novak, M., Thogersen, H. C., Edwards, P. C., Runswick, M. J., Jakes, R., Walker, J. E., Milstein, C., Roth, M., Klug, A., 1988. Isolation of a fragment of tau derived from the core of the paired helical filament of Alzheimer disease. Proc Natl Acad Sci U S A. 85, 4506-10.

Wood, J. G., Mirra, S. S., Pollock, N. J., Binder, L. I., 1986. Neurofibrillary tangles of Alzheimer disease share antigenic determinants with the axonal microtubule-associated protein tau (tau). Proc Natl Acad Sci U S A. 83, 4040-3.

Wu, H., Coskun, V., Tao, J., Xie, W., Ge, W., Yoshikawa, K., Li, E., Zhang, Y., Sun, Y. E., 2010. Dnmt3adependent nonpromoter DNA methylation facilitates transcription of neurogenic genes. Science. 329, 444-8.

Xu, G. L., Bestor, T. H., Bourc'his, D., Hsieh, C. L., Tommerup, N., Bugge, M., Hulten, M., Qu, X., Russo, J. J., Viegas-Pequignot, E., 1999. Chromosome instability and immunodeficiency syndrome caused by mutations in a DNA methyltransferase gene. Nature. 402, 187-91.

Yaffe, K., Vittinghoff, E., Lindquist, K., Barnes, D., Covinsky, K. E., Neylan, T., Kluse, M., Marmar, C., 2010. Posttraumatic stress disorder and risk of dementia among US veterans. Arch Gen Psychiatry. 67, 608-13.

Yamaguchi, T., Cubizolles, F., Zhang, Y., Reichert, N., Kohler, H., Seiser, C., Matthias, P., 2010. Histone deacetylases 1 and 2 act in concert to promote the G1-to-S progression. Genes Dev. 24, 45569.

Yu, Y., Kastin, A. J., Pan, W., 2006. Reciprocal interactions of insulin and insulin-like growth factor I in receptor-mediated transport across the blood-brain barrier. Endocrinology. 147, 2611-5. 
Zhang, B., Higuchi, M., Yoshiyama, Y., Ishihara, T., Forman, M. S., Martinez, D., Joyce, S., Trojanowski, J. Q., Lee, V. M., 2004. Retarded axonal transport of R406W mutant tau in transgenic mice with a neurodegenerative tauopathy. J Neurosci. 24, 4657-67.

Zhang, M., 1990. [Prevalence study on dementia and Alzheimer disease]. Zhonghua Yi Xue Za Zhi. 70, 424-8, 30.

Zhang, W., Bone, J. R., Edmondson, D. G., Turner, B. M., Roth, S. Y., 1998. Essential and redundant functions of histone acetylation revealed by mutation of target lysines and loss of the Gcn5p acetyltransferase. EMBO J. 17, 3155-67.

Zhao, C. Q., Young, M. R., Diwan, B. A., Coogan, T. P., Waalkes, M. P., 1997. Association of arsenicinduced malignant transformation with DNA hypomethylation and aberrant gene expression. Proc Natl Acad Sci U S A. 94, 10907-12.

Zhao, C. T., Li, K., Li, J. T., Zheng, W., Liang, X. J., Geng, A. Q., Li, N., Yuan, X. B., 2009. PKCdelta regulates cortical radial migration by stabilizing the Cdk5 activator p35. Proc Natl Acad Sci U S A. 106, 21353-8.

Zhao, H., Sapolsky, R. M., Steinberg, G. K., 2006. Phosphoinositide-3-kinase/akt survival signal pathways are implicated in neuronal survival after stroke. Mol Neurobiol. 34, 249-70.

Zheng, H., Jiang, M., Trumbauer, M. E., Sirinathsinghji, D. J., Hopkins, R., Smith, D. W., Heavens, R. P., Dawson, G. R., Boyce, S., Conner, M. W., Stevens, K. A., Slunt, H. H., Sisoda, S. S., Chen, H. Y., Van der Ploeg, L. H., 1995. beta-Amyloid precursor protein-deficient mice show reactive gliosis and decreased locomotor activity. Cell. 81, 525-31. 


\section{Appendix}
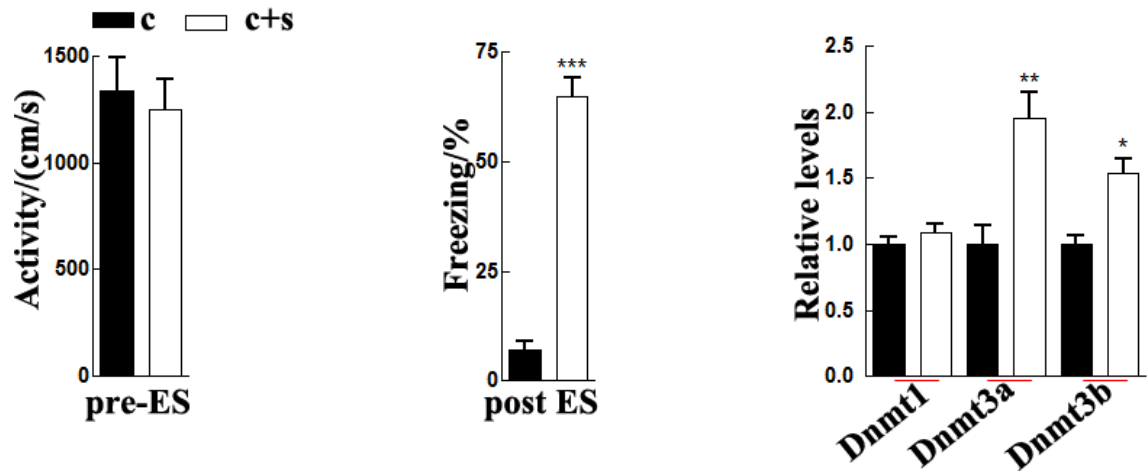

Fig. 1: Expression of Dnmts $1 \mathrm{~h}$ after fear conditioning. A: Activity of naïve and fear conditioned mice showed no difference prior to shock. B: A test of associative memory showing that fear conditioned mice showing freezing while the naïve mice did not. C: The expression level of three Dnmts after FC revealed no change in expression levels of Dnmt1 but Dnmt3a and Dnmt3b showing significant difference after FC.
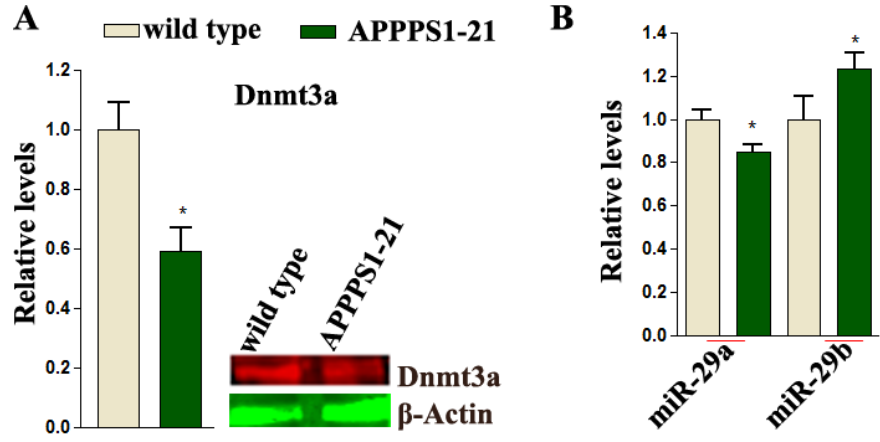

Fig. 2: Altered expression of miRNA cluster in APPPS1-21 mice. A: Immunoblot showing reduction in Dnmt3a levels in APPPS1-21 compared to controls. B: miR-29a showing significant reduction in APPPS1-21 compared to controls whilst miR-29b (one-way ANOVA, Bonferroni ${ }^{*} \mathrm{p}<0.05$ ) is increased significantly in APPPS1-21 mice relative to controls. $\mathrm{N}=4$. This indicates that regulation of Dnmt3a might be due to miR-29b. Error bars indicate s.e.m.

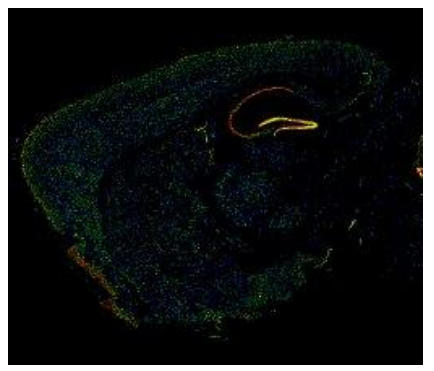

Fig. 3: In-situ hybridization showing the expression levels of SphK2 in brain. Enhanced expression could be seen in the Hippocampal formation of the brain compared to other regions (Adapted from Allen brain Atlas). 
$\mathbf{A}$

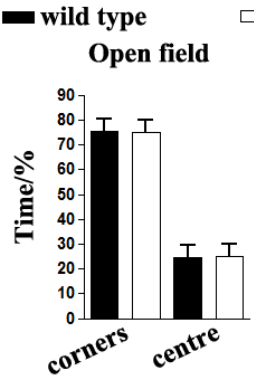

D
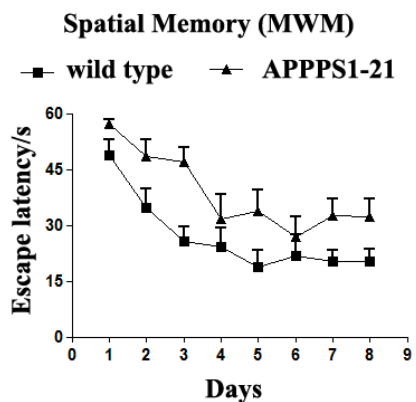

B

Elevated Plus Maze (EPM)

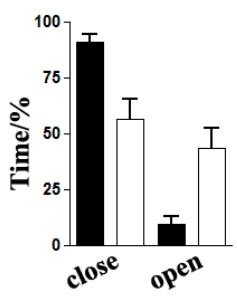

$\mathbf{E}$

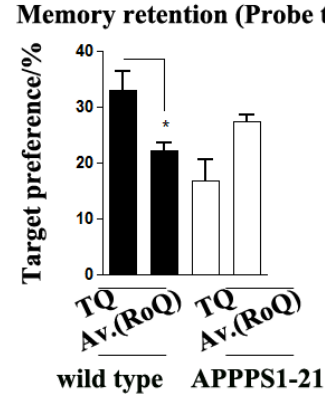

C FC, $0.70 \mathrm{~mA} \stackrel{24 \text { hours }}{\longrightarrow}$ Test

Associative memory

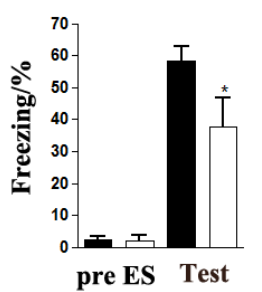

F

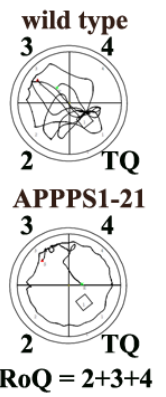

Fig.4: Behavioural characterization of 6-month old APPPS1-21 mice. A: Open field showed similar motor activity in WT and APPPS1-21 mice. B: Elevated plus maze showed difference between WT and APPPS1-21. C: Fear conditioning revealed no difference between the two groups. One way ANOVA revealed significantly impaired associative memory in APPPS1-21 mice relative to controls. D: Spatial memory acquisition showed difference between the two groups. E: Memory retention was observed to be significantly impaired in APPPS121 mice relative to controls. F: Representative swimming traces during probe test showing wild type in the upper panel shows analysis of probe test in 6-month old mice and lower panel shows representative trace pattern of swimming in control and APPPS1-21 mice in the pool $\left({ }^{*} \mathrm{p}<0.05\right)$. Error bars indicate s.e.m. 
Acknowledgement Assessment of Epigenetic profile in Alzheimer's disease

\section{Acknowledgement}

This work was carried out under the auspices of Prof. Dr. André Fischer in the European Neuroscience Institute Göttingen to whom I would like to extend my sincere gratitude for accepting and mentoring me a PhD student. A lab with cultural diversity and research focus contributed immensely to my scientific growth and maturity, learning to cope with life. It was such an epitome of everything in life. People from all walks of life with different temperament ha! ha! ha! I will really miss that. Credit to all the lab. I therefore take the opportunity to thank both former colleagues: Blom Kim, Cota Perla, Govindarajan Nambidaran, Halladyniak Ulla, Roehse Heiko, HsiaHung-En, Kuzcera Tanja, Mckechnie Lawrence, Zeiter Sergej (the emeritus Professor, the man of all times), Held Torsten, Pavelka Zsuzsa, Peleg Shahaf, Tiwari Ananya, Walter Jonas and Zoviolis Athanasois and current: Agis-Balboa Roberto Carlos, Bahari Javan Sanaz, Benito-Garagorri Eva, Burkhardt Susanne (my third mum), Dyczkowski Jerzy, Helder Rashi, Kerimoglu Cemil (Life will always be hard), Rao Pooja, Riester Daniel, Sananbenesi Faranaz, Gertig Michael, Stilling Roman, Kraemer Ulrike, and Stefan Bonn for the time together. I will really miss it. If I miss someone is not on purpose, I hope I can be pardoned.

Thanks to the entire ENI-Göttingen and other colleagues in institute for their friendship and continuous support contributing to the fantastic working environment. It is my fervent prayer that our friendship is boundary less and our paths cross again. I wish you the best in your endeavours. ENI, a congenial atmosphere to carry out research with great technical support Frank and his team were wonderful; Ali and Matthias, great combination and the administration team all kudos. ENI's pool of ladies, 'our animal care-takers', made it a smooth sailing.

I also appreciate the support and guidance of the Ph.D advisory committee Dr. Judith Stegmueller and Prof. K.A. Nave. I am highly indebted to both of them for finding time to advise me on the progress of my thesis, despite having a very busy schedule. I also thank Prof. Michael Hörner, for his effort accepting me into the IMPRS program and beyond. These are indelible marks and will never be forgotten. Prof. Detlev Schild is not forgotten. How can a child forget the mother (Sandra Druebe), mum, I do not know what I could have done without you. Coming to Germany for the first time on an adventure not well prepared for and suddenly being confronted with the realities. I appreciated every moment (Thanks to Alonso for his jacket). Thank you. I would be a saint to say I have not stepped on toes along the line. Remember one thing no matter how stinking it gets a mother does not use a knife to get rid of a child's droppings. Let us patch our differences and move on. I asked for forgiveness just as I will also try to forgive.

I owe my deepest and loving gratitude to all my family members and I dedicate everything to my beloved mother Aku Kugbeadzor. I also extend my sincere and heartfelt appreciation to Mark Leonard Kpodo, my cousin, Dr. Christian Ejike and Dr. Joseph Amikuzuno for their support. Words cannot describe how grateful I am. May God's blessing be upon you. Finally, I would like to thank the Almighty God for granting life and his care and protection throughout these years. 


\section{CURRICULUM VITAE}

\section{Contact information \\ Permanent address: \\ E-mail:}

\section{Personal information \\ Date/Place of Birth: \\ Citizenship:}

Languages spoken:

Education

2007-2012

2006-2007:

2002-2006:

1999-2001:

1996-1999:
P.O.Box AK. 11, Akatsi, Volta Rgion

hopeyao2002@yahoo.com

5th August, 1982, Akatsi

Ghanaian

English, Ewe, German and some knowledge of French
Scholarships

1999-2001:

2007-2009:

Awards:
MSc./Ph.D Neuroscience (European Neuroscience program, Goettingen)

National Service as teaching assistant in the Chemistry department

University of Ghana (BSc. Chemistry)

St. Paul's Secondary School

Akatsi No. 1 Junior Secondary School

Leadership positions held: Senior Prefect (2001) and leader of Student's Representative Council (S.R.C), 2001

Patents:

MBM-Referenznr. BioC-1421-UMG MicroRNAs 34a, b and c are a novel target to treat memory impairment

\section{Publications:}

1. Zovoilis, A.*1 ${ }^{1}$, Agbemenyah, HY. ${ }^{1}$, Agis-Balboa, R.C. ${ }^{1}$, Stilling RM. ${ }^{1}$, Rao, P. ${ }^{1}$, Edbauer, D. ${ }^{2}$, Farinelli, L. ${ }^{3}$, Delalle, I. ${ }^{4}$, Schmitt, A. ${ }^{5,6}$, Falkai, P. ${ }^{5}$, Bahari-Javan, S. ${ }^{1}$, Susanne Burkhardt ${ }^{1}$, Sananbenesi, F. ${ }^{1}$ \& Fischer, A. ${ }^{1}$ (2011). microRNA-34C IS A NOVEL TARGET TO TREAT DEMENTIAS. EMBO J. 2011 Sep 23. doi: 10.1038/emboj.2011.327

2. Agis-Balboa RC, Arcos-Diaz D, Wittnam J, Govindarajan N, Blom K, Burkhardt S, Haladyniak U, Agbemenyah HY, Zovoilis A, Salinas-Riester G, Opitz L, Sananbenesi F, Fischer A. (2011). A HIPPOCAMPAL INSULIN-GROWTH-FACTOR 2 PATHWAY REGULATES THE EXTINCTION OF FEAR MEMORIES. EMBO J.2011 Aug 26. doi: 10.1038/emboj.2011.293

3. Kifayathullah LA, Arunachalam JP, Bodha C, Agbemenyah HY, Laccone FA, Mannan AU. (2010). MeCP2 mutant protein is expressed in astrocytes as well as in neurons and localizes in the nucleus. Cytogenet Genome Res;129(4):290-7.

\section{Manuscripts in Preparation:}

4. Jordi Tomàs-Roig, Timothy Schmeil, Hope Yao Agbemenyah, Peter Falkai, Ursula Havemann-Reinecke. Role of CB1 receptor and endocannabinoids in psychosocially stressed mice (in preparation)

5. Agbemenyah HY., Balboa RCA., Stilling RM., Burkhardt S., Sananbenesi F., \& Fischer A., The role of DNA methylation in regulating Igfbp7 in Alzheimer's disease. (in preparation)

6. Agis-Balboa RC*, Held T*, Agbemenyah HY, Kerimoglu C, Zeiter S, Gertig M, Arcos-Diaz D, Sananbenesi F, Fischer A. The role of DNA methylation in the extinction of learned fear (in preparation).

7. Agbemenyah HY., Burkhardt S., Helder R., Sananbenesi F \& Fischer A, Reduced nuclear Sphingosine kinase 2 activity underlies altered histone acetylation (in preparation) 